\title{
An empirical analysis of the interactions between environmental regulations and economic growth
}

\author{
Chali Nondo \\ West Virginia University
}

Follow this and additional works at: https://researchrepository.wvu.edu/etd

\section{Recommended Citation}

Nondo, Chali, "An empirical analysis of the interactions between environmental regulations and economic growth" (2009). Graduate Theses, Dissertations, and Problem Reports. 4508.

https://researchrepository.wvu.edu/etd/4508

This Dissertation is protected by copyright and/or related rights. It has been brought to you by the The Research Repository @ WVU with permission from the rights-holder(s). You are free to use this Dissertation in any way that is permitted by the copyright and related rights legislation that applies to your use. For other uses you must obtain permission from the rights-holder(s) directly, unless additional rights are indicated by a Creative Commons license in the record and/ or on the work itself. This Dissertation has been accepted for inclusion in WVU Graduate Theses, Dissertations, and Problem Reports collection by an authorized administrator of The Research Repository @ WVU.

For more information, please contact researchrepository@mail.wvu.edu. 


\title{
AN EMPIRICAL ANALYSIS OF THE INTERACTIONS BETWEEN ENVIRONMENTAL REGULATIONS AND ECONOMIC GROWTH
}

\author{
Chali Nondo
}

Dissertation Submitted to the Davis College of Agriculture, Natural Resources \& Design at West Virginia University in Partial Fulfillment of the Requirements for the Degree of

Doctor of Philosophy

in

Natural Resource Economics

Peter V. Schaeffer, Ph.D., Chair

Jerald J. Fletcher, Ph.D., Co-chair

Tim T. Phipps, Ph.D.

Tesfa Gebremedhin, Ph.D.

Denny Smith, Ph.D.

Stratford M. Douglas, Ph.D.

\section{Morgantown, West Virginia 2009}

Keywords: Environmental Regulations, Economic growth, Growth Equilibrium Lag-Adjustment Model, and Spatial Durbin Model 


\section{Abstract \\ AN EMPIRICAL ANALYSIS OF THE INTERACTIONS BETWEEN ENVIRONMENTAL REGULATIONS AND ECONOMIC GROWTH}

\section{Chali Nondo}

This dissertation examines the relationship between environmental regulations and economic growth in the Appalachian Region. The study employs county attainment status data as a proxy for environmental regulations and allows the cross-sectional variation of the attainment variable. Cognizant of the fact that air pollution emanates from a variety of sources, the study assumes that per capita income, population, employment, and environmental regulations are jointly determined, which is the major distinction from previous studies which have assumed a unidirectional relationship between environmental regulations and economic growth.

Using endogenous growth theory, a theoretical model is developed that highlights the role of environmental regulations in economic growth. The major theoretical conclusions reached suggest that: enforcement of environmental regulations affects economic performance only in the short-term, while in the long-term, firms become more efficient in production and output increases. In the long-term, environmental regulations lead to improved environmental quality and this has a direct effect of stimulating growth in population, income, and employment.

In the empirical applications, two econometric techniques are employed. First, the structural equations are estimated using three stage least squares. Second, the Spatial Durbin Model (SDM) is applied in order to account for spatial spillovers that emanate from neighboring counties. Results from the three stage least squares and SDM model are robust. The statistical evidence supports the theoretical analyses that enforcement of environmental regulations only affects regional growth in the short-term. Additional evidence from empirical models support the 'jobs follow people' and 'people follow jobs' hypotheses. In addition, empirical estimations show that changes in population, per capita income, and employment, including socio-economic, political, and demographic characteristics influence the stringency of environmental regulations.

With regard to the SDM estimations, important findings are that a county's regional growth and environmental regulation stringency not only depend on own county characteristics, but are indirectly influenced by neighboring counties' characteristics. Furthermore, results from the SDM model indicate that there is some form of strategic interaction in environmental policymaking among some counties in the Appalachian Region in the form of a race to the top.

The research findings reinforce the need to design and implement environmental regulations that stimulate economic growth and enhance environmental quality. Another policy implication is that besides imposing stringent environmental regulations on major polluting industries, attention needs to be paid to other socio-economic and demographic forces that contribute to emission of pollutants. 


\section{Dedication}

I dedicate this work to my wife, Helen Mbewe Nondo, my daughter, Susan, and my son, Jonathan, who have stood by my side throughout my studies at West Virginia University. 


\section{ACKNOWLEDGEMENTS}

To start with, I would like to express my deepest gratitude to my advisors Dr. Jerald J. Fletcher and Dr. Peter V. Schaeffer for their guidance, encouragement, and support throughout my studies. I thank both for their dedication to see me succeed in my studies and giving me the freedom to pursue my own research interests. I would also like to thank the other members of my graduate committee, Dr. Tim Phipps, Dr. Tesfa Gebremedhin, Dr. Denny Smith, and Dr. Stratford Douglas for their expert insights, suggestions, and comments on how to improve the dissertation.

My gratitude also goes to the Division of Resource Management for accepting me as a Ph.D. student. In the same vein, I would like to thank Dr. Jerald J. Fletcher and Dr. Mark Sperow for giving me an opportunity to work on the NETL carbon capture and storage project and for providing the graduate assistantship for the first years of my studies. My special thanks go also to Jennifer McIntosh, Executive Director of WVU Office of Social Justice, and Charles Morris, Program Coordinator of the Social Justice, for providing the graduate assistantship during the final year of my studies. In addition, I would like to thank Dr. Mulugeta Kahsai for sharing ideas when writing the MATLAB codes for the Spatial Durbin Model. Many thanks also go to the faculty in the Division of Resource Management and the Department of Economics whom I worked with during my stay at WVU.

Finally, my deepest appreciation is extended to my family and my wife's family. In particular, I would like to thank my wife, Helen, and my children, Susan and Jonathan, who gave me motivation, understanding, love, and support during my studies. Without my wife's incessant encouragement to hang on even when things seemed to be tough, it would not have been possible to complete my doctoral studies. I also give my heartfelt appreciation to my parents, Chief Herbert Nondo and Mrs. Susan Nondo, and to my brothers and sisters for their support and 
encouragement. I would also like to recognize my father-in-law, Mr. Allan Mbewe, and my sister in-laws, Martha and Betty, for their generous support and encouragement during my studies. Above all, I am eternally indebted to my Lord Jesus for giving me spiritual strength and resilience to overcome the various challenges that came my way during my studies. 


\section{Table of Contents}

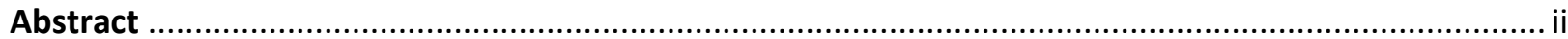

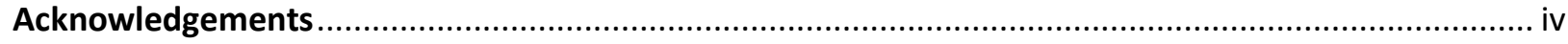

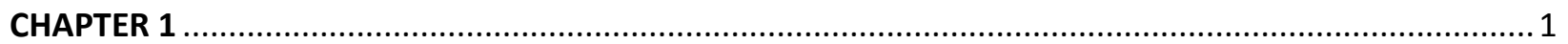

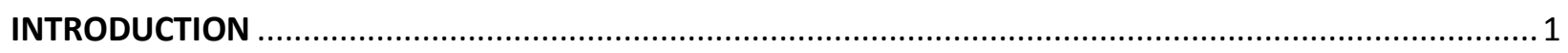

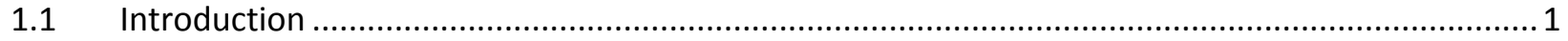

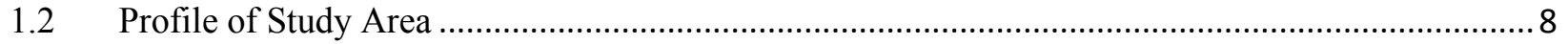

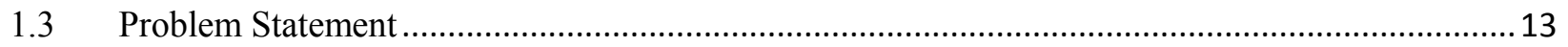

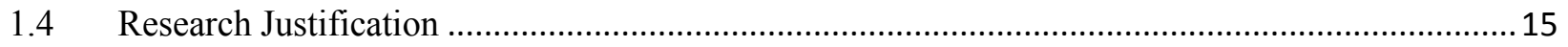

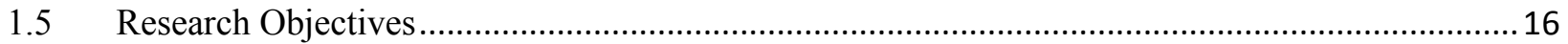

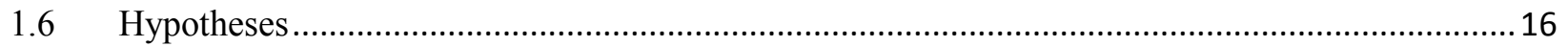

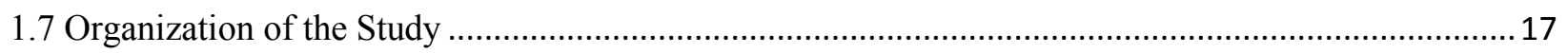

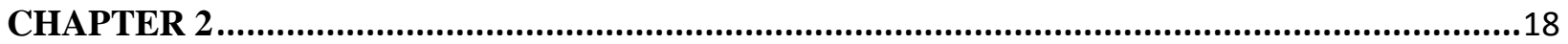

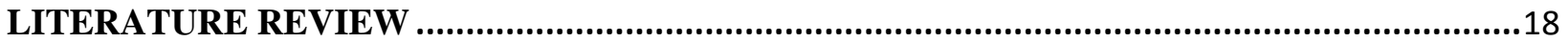

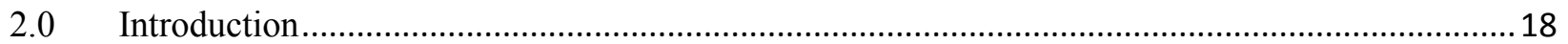

2.1 Measures of Environmental Regulation Stringency …............................................................. 19

2.1.1 National Ambient Air Quality Standards ................................................................................. 19

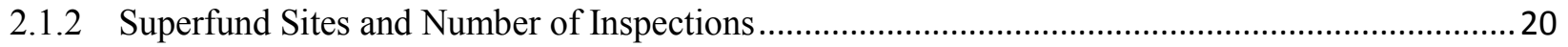

2.1.3 Pollution Abatement Costs and Expenditures........................................................................ 21

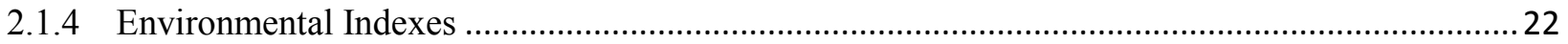

2.2 Supply of and Demand for Environmental Regulations ...........................................................23

2.3 Environmental Regulations and Economic Performance ........................................................26

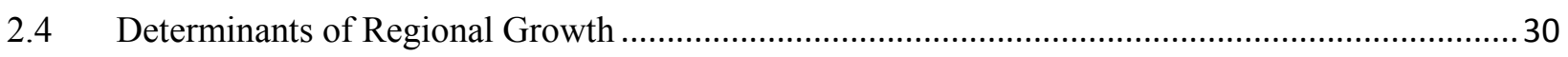

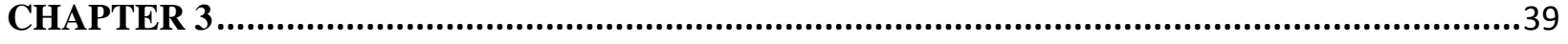

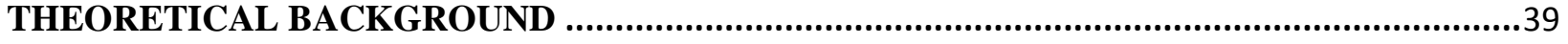

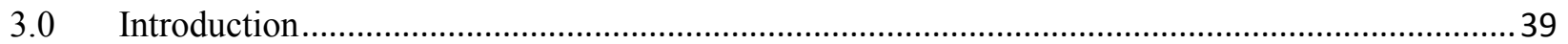

3.1 Short-Run and Long-Run Impacts of Environmental Regulations ............................................40

3.2 Environmental Quality and Economic Growth........................................................................ 44

3.3 Environmental Quality and Optimal Growth ..................................................................... 48

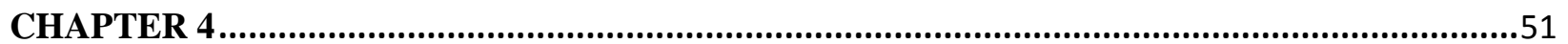

EMPIRICAL MODELS AND DATA DESCRIPTION .............................................................51

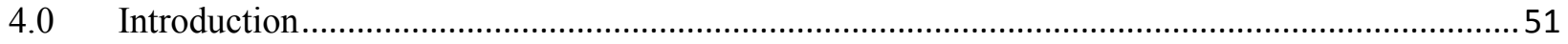


4.1 Non-Spatial Regional Growth Model (Model 1) .....................................................................5 52

$4.2 \quad$ Spatial Model of Regional Growth (Model 2) …..................................................................... 57

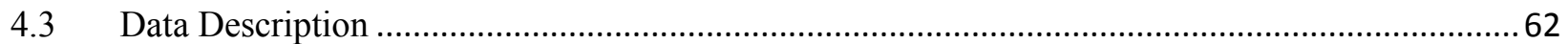

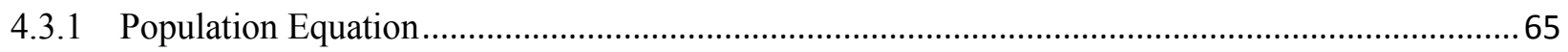

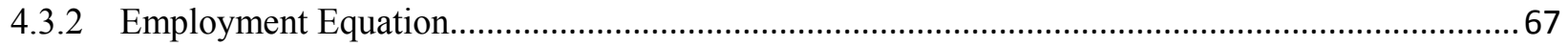

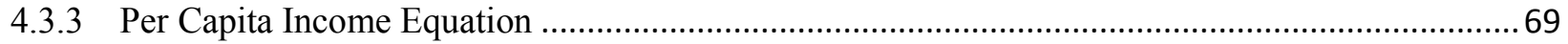

4.3.4 Environmental Regulations Equation ............................................................................. 72

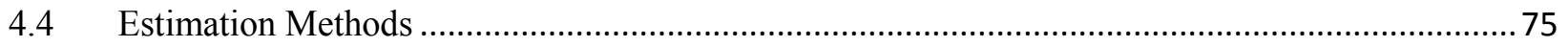

CHAPTER 5

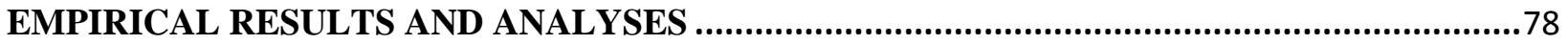

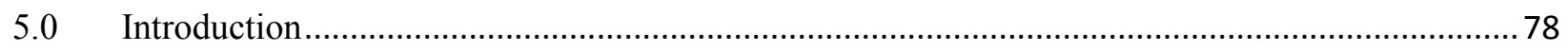

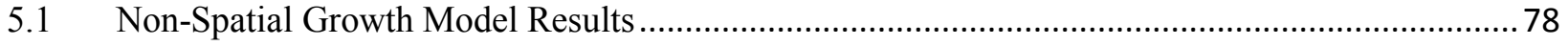

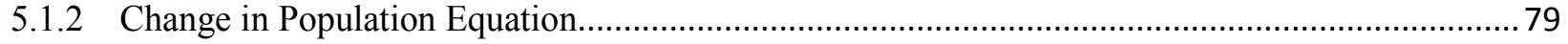

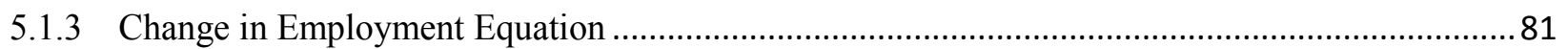

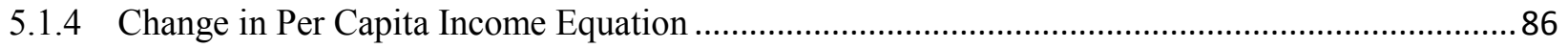

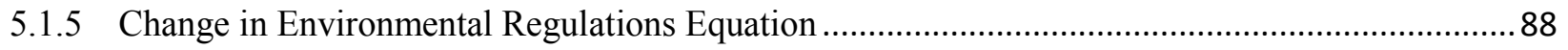

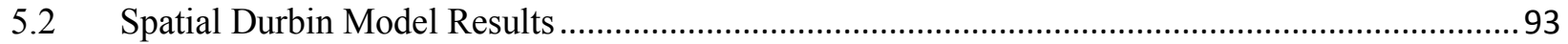

5.2.1 SDM Results for Change in Population Equation................................................................... 93

5.2.2 SDM Results for Change in Employment Equation …............................................................ 96

5.2.3 SDM Results for Change in Per Capita Income Equation .........................................................99

5.2.4 SDM Results for Change in Environmental Regulations Equation ........................................... 101

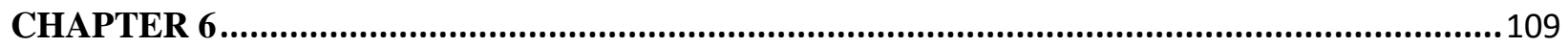

CONCLUSIONS AND RECOMMENDATIONS......................................................................110

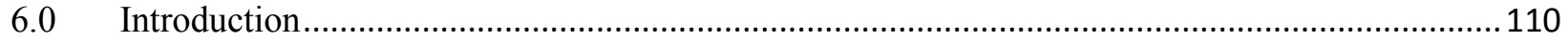

6.1 Summary and Conclusions from the Non-Spatial Models...................................................... 112

6.2 Summary and Conclusions from the SDM Model .............................................................. 114

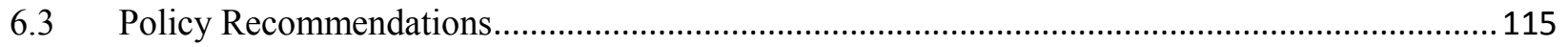

6.4 Research Limitations and Suggestions of Future Research .................................................... 117

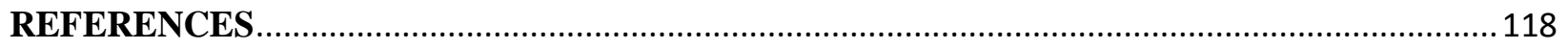

APPENDIX A 


\section{List of Figures}

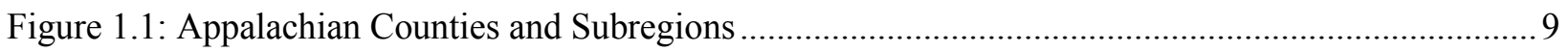

Figure 1.2: 2002 Appalachian Counties' Economic Status ..................................................................... 11

Figure 1.3: 2005 Appalachian Counties' Economic Status ............................................................. 11

Figure 1.4: Simultaneous Interactions between Environmental Regulations and Economic Growth 114

Figure 3.2: Relationship between Environmental Conditions and Economic Growth .............................48

Figure 3.3: Long-run Relationship between Environmental Conditions and Economic Growth ...............49

Figure 5.2: 2007 Attainment and Non-attainment Areas in the U.S. 8 Hour Ozone Standard ............... 1090

Figure 5.3: 2004 Attainment and Non-attainment Counties In Appalachia......................................... 1090

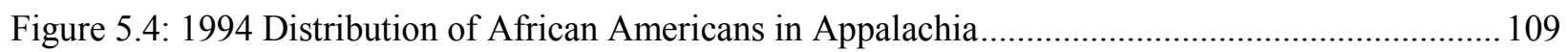

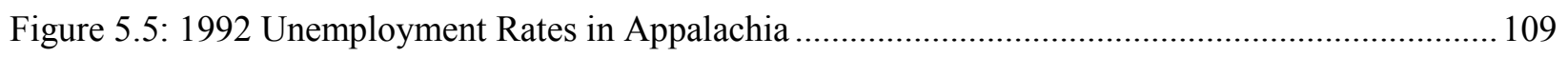

\section{List of Tables}

Table 1.1: 2000 Economic and Demographic Indicators for Appalachian Region and the U.S. . 10

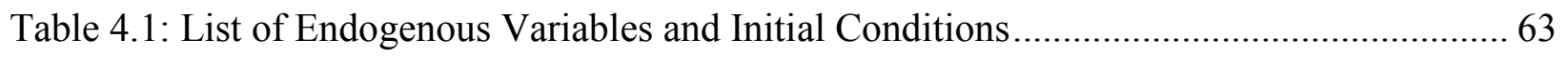

Table 4.2: Description of Exogenous Variables .............................................................. 78

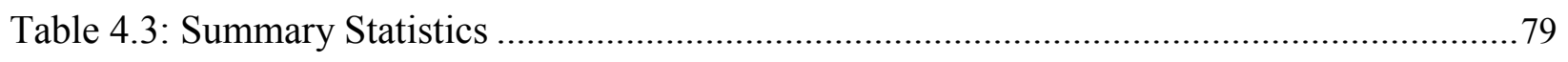

Table 5.1: 3SLS Regression Estimation of Change in Population ........................................... 81

Table 5.2: 3SLS Regression Estimation of Change in Employment ...................................... 85

Table 5.3: 3SLS Regression Estimation of Change in Per Capita Income.. Error! Bookmark not defined.

Table 5.4: 3SLS Regression Estimation of Change in Environmental Regulations.................... 91

Table 5.5: SDM Estimation Results of Change in Population............................................... 104

Table 5.6: SDM Estimation Results of Change in Employment .......................................... 105

Table 5.7: SDM Estimation Results of Change in Per Capita Income .................................. 106

Table 5.8: SDM Estimation Results of Change in Environmental Regulations ...................... 107 


\section{CHAPTER 1}

\section{INTRODUCTION}

\subsection{Introduction}

The debate over the impact of environmental regulations on economic growth has a long history (e.g., Denison, 1979; Portney, 1981; McConnell and Schwab, 1990). Generally, the belief is that environmental regulations are detrimental to economic growth; therefore, their implementation has been controversial among economists and environmental policymakers. The debates over the past three decades have been over how to design regulations that promote environmental quality without slowing economic growth. The general consensus is that many environmental problems such as global warming, water quality degradation, air quality problems, land degradation, habitat loss, resource exhaustion, municipal solid waste problems, and biodiversity loss are attributable to human activities. These environmental problems have been cited in many studies as having negative effects on the social and economic welfare of communities (e.g., Anselin et al., 2004; Waddell, 1974). For example, air pollution emanating from diverse sources generally imposes costs on society such as increased health, cleaning, and production expenses.

Concern over air quality problems culminated in the passage of the Clean Air Act [CAA] in 1970, which was amended in 1977 and 1990. The CAA gave legislative powers to the Environmental Protection Agency [EPA] to develop a national clean air program that would establish uniform air quality standards. The 1970 Clean Air Act set National Ambient Air Quality Standards [NAAQS] for six major air pollutants: tropospheric ozone $\left(\mathrm{O}_{3}\right)$, total suspended particulates (TSP), carbon monoxide $(\mathrm{CO})$, sulfur dioxide $\left(\mathrm{SO}_{2}\right)$, nitrogen dioxide $\left(\mathrm{NO}_{2}\right)$, 
and lead $(\mathrm{Pb})$. The NAAQS are a set of standards that represent the maximum permissible ambient concentrations of the six pollutants. To promote public health and welfare, the CAA has assigned the primary responsibility for air pollution regulation to state and local governments (Condliffe and Morgan, 2009). Thus, state and local governments administer the CAA by developing state implementation plans (SIP) which outline how states are going to comply with federal pollution standards. This means that U.S. states retain considerable flexibility in the implementation and enforcement of environmental regulations; this is reflected in the variation of regulatory intensity among states (Levison, 2000). Areas within a state that fail to meet the NAAQS for the six criteria pollutants established by the EPA are designated as non-attainment areas. In 2004, the EPA designated 474 counties (out of 3,140 U.S. counties or equivalent jurisdictions) from 32 states and the District of Columbia as non-attainment for the ozone standard requirements and another 225 counties from 20 states were listed as non-attainment under the TSP standard or PM 2.5 (Esworthy, 2007). Counties that violate federal air quality standards expose their populations to dangerous toxics.

Variations in environmental regulation implementation among and within states have significant impacts on the mobility of capital and other resources across local jurisdictions, and this may affect economic growth (Hosoe and Naito, 2006). For example, a county's nonattainment status entails increased regulatory restrictions on pollution sources, and this, generally, results in increased pollution control compliance costs. In addition, the federal government can withhold federal funding for highway construction in non-attainment counties and impose a ban on the construction of new plants that would significantly add to emissions. Thus, the designation of a county as non-attainment may result in loss of jobs and is likely to make a difference in whether or not it will be able to retain and attract businesses. In summary, the non- 
attainment designation puts an area at a competitive disadvantage relative to attainment areas by creating additional regulatory burdens for businesses (Harrison, 2008).

Utility maximizing individuals and profit maximizing firms will take into account variations in environmental policy and economic incentives when choosing their location. This phenomenon is akin to Tiebout's sorting hypothesis: different preferences for environmental amenities will result in self-selection (Tiebout, 1956). This means that location choice decisions for households and firms involve a trade-off between economic factors as well as the quality of the environment. It is well known that the quality of the environment in U.S. states has been determined by local and state authorities. In spite of significant improvements in environmental quality in the U.S., environmental policymaking is an area that has drawn controversy in relation to its impact on economic growth. As discussed above, the general view is that environmental regulations thwart economic growth. For the purpose of this study, environmental regulation stringency is measured by county level attainment status of the federal air quality standard for $\mathrm{O}_{3}, \mathrm{SO}_{2}, \mathrm{TSP}, \mathrm{Pb}$, and $\mathrm{CO}$.

Contrary to the view that environmental regulations thwart economic growth, Porter (1991) and Porter and van der Linde (1995) argue that environmental regulations stimulate technological innovation and lead to industrial growth. This view is known as the Porter hypothesis. The Porter hypothesis posits that well designed environmental regulations result in a number of multiplier effects such as productivity improvement and improved firm profitability. Berman and Bui (2001) present evidence that supports the Porter hypothesis by showing that manufacturing productivity for the Los Angeles Air Basin refineries increased during the period 1987-1992. The Porter hypothesis could work because firms complying with state and local environmental regulations will invest in new capital equipment that improve productivity and at 
the same time help reduce emissions of pollutants. An improvement in air quality has an amenity value and that may also affect the pattern of economic growth (Van, 2002; Grossman and Krueger, 1995).

In response to the Porter hypothesis, a number of studies have attempted to shed more light on the relationship between environmental regulations and economic performance. Within this context, conflicting empirical results emerge. Goetz et al. (1996), for instance, argue that stringent environmental regulations result in increased environmental quality, which in turn helps to attract businesses, skilled workers, and wealthy citizens to regions with better environmental quality. This means that such regions experience employment growth, income growth, and demographic changes due to improved environmental quality (Gottlieb, 1995; Mobley and Izraeli, 1995; Izraeli, 1985).

Some empirical studies have found evidence that contradicts the Porter hypothesis and show that environmental regulations negatively affect productivity and location decisions of new plants (Gray and Shadbegian, 1993; Jaffe, 1995; List and Co, 1999; Tannenwald, 1997). This means that environmental regulations can act as a barrier to the entry of polluting firms in a particular market. This may alter the structure of the market in terms of the number of firms in the industry entering a particular county and thereby reduce competition (Kohn, 1985). Standard neoclassical economic theory has shown that a profit maximizing firm takes into account environmental regulations prevailing in an area. Hence, investment decisions are influenced by the stringency of environmental regulations (Gray and Shadbegian, 1993). This view has led to the theory of a "race to the bottom," a situation where environmental regulations in a particular locale move below optimal levels in order to be more attractive to firms than competing jurisdictions (Engel, 1997). Theoretically, lax environmental regulations allow firms to have 
lower operating costs because they spend less on pollution control. Thus, reduced operating costs may result in higher profits and this may help retain businesses as well as attract businesses to a given jurisdiction.

Many studies critical of Porter's hypothesis have argued that environmental compliance results in increased cost of production for polluting firms and higher prices for consumers. Undoubtedly, this results in the diversion of inputs which contribute to industrial productivity, consequently affecting relocation and investment decisions of firms. Productivity, broadly defined as output per unit of input, is believed to be an important determinant of competitiveness as well as an essential factor in economic growth and improved standard of living (APOGEE, 1991). Yandle (1985, p. 39) points out that the "effects of environmental regulations go far beyond the physical plant closings and worker layoffs" and that the regional concentration of polluting industries may affect regional development. These views recognize the fact that manufacturing is not isolated from the rest of the national economy and that, therefore, the effects of environmental regulations on manufacturing may inadvertently affect other sectors of the economy which supply goods and services to the manufacturing sector, consequently affecting regional development. The effects may also result in welfare distortions in local communities which are heavily dependent on tax receipts and other royalties from polluting firms to finance public infrastructure programs (Tannenwald, 1997).

From the foregoing discussion, it is clear that the impact of environmental regulation stringency on economic growth remains an open question. The inconsistencies in results in the literature can be attributed to a number of factors, including estimation methods, data issues, focus of study, and stated objectives. While some of the studies provide anecdotal evidence, many of the empirical studies have failed to produce irrefutable evidence on the interactions of 
environmental regulations and regional growth. The central theme of previous studies has been to estimate the impact of environmental regulations on productivity changes and firm location choices. Previous studies have also overlooked the fact that indirect employment effects arise in firms supplying the producers of pro-environmental goods with capital or services to polluting firms. To this end, the pertinent question to be asked is: what is the role of local environmental regulation in regional development?

In order to address this question, this research extends the work of Li (2006) who examines the impact of environmental regulations on employment and population change. $\mathrm{Li}$ utilizes a regional growth model that takes into account the interdependencies between employment and population changes, and how these growth factors are affected by environmental regulation stringency. The major shortcoming of Li's study is that it does not take into account the feedback relationship between environmental regulation stringency and changes in population and employment, respectively. In this study, it is argued that environmental regulation stringency in a particular locale is likely to be jointly determined with other regional factors such as per capita income, population, and employment. Ostensibly, complying with environmental regulations results in the diversion of income from factors such as health, education, and housing that affect human welfare and economic growth. The literature on the environmental Kuznets curve shows that an increase in per capita income is associated with a decrease in pollution, because environmental quality is a normal good; hence demand for environmental quality increases through the income effect (Grossman and Krueger, 1995). This means that utility is likely to increase (decrease) as income goes up (down). By the same token, changes in some of the socio-economic and demographic factors, including firms' rent seeking 
activities, may influence the level of environmental regulations (Cole et al. 2006; Nelson et al. 1986).

The existing literature has examined only a portion of the larger problem. Therefore, any modeling attempting to understand the impacts of environmental regulations on regional growth should take into account simultaneous interactions among environmental regulations, income, population, and employment changes. Thus, the purpose of this study is to take a first step in filling the aforementioned gap in previous studies by using a four simultaneous equation model. The model captures the feedback relationships among population change, employment change, per capita income change, and environmental regulation [county attainment status].

This study differs from previous studies in two fundamental ways. First, this study focuses on the role of environmental regulations in economic growth by capturing the interdependent relationship among changes in employment, population, per capita income, and environmental regulations. Thus, the analysis is extended beyond the firms and industries directly affected by environmental regulations. Using econometric techniques, this approach uniquely traces the structural relationships of the endogenous factors by utilizing a four-equation simultaneous regional growth model, a variant of the Deller et al. (2001) growth model.

Second, the study considers the inter-jurisdictional differences in economic growth and environmental regulation stringency. This is aimed at capturing the spillover-effects resulting from the spatial heterogeneity in economic incentives and environmental policy making across jurisdictions by use of a Spatial Durbin Model (SDM). Thus, the second contribution of this study is the use of the spatial regression methodology that captures the direct effects, indirect effects (spillovers), and total effects arising from the changes in the dependent variables and 
explanatory factors. The methodology developed by LeSage and Pace (2009) will form the basis for drawing conclusions on the statistical significance of the direct, indirect, and total effects.

\subsection{Profile of Study Area}

The study area is confined to the 410 counties of the Appalachian Region, which includes all of West Virginia and parts of Alabama, Georgia, Kentucky, Maryland, Mississippi, New York, North Carolina, Ohio, Pennsylvania, South Carolina, Tennessee, and Virginia. The region is divided into three distinct geographic subregions: northern, central, and southern Appalachia, as shown in figure 1.1. Northern Appalachia includes counties of Maryland, Ohio, New York, Pennsylvania, and 46 counties in West Virginia. Central Appalachia includes counties in eastern parts of Kentucky, Tennessee, southwestern parts of Virginia, and 9 southern counties of West Virginia. Southern Appalachia consists of counties in Alabama, northern parts of Georgia, Mississippi, North and South Carolina, eastern parts of Tennessee, and western parts of Virginia. Of the three subregions, the northern region is the most urban, while the central region is the most rural.

Data from the 2000 United States census of population indicate that the Appalachian region had a population of some 23 million, equivalent to 8 percent of the U.S. population. The net change in population between 1990 and 2000 for the Appalachian region was estimated to be 9.5 percent, compared to the U.S rate of 13.1 percent. State populations range from roughly 1.8 million in West Virginia to more than 5 million in the Appalachian counties of Pennsylvania. Population growth has been uneven due to marked differences in economic opportunities, terrain, services, infrastructure, and so forth. 
Figure 1.1: Appalachian Counties and Subregions

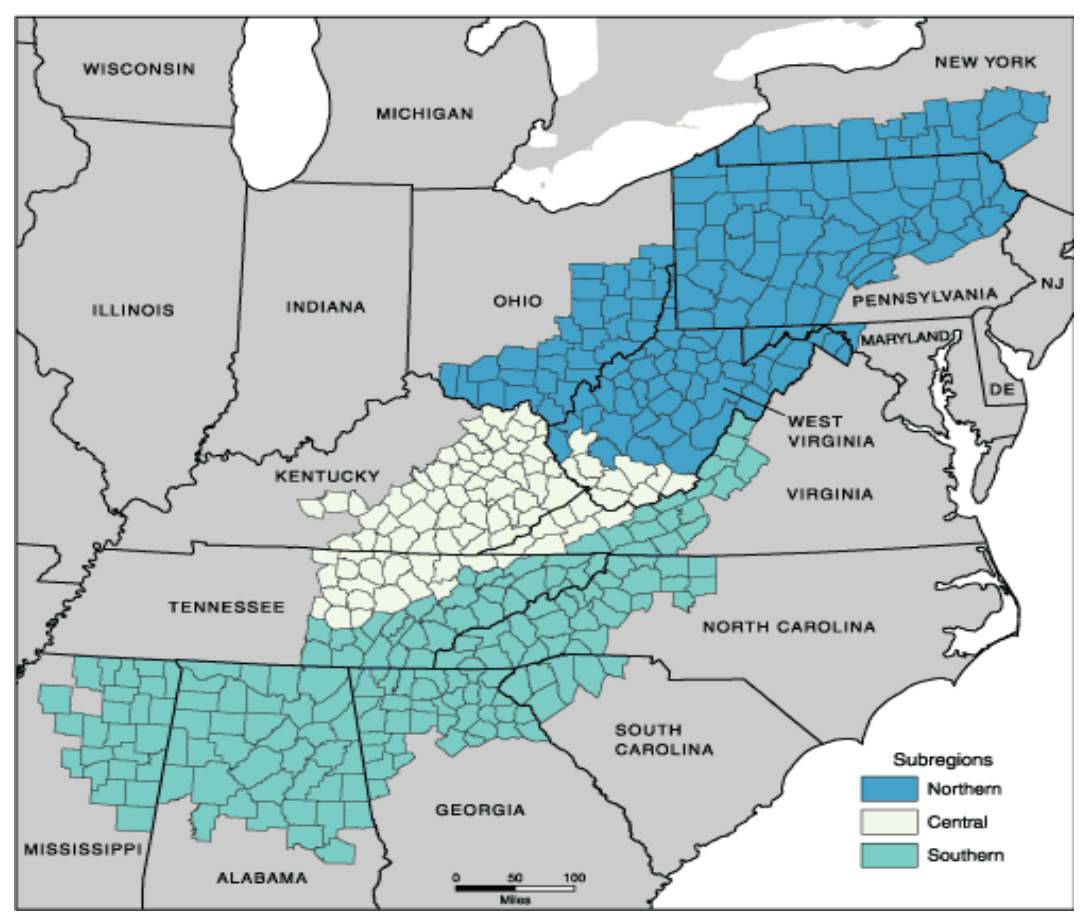

Source: Appalachian Regional Commission, 2002

Poverty continues to be a challenge to the region's population (Glasmeier and Fuellhart, 1999). In 2000, 13.6 percent of the region's population lived in poverty, as compared to 12.4 percent of the U.S. population. Educational attainment in Appalachia is well below the national average. In 2000, for example, the percent of high school and college graduates, respectively, was 76.8 and 17.7 percent versus the U.S. figures of 80.4 and 24.4 percent. Regional levels of per capita income are also below those of the U.S. as a whole and labor force participation is lower than the U.S. average (Acs and Kallas, 2007). The number of jobs per 100 people in the Appalachian region is approximately 53.09 compared to the national rate of 59.59 jobs, underscoring the relative dearth of economic opportunities in the region. Table 1 summarizes important socioeconomic indicators in the Appalachian region. 
Table 1.1: 2000 Economic and Demographic Indicators for Appalachian Region and the U.S.

\begin{tabular}{|l|l|l|}
\hline \multicolumn{1}{|c|}{ Indicator } & Appalachian Region & United States \\
\hline Population (million) & $22,894,017$ & $281,421,906$ \\
\hline Per Capita Income (\$) & 27,124 & 33,050 \\
\hline Poverty Rate (\%) & 13.6 & 12.4 \\
\hline Population 25 and Older with 4 years of College (\%) & 17.7 & 24.4 \\
\hline Number of Jobs per 100 People & 53.09 & 59.59 \\
\hline
\end{tabular}

The Appalachian Regional Commission (ARC), a state and federal partnership program, uses the level of local economic development as a basis for classifying counties into four categories: distressed, transitional, competitive, and attainment counties. Despite the fact that some counties are in better economic shape than they were in the 1990's, the region continues to grapple with economic challenges as seen by the increase in the number of distressed counties between 2002 and 2005 (see figures 1.2 and 1.3).

As of 2004, a majority of the counties in Central Appalachia and a few counties located in Southern Appalachia were classified as distressed counties. Distressed counties are those with unemployment and poverty rates that are at least 1.5 times the national rate and a per capita income no greater than two-third of the national average. Transitional counties are those whose economies are transitioning between strong and weak economies. Counties with unemployment and poverty rates better than the national average are classified as competitive counties, while counties which are at par with national levels in terms of poverty, unemployment and income are classified as attainment. 


\section{Figure 1.2: 2002 Appalachian Counties' Economic Status}

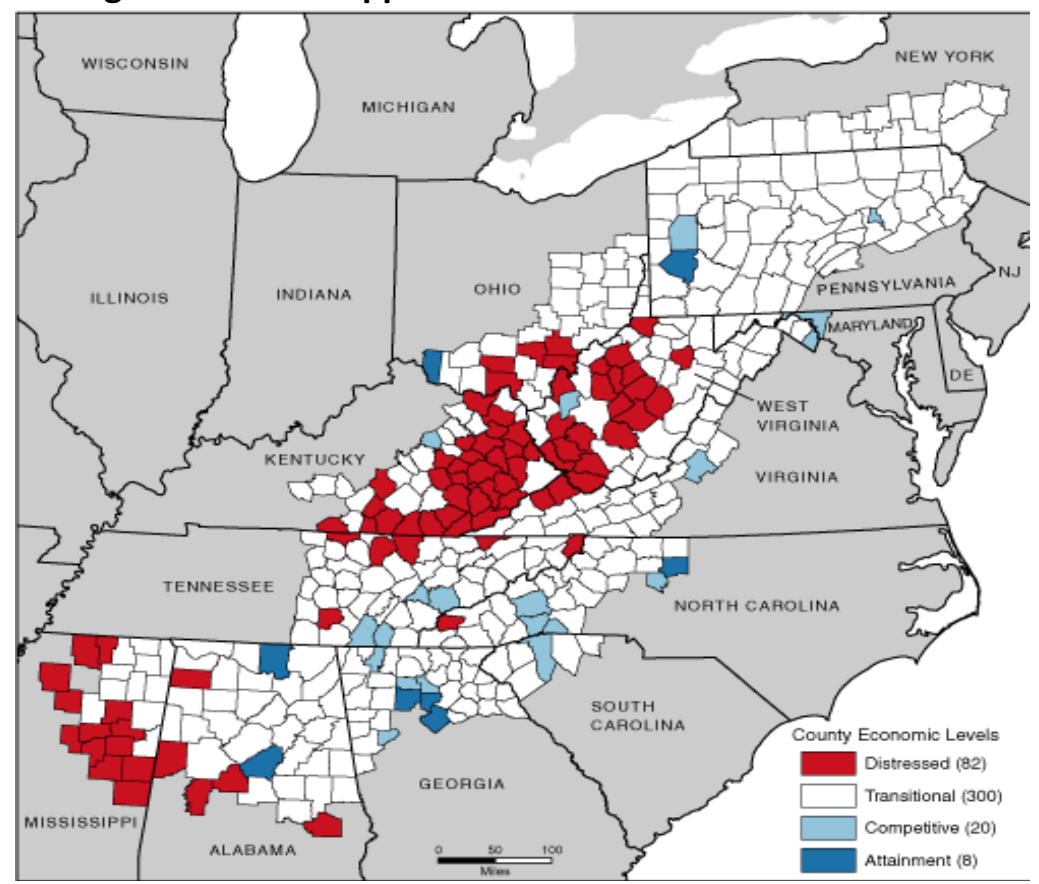

Figure 1.3: 2005 Appalachian Counties' Economic Status

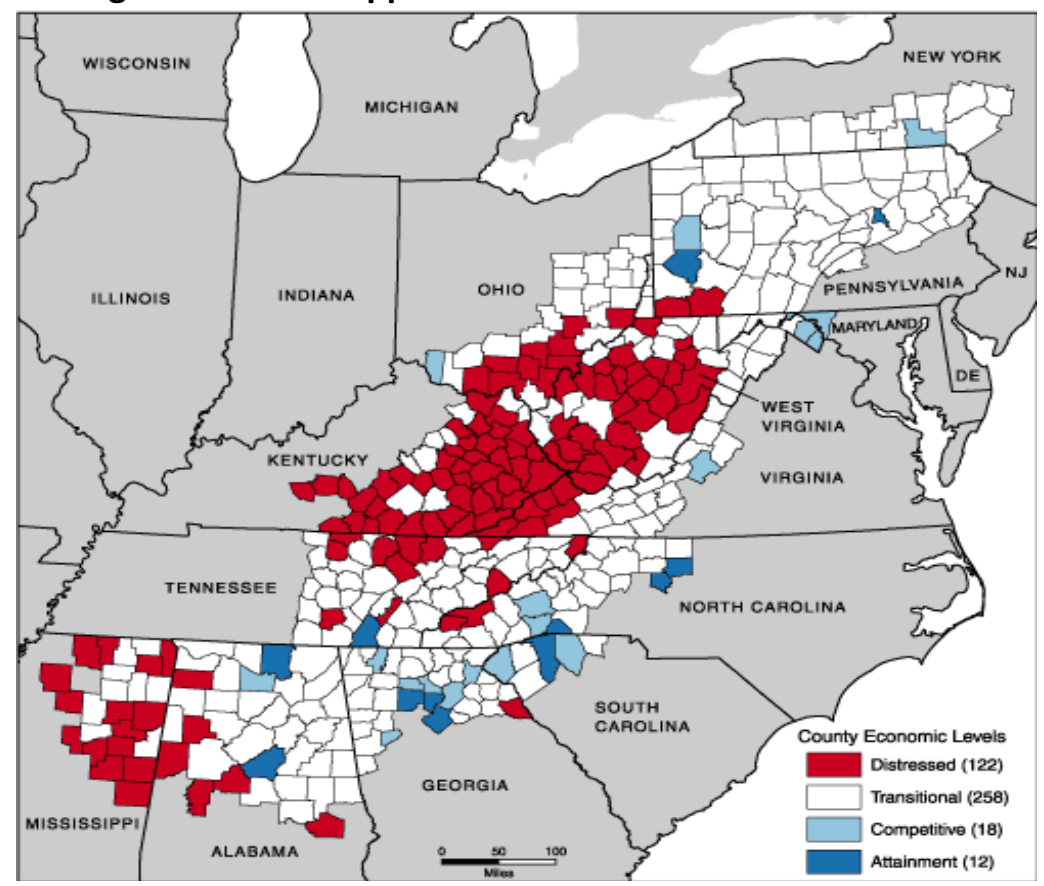

Source: Appalachia Regional Commission

The Appalachian region's economy has been transformed over the last three decades and has moved from being an economy dependent on manufacturing, agriculture, and coal mining, to 
one that is more diversified and more dependent on service sector employment (Wood, 2005). These structural changes have led to loss of jobs in the core industries of Appalachia, particularly the coal industry. Today, manufacturing, services, and government occupations account for the majority of jobs in the Appalachian region.

The Appalachian region is chosen for two primary reasons. First, the 118 coal-mining counties of the Appalachian region account for more than one-third of the coal produced in the U.S., coal mining remains a major industrial activity for the region. Some air pollution because of coal related activities is therefore unavoidable (see figures 5.2 and 5.3). Given that coal is a cheap energy source, a number of coal-fired power plants and other industries have strategically located in the Appalachian region, resulting in emissions of:

- Carbon dioxide, the major greenhouse gas that is linked to global warming.

- Sulfur dioxide, a chemical that produces acid rain when it reacts with moisture.

- Carbon monoxide, a colorless and odorless gas that has serious health impacts to both animals and humans

- Nitrogen oxides, a chemical which leads to ozone and acid rain and causes serious health and environmental problems such as damage to lungs, reduced crop yield, among others.

- Mercury, a chemical which eventually settles in water and has the potential to harm fish and other aquatic life, as well as humans.

Consequently, people who live in Appalachia are subject to environmental degradation and exposure to pollutants. Emissions of pollutants from industrial facilities, combined with emissions from vehicles and agricultural processes have contributed to counties' non-attainment status for NAAQS. Enforcement of the federal air quality regulations is likely to have significant 
impacts on manufacturing, coal mining, and other related industries, and on communities that depend on income from regulated industries.

Secondly, considering that Appalachia is mostly rural and is confronted by a host of economic problems, such as high unemployment and poverty rates and low per capita income, the question that needs to be addressed by policymakers is whether the issue of environmental injustice applies to the region. The literature on environmental justice shows that the majority of polluting industrial facilities is in low income areas-implying that people of lower socio-economic status will disproportionately suffer from environmental exposures (Morrone, 2008; Sicotte, 2009). Research also documents that residents of Appalachian coal-mining communities have increased incidences of lung cancer and mortality rates, and high hospitalization rates for cardiovascular and respiratory illnesses compared to other, non-coal mining, regions of the country (Hendryx, 2008).

\subsection{Problem Statement}

According to the U.S. Census Bureau, the U.S. population is expected to double in the next century and it is expected that this growth will cause significant environmental changes, assuming continuation of current trends in housing consumption, commuting, and infrastructure development (EPA, 2001). A growing body of literature also suggests that the increase in vehicle-miles traveled by cars and trucks is the leading source of air pollution (Cassady et al., 2004).

In order to protect the environment and safeguard public health, federal and state interventions are necessary. All environmental policy intervention causes consumers and producers to incur the cost externalities. Therefore, environmental regulation stringency 
influences firms' and households' location decisions as well as their production and consumption decisions.

There is a large body of literature on environmental regulations and economic performance, but results are ambiguous. Cole et al. (2006) assert that this is because environmental regulations have been treated as exogenous. This suggests that an accurate representation in an econometric model must account for simultaneity between environmental regulation and economic growth. Given that environmental regulation has been treated as exogenous, most previous empirical studies assume unidirectional causality, which means that OLS estimation produces biased and inconsistent results.

This study extends the knowledge by accounting for the feedback relationships, using a four equation simultaneous regional growth model that captures the interdependences among population, employment, per capita income, and environmental regulations. There is currently no study that has considered these interdependences. Figure 1.4 illustrates the simultaneous interactions between environmental regulation and economic growth.

Figure 1.4: Simultaneous Interactions between Environmental Regulations and Economic Growth

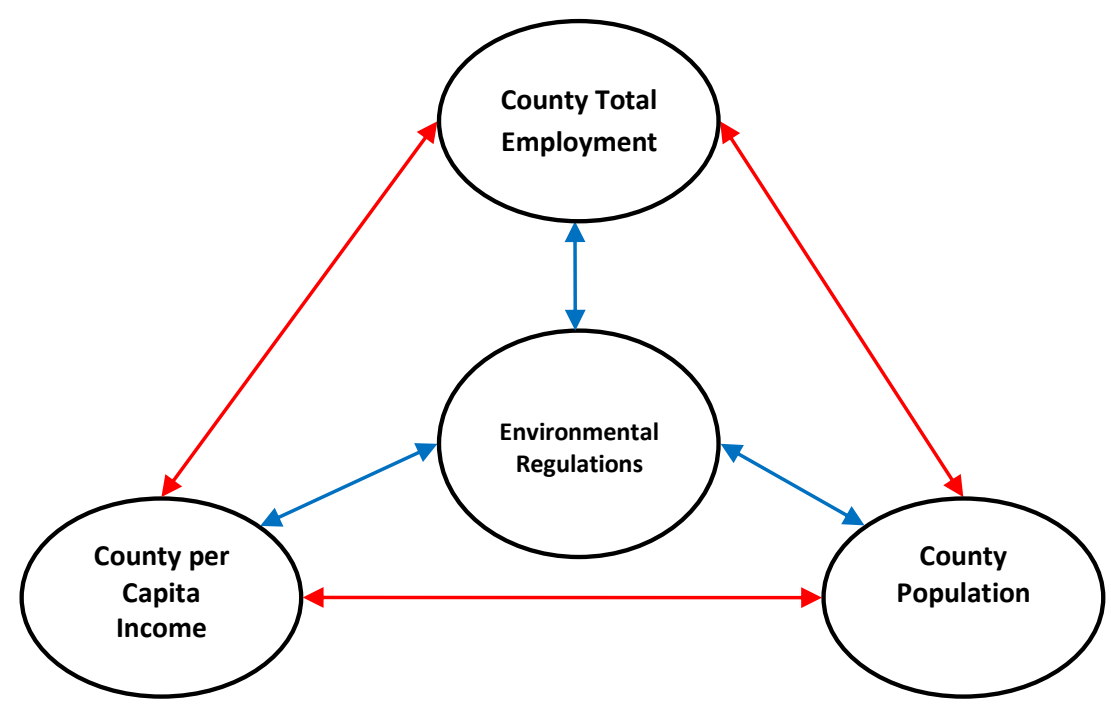




\subsection{Research Justification}

Understanding the underlying process of developing and implementing environmental regulation that promotes environmental quality and also enhances economic growth is a challenging task for policymakers. In addition, implementation of policies such as air quality regulation requires an understanding of the dynamics between air pollution and economic growth because social and economic forces cause environmental change and thus influence a county's attainment status, while attainment status impacts a county's economic performance.

The task of developing optimal policies that promote environmental quality and economic growth has become more complicated due to increased interstate economic competition. Increased interstate economic competition is hypothesized to cause a race to the bottom if states feel that they cannot adopt stricter environmental regulation than competitors ${ }^{1}$. To avert a race to the bottom, policymakers need to understand the direct and indirect effects of environmental regulation stringency on economic and demographic factors and vice versa. By extending the modeling beyond firms and industries directly affected by environmental regulations, this study is instructive regarding the impact of environmental regulations on economic performance. The results from this research are useful to local and state policymakers because they identify the potential to simultaneously promote economic growth and environmental quality.

\footnotetext{
${ }^{1}$ The theory maintains that when states are confronted with interstate competition, states have an incentive to reduce environmental standards in order to attract mobile capital and thus gain competitive advantage over other jurisdictions. Engel (1997) provides a good exposition on the issue of race to the bottom.
} 


\subsection{Research Objectives}

The general objective of this research is to empirically examine the relationship between environmental regulations and changes in regional growth in the Appalachian region. The specific objectives are:

1.0 To develop a model that takes into account the feedback relationships between income, employment, population and environmental regulations.

2.0 To empirically determine the impact of county differences in environmental regulations on population, income, and employment and vice versa.

3.0 To empirically identify the key regional growth factors that influence environmental regulation stringency.

4.0 To draw relevant policy recommendations from the empirical findings.

\subsection{Hypotheses}

In order to analyze the relationship between environmental regulations and economic growth, this study will test the following five hypotheses:

1. The share of manufacturing employment is inversely related to environmental regulation stringency but positively related to economic growth.

2. Manufacturing industry establishments have a positive effect on employment growth, per capita income, and environmental regulation stringency.

3. Environmental regulations positively affect income, population growth, and employment. This, implicitly tests the Porter hypothesis which suggests that environmental regulations, if properly designed, will spur economic growth in the long-term.

4. Higher levels of per capita income raise the public's demand for environmental regulation, which translates into improved environmental quality. 
5. Demographic variables and county characteristics such as population, unemployment rate, age, education, and race play a key role in environmental outcomes.

\subsection{Organization of the Study}

This study is organized into six chapters. Chapter 2 contains a review of the literature on environmental regulation and economic growth. Chapter 3 provides the theoretical foundation

for developing the empirical model. Chapter 4 explains the method of estimation and introduces the data types and sources. Chapter 5 presents the empirical research findings and interpretation. Finally, chapter 6 concludes with a summary of the findings, policy implications, limitations, and suggestions for future research. 


\section{CHAPTER 2}

\section{LITERATURE REVIEW}

\subsection{Introduction}

This chapter provides a review of the literature on the environmental regulationeconomic growth relationship. The vast majority of past studies have exclusively focused on affected industries in the manufacturing sector. The justification for this is that many of the environmental policies are directed at manufacturing industries and, therefore, aggregate changes in employment, firm expansion or contraction directly affect the manufacturing industry (Bartik, 1985). Consequently, several researchers including Condliffe and Morgan (2009), Duffy-Deno (1992), Gray and Shadbegian (2002), and Fredriksson and Millimet (2002) estimate the impact of environmental regulation on economic growth using a single equation. Many of these researchers agree that the variables used as proxies for environmental regulations introduce endogeneity bias in the estimation because environmental regulations can be endogenously determined by a number of factors such as income, population, and employment change, and many other socio-economic characteristics. Thus, one unexplored area in the empirical literature is the use of structural equations in estimating the environmental regulations-economic growth relationship.

The rest of the chapter is organized as follows. Section 2.2 provides a review on the measures of environmental regulations used in previous studies. Section 2.3 provides a review of

literature on the demand and supply sides of environmental regulations and section 2.4 is a review of literature on the environmental regulation-economic growth relationship. Section 2.5 provides an overview on the determinants of regional growth. 


\subsection{Measures of Environmental Regulation Stringency}

A survey of the literature reveals lack of agreement on the causal relationships between environmental regulation and regional growth (Gray and Shadbegian, 1993). There is also no agreement on the appropriate measure for environmental regulation at the county-and state-level, respectively. Consequently, various measures of environmental regulation have been used in past studies, as the following section shows.

\subsubsection{National Ambient Air Quality Standards}

The most widely used measure of environmental regulation stringency at the county-level is the attainment status of the CAA standard for NAAQS (Becker and Henderson, 2000; Fredriksson and Millet, 2001; Greenstone, 2002; List et al., 2003). Counties whose air quality meets federal standards have attainment status and counties that do not meet the standards are in non-attainment. The 1977 CAA amendments further impose stringent pollution control for new and expanding sources in non-attainment areas. In order to prevent the worsening of air quality in attainment areas, the 1977 amendments also set tougher standards for new sources in attainment areas by establishing the New Source Performance Standards (NSPS). The 1990 CAA amendments further strengthened regulations towards electric utilities by limiting the amount of sulfur dioxide and mercury emissions. In addition, the amendments introduced the sulfur dioxide emissions program and tightened motor vehicle emissions standards.

Many studies show that air quality regulation imposed when a county fails to achieve federal ambient air quality standards negatively affect firm location and investment decisions, and productivity levels. New plants locating in non-attainment areas face more stringent (costly) environmental regulation than existing firms located in attainment counties. Therefore, nonattainment is thought to discourage new business investment. Typically, new firms locating in 
non-attainment counties are subject to a standard of Lowest Achievable Emission Rate (LAER), which imposes adoption of cleanest technologies, regardless of cost, while new firms locating in attainment counties are only required to install Best Available Technology (BAT). Therefore, Maloney and McCormick (1982) assert that the regulatory bias against new sources of environmental pollution protects existing firms from competition and allows them to earn positive economic profits. Differentiated regulation provides an incentive to retard the turnover of the capital stock if only new investments are subject to stricter regulation. This increases the cost of environmental protection and retards attainment of the desired minimum environmental quality (Duffy-Deno, 1992; Fullerton and Kim, 2006).

\subsubsection{Superfund Sites and Number of Inspections}

The second measure of environmental regulation stringency is the number of superfund sites in a county and its related costs. Under the Comprehensive Environmental Response, Compensation and Liability Act (CERCLA) of 1980, the EPA is given power to place sites that pose an imminent and substantial danger to public welfare and the environment on the National Priorities List (NPL). ${ }^{2}$ The Superfund Act has also given the EPA the power to sue firms for the release of hazardous waste and compel them to clean-up, remediate, and pay monetary compensation for personal damage. Remediation costs typically include capital costs, operating, maintenance and monitoring costs. The growing importance of environmental quality, combined with the increase in the number of claims associated with contaminated site clean-ups has also provided an impetus for institutions, such as the Securities Exchange Commission (SEC), banks, insurance companies, and accounting firms to require firms to disclose their environmental

\footnotetext{
${ }^{2}$ The EPA assesses hazardous wastes sites and uses a set of criteria to place the sites that are a potential threat to human health and the environment on the National Priorities List.
} 
liabilities and costs (Harper and Adams, 1997). ${ }^{3}$ Within this context, previous studies have estimated economic benefits and impacts of the Superfund program and have determined that compliance with the Superfund legislation can result in improvements of public welfare (Greenstone and Gallagher, 2005) as well as affect corporate earnings, ability to obtain a loan, and consequently affect investment activities (Lawrence and Khurana, 1997; Walden and Schwartz, 1997).

A less commonly used measure for environmental regulation stringency is the number of regulatory inspections of a firm. This measure of environmental regulation has been applied in county-level and state-level studies (Anton et al., 2004). If a firm that has been subjected to a higher number of inspections in the past faces a greater chance of receiving penalties, then it is more likely to adopt measures that reduce compliance costs. Brunnermeier and Cohen (2003) point out that increased monitoring activities may result in the loss of reputation of the polluting firm as well as loss of contracts.

\subsubsection{Pollution Abatement Costs and Expenditures}

Many state-level empirical studies have used pollution abatement costs and expenditures (PACE) as a proxy for environmental regulation stringency. The PACE survey covers data on U.S. manufacturing, mining, and electric facilities' costs of complying with environmental regulations, including operating and capital expenditures for air, water, and solid waste pollution abatement efforts. It is conducted jointly by the U.S. Census Bureau and the EPA. Studies that have used PACE as a measure of environmental regulation stringency have focused on a wide array of issues, and results from these studies generally indicate that pollution abatement costs

\footnotetext{
${ }^{3}$ The Emergency Planning and Right-to-Know Act enacted in 1986 mandated all manufacturing facilities in the U.S. to disclose to the public their release of all toxic chemicals in air, water, and land. Arguably, the environmental disclosure Act has provided an impetus for some companies to improve environmental performance in order to improve their corporate image as well as avoid liabilities, and consumer boycotts.
} 
negatively affect industry productivity. Duffy-Deno (1992) examines the impact of PACE on manufacturing employment and earnings in the United States and shows that PACE has a negative effect on manufacturing employment and earnings. Gray and Shadbegian (1993) also use PACE as a measure of environmental regulation and their results show that PACE is negatively related to total factor productivity and to the growth rate. These research findings corroborate results from other studies that find that PACE negatively affects economic production (Barber and McConnell, 1986; Denison, 1979).

\subsubsection{Environmental Indexes}

In addition to direct costs of complying with environmental regulation, a variety of indexes representing state environmental regulation stringency has been used to measure environmental regulation stringency. Two of the most widely used environmental regulation indexes are the FREE index and Green index. The Fund for Renewable Energy Environment (1987) developed the FREE index that indicates U.S. states' strength of environmental regulation programs on air quality regulation, hazardous waste, and groundwater pollution. The FREE index measures the number of monitoring stations in a state and the number of enforcement actions initiated by a state (Potoski, 2002). Hall and Kerr (1989) developed the Green index which is based on 256 measures of state environmental standards and public policy. The Green index includes an air quality index, water quality index, and toxic index. Other indexes less commonly used include the Southern Studies index and the League of Conservation Voters index (LCV). Sanyal (2007) used the LCV to capture political attitude towards environmental issues. The LCV keeps track of state senators' and congressmen's votes on environmental issues ranging from global warming, biodiversity loss to wetland conservations. It assigns a value to each pro-environment vote. 
For the purpose of this study, county attainment status of the federal air quality standards will be used as a proxy for environmental regulation stringency. Attainment status of a county is an appealing proxy for environmental regulation stringency because air quality problems result from several stationary pollution sources including power plants, factories, farming, heating of buildings, as well as cars, buses, and other mobile sources. Together, these sources represent production and consumption activities that contribute to environmental degradation. It can also be argued that county attainment status is an appropriate measure for environmental regulation stringency because its enforcement is felt by the county's households and firms; therefore, the analysis of such impacts must be made at county-level (Greenstone, 2002; Jeppesen et al. 2002; List et al. 2003).

\subsection{Supply of and Demand for Environmental Regulations}

Welfare economics shows that without any form of regulation society will not allocate resources optimally because of market failure. Market failure manifests itself in forms such as sub-optimal air pollution, water quality degradation, and land degradation that impose unreimbursed costs on people and firms not responsible for the pollution. Typically, when production of a good generates significant negative externalities, profit maximizing firms in a competitive market supply too much of that good. Consumers benefit from lower prices and consume more of the good than is socially optimal. This occurs because the externalities are not accounted for in the cost of production and consumption. Therefore, the principal rationale for the supply of environmental regulation is market failure (Swanson, 2008). Environmental regulation is therefore supplied proactively, placing constraints on the use of resources and providing the basis for sustainable economic development (Swanson, 2008). 
According to the political economy literature, the supply side of environmental regulation consists of appointed bureaucrats and elected politicians (Hacket, 2001; Schluga, 2004). Political forces are assumed to be crucial in influencing economic behavior of individuals, firms, and markets. The bureaucrats' role is to design environmental regulation that is fair, efficient, and compatible with the existing institutional framework. Institutional structure relates to issues such as party control, seniority, the role of committees and committee chairs, voting rules, and other aspects of procedure that have impacts on legislative and administrative outcomes (Hacket, 2001).

Environmental regulation imposes constraints on the use of a resource by polluters. This creates a shadow price for the resource's use and stimulates technological innovation. Politicians, on the other hand, enact (supply) regulations that are appealing to their constituents, while also accommodating interest groups (Schluga, 2004). The assumption is that politicians, like other economic agents, are motivated by incentives such as ideology, economic prosperity, reelection, and power when selecting policies that best serve the public (Hacket, 2001). Politicians try to supply environmental regulations that satisfy the interest groups in order to maximize their chance of electoral success (Fredriksson and Millimet, 2001).

Because environmental regulation stimulates technological innovation, regulatory outcomes also depend on the expected costs of pollution control, which are a function of current and future costs (Schluga, 2004). Thus, another important determinant of the supply of environmental regulation is induced innovation, which forms the basis for improved productivity and competitiveness.

The demand for environmental regulations originates from individuals and firms (Hacket, 2001). As perceived health risks or damage to the environment increase, demand for environ- 
mental regulation increases because individuals react to prevent a significant reduction in their welfare.

Firms that are negatively affected by environmental regulation may organize themselves in trade associations and lobby for lower environmental standards (Hackett, 1995). Strict environmental regulation often also results in the loss of jobs. Consequently, workers in polluting industries may also oppose tougher standards. However, other firms may demand restrictive environmental regulation because it creates a new market for their products or services while erecting entry barriers for potential new entrants (Schluga, 2004).

Kahn (2008) examines the determinants of environmental regulations and finds that demographic factors such as educational attainment, income, age, population, and race significantly influence the demand for environmental regulations in the United States. Higher levels of education mean that people are better informed about environmental risks and this may increase demand for environmental regulation.

Using the Green index as a measure of environmental regulation stringency, Hay et al. (1996) examine factors that influence environmental policymaking. They use six factors to capture the demand side of environmental regulation: environmental conditions, economic resources, state pressure, political ideology, institutional characteristics and federal activity. State pressure is represented by state membership in environmental groups and percentage of employees in the manufacturing sector. Hay et al. find that membership in environmental groups, percentage of employees in manufacturing, and political ideology are positively associated with environmental regulation stringency.

Fredriksson and Millimet (2001) analyze the determinants of environmental policymaking in the 48 contiguous U.S. states. Their primary research objective is to examine if there 
is a "California effect" when U.S. states adopt environmental policies. ${ }^{4}$ Fredriksson and Millimet posit that environmental policymaking in one state is affected by the environmental standards in neighboring states, as well as other factors such as per capita income, population, population density, and urbanization. In their estimation, they recognize that environmental regulation stringency can be endogenously determined with other factors. To circumvent the endogeneity problem, they use instrumental variable estimation. Fredriksson and Millimet find that abatement expenditures in one state are influenced by abatement expenditure in the neighboring state and that California has a marginal leadership role in other states' automobile emission standards. This is consistent with previous research on strategic environmental policymaking that indicates that the level of environmental regulation stringency in one jurisdiction will impact the level in neighboring jurisdictions. ${ }^{5}$

\subsection{Environmental Regulation and Economic Performance}

Since its inception, the EPA has been concerned about the effects of environmental regulation on promoting opportunities for economic and industrial growth (APOGEE, 1991). To that end, the EPA has conducted economic-impact analyses to determine the impact of environmental regulation enforcement on society and regulated industries. The EPA concluded that environmental regulation has impacts at the community-level, facility or industry-level, company-level, and market-level (EPA, 1999). The EPA recognizes that regulatory compliance costs are incorporated into the production decisions of polluting firms, and this raises the cost of

\footnotetext{
${ }^{4}$ Vogel (1995) provide anecdotal evidence that indicate that California's high automobile emission standards influence emission standards adopted by other states in the U.S. He refers to this phenomenon as the 'California effect.' In general, California effect refers to a situation in which environmental regulations adopted by one jurisdiction are adopted by other jurisdictions.

${ }^{5}$ Fredriksson and Millimet (2001) develop a model of yardstick competition that shows that California's environmental standards have an impact on other U.S. states' environmental decisions. Additional insights on strategic environmental policymaking are found in Wilson (1996) who provides a succinct survey of the literature.
} 
production. These effects cause an upward shift in the supply function of the regulated firms; an upward shift in the supply function represents an additional cost per unit of output. The interactions between changes in supply and demand will result in a new equilibrium price and quantity. Therefore, in the aggregate environmental regulation stringency impacts employment, profit, facility closures, and tax revenue.

Over the last 30 years economists have developed and applied various tools to understand the determinants of state economic growth and how regulatory policies (both economic and environmental policies) influence economic outcomes. Researchers analyzing the impact of environmental regulation stringency have used techniques such as survey methods, general equilibrium models, partial equilibrium models, and the social accounting matrix approach.

Denison (1979) is one of the pioneers to study the relationship between environmental regulations and economic performance. Denison uses a growth accounting model to analyze the impact of environmental policies on U.S. economic growth. The results show that environmental compliance costs are responsible for a productivity loss of $13-20 \%$ over the period 1976-1978. In a related study, Jorgenson and Wilcoxen (1990) use a general equilibrium macro-model to quantify the impacts of environmental regulation stringency. Their model includes a long-term growth component with and without environmental regulations. They find that in an economy without environmental regulations the capital stock would be 3.792\% higher and GNP would be 2.5\% higher. Like Denison, Jorgenson and Wilcoxen find that mandated investments in pollution control equipment negatively affect GDP growth.

While many studies have shown that environmental regulation enforcements affect the marginal production cost, other studies have attempted to explain the economy-wide impacts of environmental regulations. Lieu (1991) utilizes a REMI model to understand economic and 
demographic impacts of complying with the South Coast Air Quality Management Rule (SCAQMD) applied to electric utilities in Southern California. The REMI model consists of 53 industries, 94 occupations, and 25 final demand sectors. He builds the model based on the assumption that producers and consumers in all regions of the country have similar behavioral characteristics. Simulation results for the 53 sector REMI model indicate that complying with SCAQMD increases the cost of doing business for affected facilities. Lieu asserts that affected firms may hike electricity rates in order to recover the increased control expenditures. He also finds that, on average, job growth is slowed and this translates into slower population growth. Theoretically, the rise in the electricity price causes the substitution of labor and capital for fuel in production. In effect, this increases demand for labor and capital and generates upward pressure on the wage rate and the cost of capital.

Harrison and Dreyfus (1995) quantify the socioeconomic impacts of proposed environmental regulations on electric utilities in Minnesota. Their study links the treatment of environmental externalities from utilities to statewide socioeconomic effects. They find that any attempt to increase regulations on utilities negatively affects growth in employment, population, personal income, and other economic indicators. This is due to the fact that efforts by utilities to internalize externalities result in increased production costs. Ultimately, part of the economic burden is transferred to consumers. Harrison (2008) suggests that complying with the NAAQS increases the financial burden of businesses and results in lower regional gross domestic product; loss of jobs; reduction in population; and loss of tax revenue.

Other studies adopt a different perspective and examine the impact of pollution on productivity and learning ability. Margulis (1992) examines the impacts of air quality on the economy of Mexico City and argues that air pollution, particularly particulate matter and ozone 
concentration negatively affect a person's productivity and learning ability. He finds that particulate matter is the most damaging pollutant in Mexico City and causes significant economic losses through increased mortality, workday losses, and reduced productivity. He estimates that the annual cost of particulates in the air is $\$ 850$ million and the related health costs $\$ 1.1$ billion. Margulis' findings are consistent with a growing body of work that links air pollution to chronic and acute health problems and premature death (e.g., Ostro, 1983; Wadell, 1974).

The influence of environmental regulation stringency on firm location decisions has also received considerable attention. To some extent, this has been precipitated by increased interstate economic competition. Condliffe and Morgan (2009) examine the impact of county-level attainment status (as a proxy for environmental regulation stringency) on plant births of polluting manufacturing firms. Their results indicate that stringent environmental regulation impacts pollution-intensive capital flows by deterring new plant births and conclude that this affects economic growth. More generally, they find that the impact of stricter environmental regulation varies by pollution intensity of manufacturers.

Similarly, List and McHone (2000) examine the effects of air quality regulation on the location decisions of pollution-intensive manufacturing plants in New York counties. They find that enforcement of the federal air quality standards has a significant effect on location decisions of new pollution-intensive plants. Their results also indicate that capital flows were diverted to counties with less stringent environmental regulation, a finding that supports the "race to the bottom" hypothesis.

In spite of anecdotal evidence supporting the race to the bottom hypothesis, some economists are critical of its validity (e.g., Millimet and List, 2003; Potoski, 2002). They conclude that environmental regulation stringency has no impact on firm location decisions and 
productivity. Dean, Brown, and Stango (1999) examine the impact of environmental regulation stringency on the formation of manufacturing establishments and find no effect on the establishment of large manufacturing firms. However, regulation discourages smaller manufacturing establishments from locating in areas with stringent regulations.

\subsection{Determinants of Regional Growth}

Because of the importance of state and local governments in structuring and financing economic development it is critical for policymaker to understand the factors that explain differences in states' economic growth. As Kale (1984, p. 31) observes, "the concern over state development incentives will probably intensify, both regionally and nationally as the federal government cuts taxes and the states are left to shoulder an increasing tax burden.” These sentiments reflect the challenges that state policymakers continue to face while trying to find ways of stimulating regional growth and development. Within this context, regional economists have determined that public policy, human capital, political factors, wages, environmental quality, industrial mix, amenities, including other socio-economic indicators play an integral role in regional growth and development.

Previous studies have measured growth and development using population, total employment, personal income, per capita income, and gross state product (Goetz, 1996; Barro and Sala-i-Martin, 1991; Carlino and Mills, 1987; Deller et al., 2001). At the regional level, a number of studies use simultaneous equations models to empirically test the "people follow jobs and jobs follow people" hypothesis. Another dimension added to these growth studies is the recognition that space plays a significant role in the variations among regional economies. Because of this, spatial econometric models have been adopted to explain regional growth disparities and dependencies across jurisdictions. 
Lundberg (2004) tests the hypothesis that the average income growth rate and net migration rate in one municipality lead to spillovers that affect the growth rates of neighboring municipalities. Lundberg finds a positive correlation between net migration rates in neighboring municipalities, suggesting that there is a spillover effect across neighboring municipalities. Likewise, Lundberg finds that an increase in the average income level in one municipality spills over into jurisdictions and affects their average income growth rates. ${ }^{6}$

Kunce (2006) employs panel estimation techniques to analyze the factors that influence growth in state manufacturing employment in the U.S. for the period 1974-1994. The model includes five key policy variables as explanatory variables: highway miles, union membership, pollution abatement expenditures, tax effort, and right to work. Recognizing that pollution control costs can be determined endogenously with firm location patterns, Kunce splits the data into five periods. While some policy variables reveal counter-intuitive results, the overall results show that pollution control expenditures, the state's tax effort, and union membership negatively affect employment growth. In addition, Kunce's results show that a state's infrastructure and right-to-work laws positively influence employment growth.

Plaut and Pluta (1983) examine the relationship between business climate and industrial growth. They argue that a good business climate is characterized by low state and local taxes, right to work, little union activity, and a cooperative governmental structure. They specify a three equation model for industrial growth represented by change in real value added, change in employment, and change in capital stock and use various explanatory variables that include climatic conditions. They find that tax effort, hot-humid weather, union activity and cost of land are negatively related to growth in real value-added, employment, and capital stock, while

\footnotetext{
${ }^{6}$ Numerous studies have emphasized the importance of strategic policymaking. For example, Case, Hines, and Rosen (1993) show that a state government's spending is positively influenced by expenditure levels of its neighbor while Brueckner (2000) discusses the role of strategic competition in relation to welfare benefits across jurisdictions.
} 
unemployment rates positively influence growth in employment and value-added. Plaut and Pluta also find that property taxes, wage rate, total education expenditure, cost and availability of land are positively related to growth in value-added, employment, and capital stock. In addition, their study shows that labor-related and climate factors are important determinants of state output and employment growth.

Goetz et al. (1996) develop an income growth model of the 50 U.S. states that includes state environmental regulations, initial levels of income, environmental quality, education, percent of jobs in nine sectors, and poverty rate. Goetz et al. find that there is convergence in income as revealed by the negative coefficient on initial income. On the other hand, the impact of education on income growth reveals a counter-intuitive effect, indicated by the negative coefficient for education. Other results show that state environmental regulations and environmental quality have a positive effect on income growth. The percent of jobs in each of the nine sectors markedly shows different impacts on income growth, with construction, manufacturing, transportation, fire, and service sectors having a positive relationship with income growth. This can be explained by the fact that these sectors are high paying and account for a large share of employment in some parts of the U.S. The study also concludes that strict environmental regulations impose costs on polluting facilities, which in the short-run negatively affect economic growth, but in the long-run have a positive effect thanks to improved environmental quality.

A recent research by Mojica (2009) is related to the general economic development problem of the Appalachian region. She uses a regional growth model to analyze the impact of entrepreneurship on economic growth, but her model does not take into account spatial spillovers. The model implicitly tests for convergence by including initial conditions of the depen- 
dent variables as explanatory variables. Mojica measures entrepreneurship using proprietorship and firm births and deaths data. Results from the population equation show that employment growth, firm birth, and entrepreneurship positively affect population growth while firm deaths shows a negative relationship. Similar to Carlino and Mills (1987) and Deller et al. (2001), Mojica finds that employment growth is positively influenced by population growth and per capita income growth. This suggests that income, population, and employment play an important role in regional growth. Mojica's results also show that population growth and firm death negatively affects per capita income growth.

Gebremariam et al. (2007) utilize a non-spatial and spatial growth equilibrium model to analyze the interdependences among employment growth, in-migration, out-migration, local public expenditures, and median household income for 410 Appalachian counties. The five dependent variables are regressed against a vector of independent variables and the initial conditions of the dependent variable. Gebremariam et al. find that income growth positively influences employment growth, but is negatively related to initial conditions of employment. Accordingly, an increase in income creates wealth and this leads to increased consumer demand for goods and services, which in turn stimulates formation of small businesses. He also finds that the proportion of population employed in manufacturing and the per capita income tax are negatively related to small business employment growth. Other results show that growth rate of in-migration strongly depends on employment growth rate, median household income, and direct local expenditures. This supports the hypothesis that counties which are experiencing growth in employment and incomes will have more in-migration. Results also indicate that there is convergence in out-migration growth rate and that employment growth rate positively affects income growth, while in-migration is negatively related to income growth. 
Li (2006) utilizes a regional growth equilibrium model to analyze the impact of environmental regulations and economic policies on population and employment growth in U.S. counties. Li employs a non-spatial and spatial simultaneous regional growth model that includes various explanatory variables such as population density, amenity index, regional dummies, air quality, manufacturing concentration, fiscal variables, taxes, human capital, and other relevant regional variables. Li determines that environmental regulations and economic policies are endogenous in the employment equation. Therefore, to circumvent simultaneity bias Li utilizes instrumental variables. Results reveal that population growth has a positive effect on employment growth and vice versa, supporting the hypothesis that people follow jobs and jobs follow people. Li's spatial model reveals that local environmental policies have a positive effect on employment growth in metro counties and a negative effect on population growth, while economic development policies have no effect on employment growth. Like previous studies, Li finds that high crime rate, population density and per capita income tax retard population growth.

Using panel data, Helms (1985) investigates the effect of state and local taxes on economic growth. He specifies a single equation model where economic growth is measured by state personal income. Helms find that taxes have different effects on business activity depending on how tax revenues are spent. He contends that if the tax revenues are used to redistribute income, economic growth will be negatively affected, while if taxes are used to improve public capital and human capital, taxes will be positively related to economic growth.

Helms' finding of the importance of infrastructure investment in economic growth is supported by Jones' (1990) work. Jones examines economic growth in relation to state's public spending policies on education, highways, welfare, police and fire services, and health/ hospitals. He finds that spending on welfare and health/hospital negatively affects economic growth while 
spending on police/fire services, education, and highways positively influences economic growth. These results are consistent with the theory that infrastructure development policies can be effectively used to stimulate economic development. Munnell (1990) has done similar work on the impact of public infrastructure on the productivity. Munnell finds a statistically significant positive relationship between public capital investment and the level of labor productivity. Munnell also finds that public capital positively influences employment growth and explains that public investment in roads enables private companies to produce their goods at a lower cost.

Pagoulatos et al. (2002) use a three equation disequilibrium adjustment model to explore the interactions among changes in employment, earnings per worker, and pollution per square mile for 3,036 U.S. counties. They find that counties with high initial levels of employment, pollution per square mile, and per worker earnings correspondingly experienced lower employment, pollution, and earnings growth. In addition, their results reveal that employment growth is deterred by union involvement, high energy and land costs. Not surprisingly, counties with higher pollution levels are found to experience slower employment growth but faster growth in earnings per worker. This reinforces the notion that workers residing in highly polluted counties will demand higher wages. In addition, this finding counters the theory which suggests that employment growth is associated with high pollution. By and large, the findings of Pagoulatos et al. support the hypothesis that better environmental quality is associated with higher employment growths. A growing number of empirical studies emphasize that environmental quality and amenity attributes play important roles in growth and development.

Evidence of the importance of environmental quality comes from Tannenwald (1997) who asserts that the central objective of environmental regulations is to promote economic welfare through the internalization of externalities. Tannenwald adds that internalization of the 
externalities can enhance a jurisdiction's attractiveness as a place to live, work, vacation, and establish businesses. As such, workers and executives may be willing to sacrifice for monetary compensation in order to work and live in communities that have better air quality. To that end, Tannenwald explains that a jurisdiction's dirty air can stunt economic growth in two basic ways. In the first place, a jurisdiction's dirty air will make the area to be unattractive to workers, thereby constrain labor supply and thus drive labor costs up. All else equal, profit maximizing firms and utility maximizing individuals migrate to an area with better environmental quality and this increases the labor supply and places downward pressure on wages. Secondly, the jurisdiction's dirty air precipitates more stringent regulation, thereby increasing environmental compliance costs for existing and new firms. However, considering that environmental regulations are more stringent on new plants, this will deter new plant establishment and thus retard economic growth.

McGranahan (1999) develops an amenity index and relates it to employment growth. He finds that for a period of 25 years employment growth is positively related to the natural amenity index. By and large, McGranahan finds that high amenity counties have three times as many jobs than low amenity counties. Like McGranahan, Deller et al. (2001) find five amenity attributes that are positively related to economic growth. Deller et al. find that climate related attributes strongly influence population, employment, and per capita income growth.

Along Similar lines, Kahsai (2009) utilizes a Spatial Durbin Model to analyze the relationship between regional growth and amenity factors for counties in the northeast region of the U.S. He uses a three-equation simultaneous growth model to account for the feedbacks among income density, population density, and employment density. Kahsai employs various measures of amenities, including other exogenous factors to explain changes in employment 
density, per capita income density, and population density. Results from the non-spatial model indicate that amenity factors positively influence population growth. Kahsai finds that only landbased and water-based amenities positively influence employment growth and per capita income growth, respectively. Kahsai's spatial analyses complement findings by Hailu (2006) by showing that county employment growth is not only affected by own-county socio-economic factors, but also by those of neighboring counties. These findings underscore the importance of utilizing spatial models that take into account interdependences among spatial units in order to explain the impacts of neighborhood characteristics on the variations in regional growth.

Building on Krugman's (1991) model, Hosoe and Naito (2006) examine the impact of environmental damage on the urban structure using an economic geography model of two regions. In this model, they show that agglomeration economies affect the productivity of other sectors via water pollution and air pollution. They argue that equilibrium distribution of population in one region relative to another depends on the pattern of environmental damage. To test this hypothesis, they consider a situation where there is transboundary pollution between two regions. In their analysis, an environmental tax is imposed on manufactured goods produced in one region, while the other region does not control for pollution. Their findings show that the tax policy leads to a decrease in population in the region without environmental controls because the region with environmental controls results in improved environmental standard. The findings by Hosoe and Naito are consistent with studies that have shown that environmental quality has a direct impact on population migration.

A study by Templet (1995) analyzes the relationship between risky environmental conditions (such as presence of high pollution-intensive plants) and economic performance in U.S. states. Templet finds a negative relationship between environmental risks and economic 
performance. The results reveal that states with a large number of pollution-intensive plants exhibit greater poverty, higher unemployment, lower retail sales growth, greater number of business failures, and lower personal income. This means that neighborhood characteristics influenced environmental outcomes.

In summary, the last 30 years produced many studies providing insights in the factors underlying differences in regional growth. Findings overwhelmingly show that education, infrastructure investment, industry mix, taxes, environmental characteristics, amenity attributes, including state economic policies play an integral role in economic development. Therefore, inclusion of policy variables like environmental regulations in regional growth models is highly relevant in order to determine economic outcomes. Unfortunately, growth effects of local economic and environmental regulation policies have not been examined in a manner which takes into account all the feedback effects. In this regard, no empirical effort has been rendered to examine the interdependences among employment, income, population, and environmental regulations in a simultaneous framework.

This study resolves the issue regarding endogeneity bias discussed in the introduction to this chapter by utilizing a regional growth model that takes into account the feedback relationship among environmental regulation stringency, income, population, and employment changes. In addition, many of the previous studies on the environmental regulations-economic growth relationship have been done at state level, consequently failing to capture the heterogeneity at local levels. This study fills that gap by conducting the empirical analysis at the county-level. 


\section{CHAPTER 3}

\section{THEORETICAL BACKGROUND}

\subsection{Introduction}

Interactions between economic growth and the environment have been modeled using growth models which typically view the environment as an input in the production function and which explore the relationship between economic growth and environmental quality (Smulders, 2000; Aghion and Howitt, 1998). Broadly, these studies show that economic growth and the environment interact in a number of ways. In the first place, the environment provides the basic inputs for production and consumption and this subsequently leads to economic growth. Secondly, the environment will act as a sink for wastes generated from economic activities of production and consumption - thereby intensifying the problem of environmental degradation. For instance, air pollution emanating from sources such as transportation systems, production activities, and so forth, will arguably affect society's economic and social welfare.

Viewed in this manner, the degradation of the environment lowers the utility of consumers as well as diminishing the productivity of factors. Hence, because of the amenity and productive values associated with the environment, this may result in society's preference for a clean environment (Smulders, 2000). Conceptually, environmental quality cannot be sustained without any form of intervention. Within the framework of endogenous growth theory, long-run growth rates are affected by government policies such as taxation and regulation (Xepapadeas, 2000). As a consequence, a modern approach to endogenous growth theory suggests that sound environmental standards promote economic and social welfare by correcting for externalities generated from production and consumption activities. Another recurrent theme in the endogenous growth theory is that environmental regulations provide a strong stimulus for 
technological progress and stress that technological progress is the engine to economic growth (Romer, 1990). The argument is that investments in physical capital and other man-made productions play important roles in expanding the available factors of production, and to the subsequent growth in output.

\subsection{Short-Run and Long-Run Impacts of Environmental Regulations}

To formalize the environmental regulations-economic growth relationship, particularly how environmental regulations affect economic growth in the short-run and long-run, let us assume that a representative manufacturing firm in the economy uses a Cobb-Douglas technology to produce aggregate output $Q$. The production function uses productive capital stock $K_{P}$, effective labor $A L$, and an aggregate of raw materials $X$, as inputs. Formally, the production function is specified as:

$$
\text { (3.1) } Q=F\left(K_{P}, A L, X\right)
$$

Labor and capital are assumed to be substitutable while technological change is endogenous and there are constant returns to scale. Other assumptions made are that the inputs contribute nonnegatively to production: $\frac{\partial F}{\partial L} \geq 0, \frac{\partial F}{\partial K} \geq 0, \frac{\partial F}{\partial X} \geq 0$.

Arrow et al. (1995) point out that the flow of emissions per time unit is related to production output, hence the environmental quality function is specified as:

$$
\text { (3.2) } E=\varphi(Q)
$$

In equation (3.2), $\varphi$ denotes the unit emissions coefficient, or simply emissions per unit of output, and $E$ is environmental quality. In this formulation, emission reduction technologies are not incorporated and thus, it can be deduced that environmental quality $E$ is decreasing in $X$ and $K_{P}$. This means that increases in the use of production technology $K_{P}$ as well as use of raw 
materials $X$ lead to changes in output and environmental quality. This raises the question whether a tradeoff exists between environmental quality and economic growth.

To examine the possible tradeoff between environmental quality and economic growth, the concept of the transformation frontier suggested by Crissman et al. (1997, p. 27) is adopted. Crissman et al. use the transformation frontier concept to show how government intervention through environmental policies and adoption of abatement technologies affects the relationship between agricultural production output and environmental quality. Figure 3.1 presents the tradeoff curve that captures the relationship between manufacturing production, $Q$ and environmental quality, $E$.

Following the specifications of the production function in equation (3.1), $K_{P}$ in figure 3.1 represents the production technology that does not incorporate pollution abatement efforts, which produces $Q_{1}$ units of output—with a corresponding air quality standard (or environmental quality) of $E_{1}$. In the short run, $K_{P}$ is fixed and thus the only variable inputs used in production are labor and raw materials. This means that an increase in the use of raw materials, $X$, will result in more output and more pollution, or equivalently a decline in environmental quality. According to figure 3.1, production of $Q_{1}$ will result in emission of pollutants which exceed the federal air quality standards, and this will lead to an areas' designation of the non-attainment status.

One way of preventing accumulation of ambient pollution levels in this model is to allow for adoption of cleaner technologies that have the ability to enhance productivity and reduce pollution. Within this context, imposition of a restrictive environmental policy will compel polluting firms to adopt abatement technologies which decrease the flow of emissions (or improve environmental quality). Assuming that $K_{a}$ is the pollution abatement technology adopted by the polluting firm, figure 3.1 shows that the short-run effect of environmental 
regulations is an improvement in environmental quality and reduced output. In the short-run, output falls from $Q_{1}$ to $Q_{2}$, while environmental quality increases from $E_{1}$ to $S R E_{2}$. Theoretically, this means that firms in the short-run will incur higher production costs due to investments in abatement technologies, and accordingly, the diversion of resources from production and investment activities will lead to slower economic growth. The reduced output $\left(Q_{1}-Q_{2}\right)$ represents the opportunity cost of environmental regulations that result in improved environmental quality relative to forgone output.

Figure 3.1: Tradeoff Relationship Between Environmental Quality and Manufacturing Output

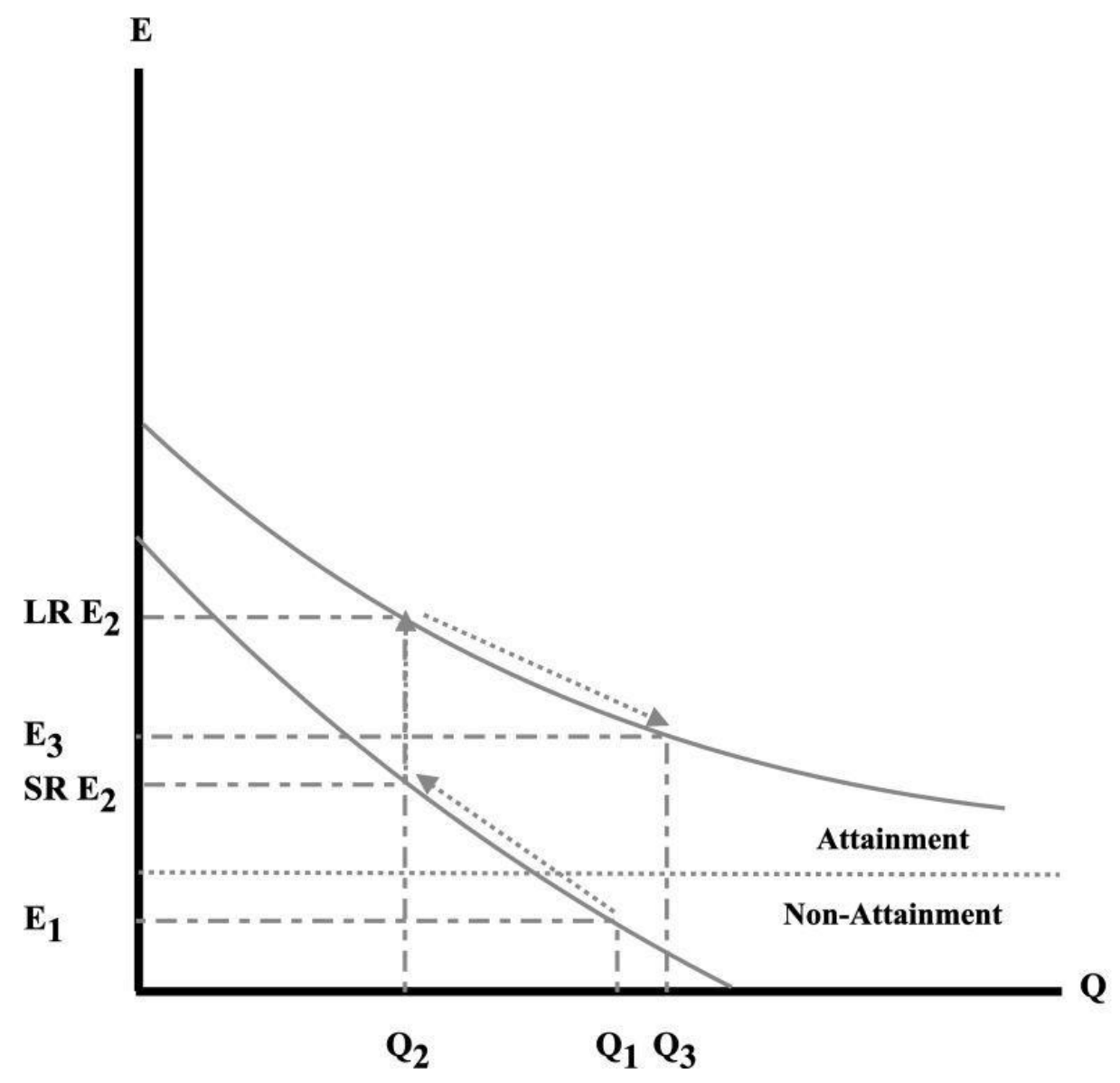


In the medium-term and long-term, firms invest in other productive technologies as well as in human capital that effectively augment output from $Q_{2}$ to $Q_{3}$ and improves environmental quality from $S R E_{2}$ to $L R E_{2}$. Within this context, technological progress enables firms to lower the marginal cost of pollution control, and this allows firms to produce more with less pollution. Figure 3.1 shows that in the long-run, adoption of abatement technologies by firms makes it possible that a region's air quality is in compliance with the federal air quality standards-leads to the attainment status $\left(E_{3}\right)$-and still allows firms to increase output from $Q_{2}$ to $Q_{3}$.

The above model shows that economic growth and environmental quality can be reconciled by allowing for technological progress. This view is supported by endogenous growth theories which posit that environmental regulations generate external effects which enhance productivity and long-run growth (Barro, 1999; Romer, 1990). Similarly, Porter and van der Linde (1995) argue that additional constraints placed on firms in the form of environmental regulations can induce technological innovations that are capable of expanding production possibilities. In this case, investments in pollution abatement technologies will lead to environmental improvements inasmuch as enhance productivity of factors of production, and thus lead to economic growth.

Because environmental policy imposes additional costs, profit-maximizing firms devote more resources to $R \& D$ in order to be more competitive. $R \& D$ activities result in more innovations in the form of new production methods, new products, and so forth (Romer, 1987; Smulders and Gradus, 1996). Insights from endogenous growth theory also indicate that the accumulation of knowledge plays an integral role in stimulating economic growth by offsetting diminishing returns (Grossman and Helpman, 1991). Smulders (1995) suggests that growth is sustainable only if abatement has a knowledge dimension which allows for growth in production 
with constant pollution. Like Smulders, Barro (1999) explains that the engine of growth is the accumulation of knowledge as this leads to R\&D activities. Under these circumstances, environmental regulations that encourage new technological development could improve efficiency.

\subsection{Environmental Quality and Economic Growth}

The graphical analysis in the preceding section illustrates tradeoffs between environmental quality and economic growth and emphasizes the importance of technological innovation in reconciling environmental quality with economic growth. It also forms the basis for analyzing the role of environmental quality in economic growth. Applying the insights from section (3.2), we assume that, besides capital and labor, environmental quality plays an important role in economic growth. Against that background, the production function in equation (3.1) is respecified to include environmental quality, $E$, effective labor $A L$, and capital stock $K$ (productive capital $K_{p}$ plus abatement technology $K_{a}$ ) as factors of production. In this case, the appropriate way of reducing emissions or improving environmental quality is to invest in two types of manmade capital stocks: productive capital, $K_{p}$ and abatement technology, $K_{a}$. The production function is expressed as:

$$
Y=F(K, A L, E) ; \text { with } \frac{\partial Y}{\partial K}>0, \frac{\partial Y}{\partial L}>0, \text { and } \frac{\partial Y}{\partial E}>0
$$

Differentiating equation (3.3) with respect to time, after re-arrangement, yields the rate of technological progress, $g$ :

$$
\left(\frac{F_{A} A}{Y}\right)\left(\frac{\dot{A}}{A}\right) \equiv g=\frac{\dot{Y}}{Y}-\left(\frac{F_{K} K}{Y}\right)\left(\frac{\dot{K}}{K}\right)-\left(\frac{F_{L} L}{Y}\right)\left(\frac{\dot{L}}{L}\right)-\left(\frac{F_{E} E}{Y}\right)\left(\frac{\dot{E}}{E}\right)
$$

According to equation (3.4) economic growth $(Y)$ depends on capital growth, labor, and environmental quality. Since environmental quality is an input in the production, it can be 
inferred that productive capital $K_{p}$ and abatement technology $K_{a}$ jointly determine the environmental quality standard according to the following function: $E=F\left(K_{p}, K_{a}\right)$. With this definition, the change in environmental quality can thus be specified as a renewable resource given that it is affected by extraction of resources and production processes; however, environmental degradation can be mitigated by putting in place environmental standards that restrict extraction of resources and limits pollution from economic activities. Following Xepapadeas (2000), environmental quality will evolve according to:

$$
E=\dot{R}(E)-Z\left(K_{a}, K_{P}\right)
$$

$R(E)$ represents an environmental regeneration function and $\mathrm{Z}$ denotes reductions in environmental quality due to emissions from economic activities. The regeneration function represents nature's capacity to absorb pollution and renew itself (Xepapadeas, 2000). Emissions, Z, are a function of productive capital $K_{p}$, and abatement technology, $K_{a}$.

Theoretically, without production emissions are zero $(Z=0)$, and environmental quality is at its maximum. Thus, we can infer that the emissions function has the following properties:

$$
\frac{\partial Z}{\partial K_{p}}>0, \frac{\partial^{2} Z}{\partial K_{p}^{2}} \geq 0, \frac{\partial Z}{\partial K_{a}}<0, \frac{\partial^{2} Z}{\partial K_{a}^{2}} \geq 0, \frac{\partial^{2} Z}{\partial K_{a} \partial K_{p}} \leq 0
$$

Equation (3.6) shows that net emissions are increasing and convex in productive capital stock, $K_{p}$, and decreasing and convex in abatement technology, $K_{a}$. The last equation indicates that a given unit of abatement may become more efficient the more polluting capital there is (Vogel, 1999). Ariga (2002) shows that the elasticities of environmental quality with respect to productive capital and abatement technology play an important role in determining the growth rate of the environment. For this reason, well-designed environmental regulations are presumed to encourage technological innovation, while poorly designed regulations can inhibit 
technological progress (Porter and van der Linde, 1995). This is the premise of the Porter hypothesis.

A clean environment means that an area is attractive to new businesses and in-migrants. In the long-run, this leads to economic growth. Goetz et al. (1996) assert that improved environmental quality has an amenity value, and therefore, has a positive effect on per capita income; it also influences firms' and households' (workers) location decisions. If the health of workers improves there is a further boost in labor productivity. This kind of relationship is illustrated in figures 3.2 and 3.3, which captures the channels of transmission of environmental regulations to economic growth.

Figure 3.2: Relationship between Environmental Conditions and Economic Growth

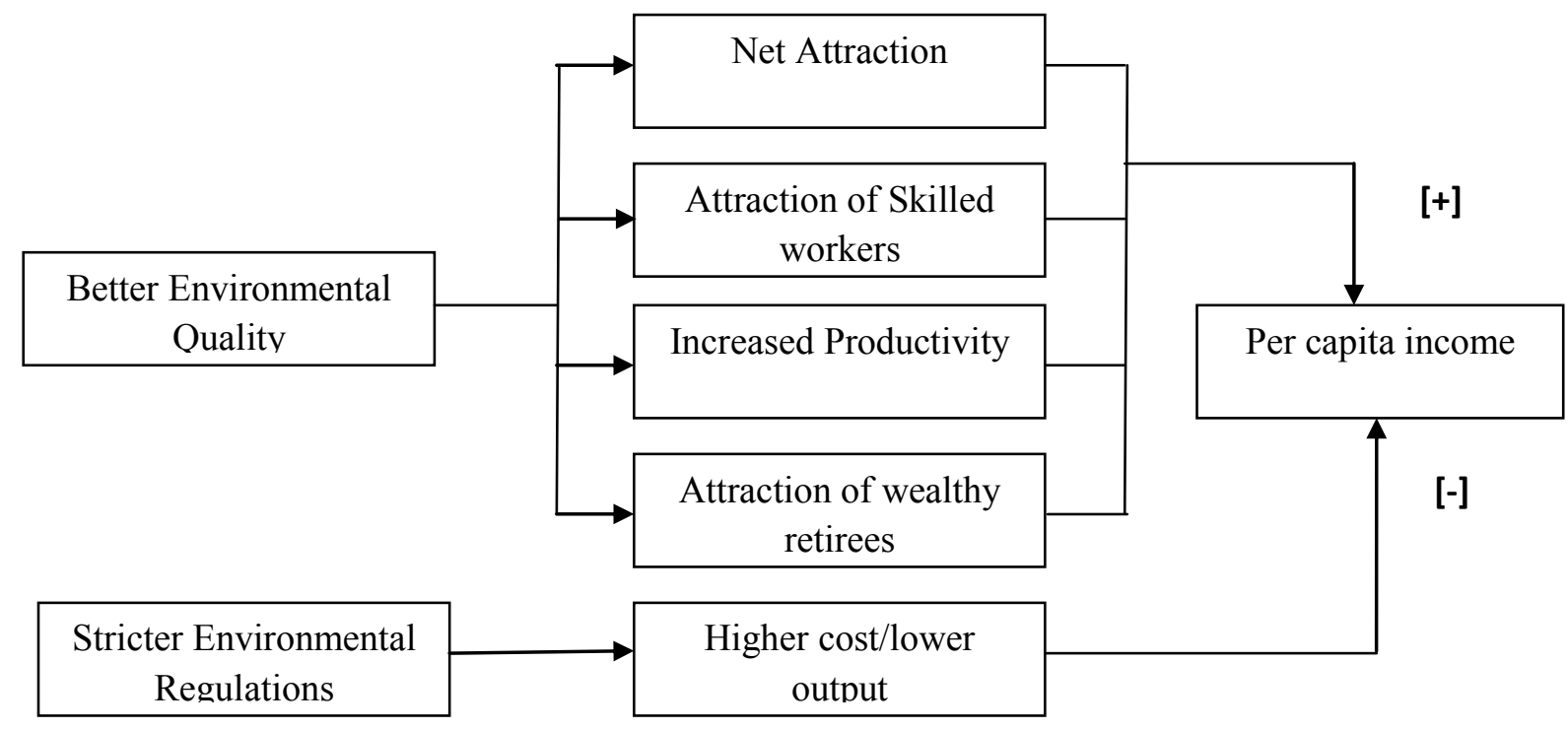

Adapted from Goetz et al. 1996

Figure 3.2 shows that the initial impact of environmental regulation is increased production costs, which result from the initial shocks of environmental regulation implementation; this culminates into reduced production output as shown by the negative sign. However, since 
environmental quality can evolve as a renewable resource in the form shown in equation (3.1), we deduce that investments in the environment in the form of abatement technology enhance the absorption capacity of the environment $\dot{R}(E)$.

\section{Figure 3.3: Long-Run Relationship between Environmental Conditions and Economic Growth}

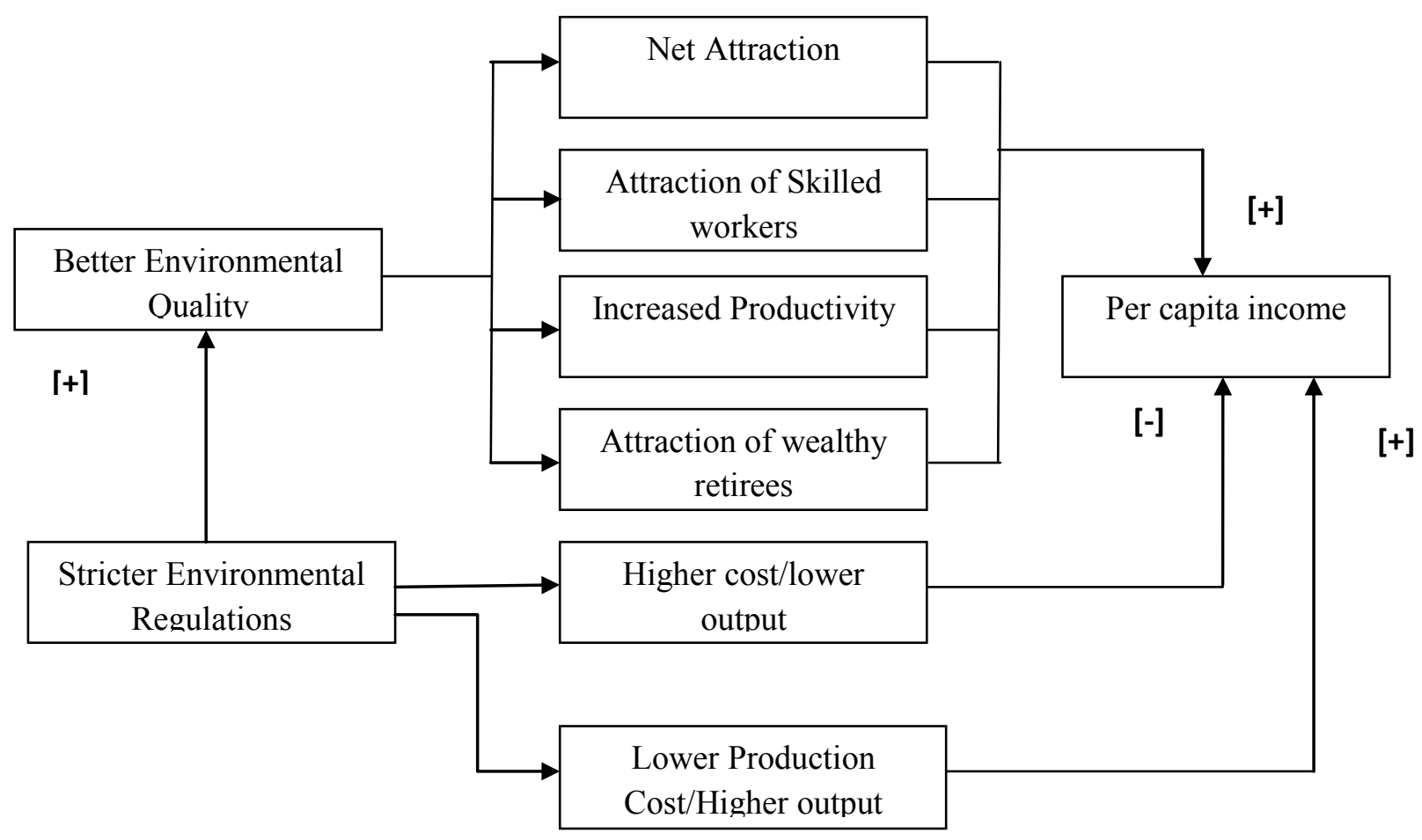

Modified version of Goetz et al. (1996)

As illustrated in figure 3.3, the long-run gain of environmental regulation is reduced production cost for regulated firms and improved environmental quality. These effects have multiplier effects in terms of attracting new firms, skilled workers, and wealthy retirees. In the long-run, this affects the living standards of households by increasing per capita income and improving the health of workers because of less exposure to environmental pollution. Therefore, government measures that are designed to reduce pollution through environmental regulations play a crucial role in promoting long-run economic growth. 


\subsection{Environmental Quality and Optimal Growth}

When discussing social optimization, it is apparent that environmental improvements will affect the behavior of households in terms of consumption, investment rates, and therefore, the pattern of economic growth. Assuming that a representative consumer derives utility from consumption of goods, $c$, and environmental quality, $E$, an ith individual's utility function can be specified as:

$$
U_{i}(c, E)
$$

Following Aghion and Howitt (1998), the utility function in equation (3.7) comes from the family of isoelastic utility functions which reflect the case of perfect complementarity (without any substitution) between produced goods, $c$, and environmental quality, $E$. Formally, this type of utility function will take the following CES structure:

$$
U(c, E)=\frac{\left(c^{\mu} E^{\omega}\right)^{1-\sigma}-1}{1-\sigma}, \sigma \in(0,1)
$$

In the above formulation, utility from consumption and environmental quality is assigned the same weight $((\mu$ and $\omega)$ and it is assumed that the utility function is strictly concave in consumption $c$, and environmental quality, $E$, according to the following functions:

$$
\text { (3.9) } \frac{\partial U}{\partial c}>0, \frac{\partial^{2} U}{\partial c^{2}}<0, \frac{\partial U}{\partial E}>0, \frac{\partial^{2} U}{\partial E^{2}}<0, \frac{\partial^{2} U}{\partial E \partial c}>0 \text {. }
$$

The last property in equation (3.9) indicates that an improvement in environmental quality will increase the marginal utility of consumption, and vice versa.

It was argued in the previous section that environmental improvements $E$ will arise due to investment in abatement technology which reduces emissions, $Z$. This entails that the aggregate capital stock $K$ consists of productive capital and abatement capital. Assuming that output $Y$ or $F(K, E)$ is used for consumption, $c$, and invested in abatement activities, $A$, the capital accumulation function can be expressed as: 


$$
\dot{K}=F(K, E)-c-A
$$

Based on the utility function specified in equation (3.7), the social planner's problem is to choose time paths for $c, E$ and $\dot{K}$ that maximize the intertemporal utility function according to:

$$
\int_{0}^{\infty} e^{-\rho t} U(c, E) d t \quad \text { subject to: } E=\dot{R}(E)-Z \text { and } \dot{K}=F(K, E)-c-A,
$$

where $\rho$ is the discount rate, $\dot{E}$ is an indicator of environmental quality while $\dot{K}$ represents the investment in man-made capital and abatement technology. The current value Hamiltonian is defined as:

$$
\left.H=U(c, E)+\lambda_{1}[F(K, E)-c-A)\right]+\lambda_{2}[\dot{R}(E)-Z(K, A)]
$$

$\lambda_{1}$ and $\lambda_{2}$ represent the co-state variables related to capital, $K$ and environmental quality, $E$. With differentiation, the following first order conditions are obtained:

$$
\begin{aligned}
& \frac{\partial H}{\partial A}=0=-\lambda_{1}-\lambda_{2} \frac{\partial Z}{\partial A} \leftrightarrow \lambda_{2}=-\frac{\lambda_{1}}{\partial A / \partial Z} \\
& \frac{\partial H}{\partial c}=0=U_{c}-\lambda_{1} \leftrightarrow \frac{\partial U}{\partial c}=\lambda_{1} \\
& \frac{\partial H}{\partial K}=0=\lambda_{1} \rho-\dot{\lambda_{1}} \\
& \frac{\partial H}{\partial E}=0=\lambda_{2} \rho-\dot{\lambda_{2}}
\end{aligned}
$$

Results in equation (3.13) show that the shadow price of environmental quality is equal to the abatement cost represented by $-(\partial A / \partial Z)^{-1}$, times the shadow price of capital, $\lambda_{1}$, whereas the conditions in equation (3.14) indicate that the shadow price of man-made capital is equal to the marginal utility of consumption. Equations (3.16) and (3.17) capture the benefits of capital investments and environmental improvements, respectively.

Endogenous growth theory shows that investments in productive capital lead to increased productivity (that is $\left.\frac{\partial F}{\partial K}>0\right)$ and may also result in increased emissions. However, the abatement technology incorporated in the model offsets emissions from production and thus 
results in environmental quality improvements. Environmental quality improvements in turn positively affect consumer utility. As shown by Smulders and Gradus (1996), when environmental quality and consumption enter the utility function, balanced growth depends on two conditions. First, consumption levels (or utility) should be non-decreasing, and second, environmental quality should be increasing or improving. This also implies that the marginal increase in consumption and environmental quality will increase utility. Thus the social optimum entails that when environmental quality is used as input in the utility function, abatement activities have to be undertaken in order to enhance social welfare.

It can be concluded that when environmental concerns are not addressed, long-term growth will result in deterioration of the environment, and thus growth will not be optimal. In this regard, increased output comes at the expense of reduced environmental quality; therefore, indicating the incompatibility between economic growth and environmental quality. However, this incompatibility can be ameliorated by imposition of environmental regulations which explicitly translate into increased cost of production for polluting firms, a decline in output (in the short-run) and improved environmental quality. In this manner, environmental quality improvements can be influenced by adopting environmental regulations or by restructuring production through the adoption of cleaner technologies. In accordance with endogenous growth theory, environmental quality enhances productivity of factors of production, and positively affects consumer welfare through the amenity and productive values; hence, in the long-run, economic growth will improve. Under these conditions, it seems possible that economic growth and environmental regulations can be compatible. 


\section{CHAPTER 4}

\section{EMPIRICAL MODELS AND DATA DESCRIPTION}

\subsection{Introduction}

Chapter three explored the theoretical relationships between economic growth and environmental regulations. It was established that without any form of intervention, economic activities can result in the degradation of environment and in turn affect productivity and social welfare. In accordance with the endogenous growth literature, it was established that well designed environmental regulations can be used to promote economic and social welfare by correcting for the externalities. Within the context of the environmental Kuznets curve literature, factors such as population density, income, industrial composition, and other socio-economic indicators can influence the level of environmental pollution. This argument implies that factors that influence the level of pollution also have a bearing on environmental regulation stringency. In addition, because of spatial variations in economic activities, different locations will supply different environmental regulations. From the concepts of utility and profit maximization, it is conceivable that consumers and firms respond to spatial variations in environmental regulation stringency, thereby resulting in different levels of population, employment, and income growth across regions. In other words, the economic development impacts of environmental regulation stringency will differ across sectors and jurisdictions.

From the foregoing discussion, the regional development impacts of environmental regulations can be understood using regional growth models which emphasize the interdependences of household residential and firm location choices. The underlying assumption of these models is that jobs follow people and people follow jobs (Steinnes, 1982). The aim of this chapter, therefore, is to discuss the empirical regional growth models for conducting the 
hypothesis tests outlined in chapter one and also to discuss the data types and sources. The rest of the chapter is organized in the following manner. Section 4.2 discusses models of regional economic growth, taking the form of non-spatial regional growth model while section 4.3 extends the non-spatial model by introducing the Spatial Durbin Model (SDM). Section 4.4 introduces a discussion on the data types and sources, including a discussion on the variables used in the equations and their expected signs. The last section (4.5) provides an overview of the estimation techniques to be used.

\subsection{Non-Spatial Regional Growth Model (Model 1)}

Since the development of causality models by Steinnes (1982) that tested whether jobs follow people or people follow jobs, models of regional development have been specified to reflect the interdependence between household residential choices and firm location decisions. Carlino and Mills (1987) modified Steinnes' model by constructing a two-equation non-spatial simultaneous model, which captured the interdependence between population and employment changes. Deller et al. (2001) extended the Carlino-Mills model by specifying a three equation simultaneous model which captured the interdependences among income, population and employment change.

The premise of these regional growth models is that utility maximizing consumers migrate in search of utility derived from the consumption of market and non-market goods, and profit maximizing firms, on the other hand become mobile when looking for regions that have lower production costs and higher market demand. As discussed in the theoretical chapter (sections 3.3 and 3.4), the long-run gain of environmental regulation is improved environmental quality and this has multiplier effects in terms of attracting new firms and workers, improved productivity, increased income, and so forth. Within this framework, this study presumes that 
interdependences exist between income, employment, population, and environmental regulation. Utility maximizing consumers and profit maximizing firms migrate to areas with better environmental quality, which are a result of increased environmental regulation. Within the neoclassical framework, households migrate in order to maximize their utility, and this migration can be stimulated by wage or income differentials, including variations in the provision of public goods and services.

Thus, this study extends Deller et al.'s model by specifying a four-equation simultaneous model. Like previous studies, it assumes that there is a lag-adjustment process between a change in one of the endogenous variables and the other endogenous variables. In a general equilibrium framework, population, employment, income, and environmental regulations are not only interdependent upon each other, but will also interact with exogenous factors, including the lagged values of the endogenous variables. The general form of the four-equation simultaneous model representing the interactions among population $(\mathrm{P})$, employment $(\mathrm{E})$, income $(\mathrm{Y})$, and environmental regulations (ER) is specified as:

(4.1) $\quad P^{*}=f\left(E^{*}, Y^{*}, E R^{*} \mid \Omega^{P}\right)$

(4.2) $\quad E^{*}=f\left(P^{*}, Y^{*}, E R^{*} \mid \Omega^{E}\right)$

(4.3) $\quad Y^{*}=f\left(E^{*}, P^{*}, E R^{*} \mid \Omega^{Y}\right)$

$$
E R^{*}=f\left(E^{*}, Y^{*}, P^{*} \mid \Omega^{E R}\right)
$$

Where $P^{*}, E^{*}, Y^{*}$, and $E R^{*}$ represent equilibrium levels of population, employment, per capita income, and environmental regulations, respectively in the ith county; $\Omega^{P}, \Omega^{E}, \Omega^{Y}$, and $\Omega^{E R}$ represent a set of exogenous variables that have either a direct or indirect effect on population, employment, income, and environmental regulations. 
Equations (4.1) through (4.4) state that equilibrium levels of population, employment, income, and environmental regulations depend on actual population, employment, income, and environmental regulations, including other exogenous variables in $\Omega s$. The general equilibrium condition specified in equations (4.1) to (4.4) can be specified as a linear relationship in the following manner:

$$
\begin{aligned}
& P^{*}=\alpha_{0 P}+\beta_{1 P} E^{*}+\beta_{2 P} Y^{*}+\beta_{3 P} E R^{*}+\sum \delta_{I P} \Omega^{P} \\
& E^{*}=\alpha_{0 E}+\beta_{1 E} P^{*}+\beta_{2 E} Y^{*}+\beta_{3 E} E R^{*}+\sum \delta_{I E} \Omega^{E} \\
& Y^{*}=\alpha_{0 Y}+\beta_{1 Y} P^{*}+\beta_{2 Y} E^{*}+\beta_{3 Y} E R^{*}+\sum \delta_{I Y} \Omega^{Y} \\
& E R^{*}=\alpha_{0 E R}+\beta_{1 E R} P^{*}+\beta_{2 E R} Y^{*}+\beta_{3 E R} E^{*}+\sum \delta_{I E R} \Omega^{E R}
\end{aligned}
$$

It is assumed that endogenous variables are not fully adjusted and that the endogenous variables adjust to equilibrium levels with substantial lags (Mills and Price, 1984). Following this relationship, the distributed partial adjustment models for the equilibrium levels for population, employment, income, and environmental regulations are specified as:

(4.11) $Y_{t}=Y_{t-1}+\lambda_{Y}\left(Y^{*}-Y_{t-1}\right)$

$$
\text { (4.12) } E R_{t}=E R_{t-1}+\lambda_{E R}\left(E R^{*}-E R_{t-1}\right)
$$

The subscript $(t-1)$ refers to the initial conditions of the endogenous variables, which in this case are the 1992 values; $\lambda_{P}, \lambda_{E}, \lambda_{Y}$, and $\lambda_{E R}$ represent the speed-of-adjustment coefficients to desired levels of population, employment, per capita income, and environmental regulation. Adjustment coefficients are assumed to be positive and between zero and one. 
Equations (4.9) through (4.12) show that current employment, population, income, and environmental regulations are dependent on their initial conditions and on the change between equilibrium values and on its lagged values. After rearranging equations (4.9) to (4.12), we obtain population, employment, income, and environmental regulation changes as shown below.

$$
\Delta P=P_{t}-P_{t-1}=\lambda_{P}\left(P^{*}-P_{t-1}\right)=>P^{*}=\frac{1}{\lambda_{P}}\left(P_{t}-P_{t-1}\right)+P_{t-1}
$$

$$
\Delta E=E_{t}-E_{t-1}=\lambda_{E}\left(E^{*}-E_{t-1}\right)=>E^{*}=\frac{1}{\lambda_{E}}\left(E_{t}-E_{t-1}\right)+E_{t-1}
$$

$$
\Delta Y=Y_{t}-Y_{t-1}=\lambda_{Y}\left(Y^{*}-Y_{t-1}\right)=>Y^{*}=\frac{1}{\lambda_{Y}}\left(Y_{t}-Y_{t-1}\right)+Y_{t-1}
$$

$$
\Delta E R=E R_{t}-E R_{t-1}=\lambda_{E R}\left(E R^{*}-E R_{t-1}\right)=>P^{*}=\frac{1}{\lambda_{P}}\left(P_{t}-P_{t-1}\right)+P_{t-1},
$$

where $\Delta$ represents the change in population, employment, income, and environmental regulations, respectively. The changes in the endogenous variables are derived from the difference between the 2007 observations and 1992 observations as shown below.

$$
\Delta P=\left(P_{2007}-P_{1992}\right)
$$

(4.18) $\Delta E=\left(E_{2007}-E_{1992}\right)$

$$
\Delta Y=\left(Y_{2007}-Y_{1992}\right)
$$

$$
\Delta E R=\left(E R_{2007}-E R_{1992}\right)
$$

Substituting equations (4.13) through (4.16) into the right-hand side of equations (4.5), (4.6), (4.7), and (4.8), respectively, adopting of linear forms, and replacing the right hand unobservable variables, this results in the econometric model to be estimated. Thus, the proposed non-spatial model to be estimated consists of a system of four simultaneous equations describing population, employment, per capita income, and environmental regulation changes, respectively. The nonspatial four systems of equations are specified as: 


$$
\begin{aligned}
& \Delta P O P=\alpha_{0 P}+\beta_{1 P} P O P_{1992}+\beta_{2 P} Y_{1992}+\beta_{3 P} E R_{1992}+\beta_{4 P} \Delta E M P+\beta_{5 P} \Delta Y+ \\
& \beta_{6 P} \Delta E R+\sum \delta_{I P} \Omega^{P}+\mu_{1} \\
& \Delta E M P=\alpha_{0 E}+\beta_{1 E} E M P_{1992}+\beta_{2 E} P O P_{1992}+\beta_{3 E} E R_{1992}+\beta_{4 E} \Delta P O P+\beta_{5 E} \Delta Y+ \\
& \beta_{6 E} \Delta E R+\sum \delta_{I E} \Omega^{E}+\mu_{2} \\
& \Delta Y=\alpha_{0 Y}+\beta_{1 Y} E M P_{1992}+\beta_{2 Y} Y_{1992}+\beta_{3 Y} P O P_{1992}+\beta_{4 Y} E R_{1992}+ \\
& \quad \beta_{5 Y} \Delta P O P+\beta_{6 Y} \Delta E M P+\beta_{7 Y} \Delta E R+\sum \delta_{I Y} \Omega^{Y}+\mu_{3} \\
& \Delta E R=\alpha_{0 E R}+\beta_{1 E R} Y_{1992}+\beta_{2 E R} P O P_{1992}+\beta_{3 E R} E R_{1992}+\beta_{4 E R} \Delta P+\beta_{5 E R} \Delta Y+ \\
& \beta_{6 E R} \Delta E+\sum \delta_{I E R} \Omega^{E R}+\mu_{4}
\end{aligned}
$$

The dependent variables $\triangle P O P, \triangle E M P, \triangle Y$, and $\triangle E R$ denote county changes in population, employment, per capita income, and environmental regulation, respectively; where $\mu_{1}, \mu_{2}, \mu_{3}$, and $\mu_{4}$ represent the structural error terms, and $\Omega$ is a vector of exogenous variables. The year 1992 is taken as the initial period (subscript $t-1$ ). As already discussed, the lag adjustment models assume that the endogenous variables do not adjust instantaneously to their equilibrium levels but rather over a period of time. Deller et al. (2001) point out that the speed of adjustment to equilibrium levels is embedded in the coefficients $\alpha, \beta$, and $\delta$. Therefore, equations (4.21) to (4.24) estimate the short-term adjustments of population, employment, income, and environmental regulations to their long-term equilibrium levels of $\left(P^{*}, E^{*}, Y^{*}\right.$, and $\left.E R^{*}\right)$.

Millimet and Fredriksson (2002) show that state regulatory outcomes respond to regulatory decisions in other states. Implicit in this discussion is that the stringency of environmental regulations in one jurisdiction is a function of the level of environmental regulations in another jurisdiction. Under these circumstances, it is probable that pollution levels in a given area will be influenced by pollution levels in a neighboring area due to the transboundary problem of pollution, and thus the stringency of county environmental regulations are likely to exhibit spatial dependence. In addition, LeSage and Fischer (2009), point out that spatial 
dependence is a common phenomenon in regional growth analysis, particularly with regard to variables such as per capita income, population, and employment levels. Thus, the major shortcoming of the models outlined in equations (4.21) through (4.24) is the lack of consideration of the cross-sectional spatial dependences, as environmental outcomes and growth outcomes in one county may be related to outcomes and activities in adjacent counties. Therefore, equations (4.21) through (4.24) need to take account of the spatial spillovers.

\subsection{Spatial Model of Regional Growth (Model 2)}

Despite the fact that the EPA has the overall responsibility for the implementation of U.S. air quality regulations, the CAA gave U.S. states the mandate to implement and enforce federal air quality regulations. Accordingly, each state is required to develop a state implementation plan (SIP) outlining how federal air quality standards are going to be achieved. As consequence, it is conceivable that the state's discretion in developing implementation plans will inevitably result in differences in environmental stringency across the U.S. states. The concern with this decentralized approach is that when states are faced with intense interstate economic competition, states have the incentive to relax environmental regulations in order to attract capital investment (Engel, 1997; Konisky, 2007). The result is that states may engage in strategic regulatory competition when setting environmental standards. This means that states will take into account the level of environmental regulations existing in neighboring states when setting their environmental standards in order to gain economic advantage over other states.

Overall, the interactions between environmental regulations and economic growth suggest that there is spatial dependence associated with environmental regulation stringency and economic growth outcomes across regions (Anselin et al. 2004). For example, an improvement in air quality in one county is likely to benefit neighboring counties and this may improve the 
attractiveness of the area for investment and retirement relative to other areas. This series of events may result in increased population, income, and employment in the area with improved environmental quality. In the presence of spillovers, Anselin (1988) points out that ignoring spatial dependence in econometric modeling leads to inefficient or biased estimates and spurious inferences. Anselin (1988) shows that OLS estimation produces inconsistent results.

This means that the simultaneous equations specified in (4.21) through (4.24) should be estimated by incorporating spatial dependencies. The two most widely used econometric approaches for incorporating spatial dependencies are the spatial error model (SEM) and the spatial lag model (SLM). The SEM assumes that spatial dependence is caused either by unmeasured variables that are correlated across space, which results in omitted variable misspecification error, or the use of spatial data that does not match with the actual behavioral units being studied (Anselin, 1998). Thus, the general assumption is that the spatial errors across different units are correlated - thus violating the OLS assumption, and thereby making OLS estimates inefficient and biased.

(4.25) $y=X \beta+\varepsilon$,

Where $\mathrm{y}$ is the $n \times 1$ vector of dependent variables, $X$ is the $n \times k$ matrix of observations on $k$ exogenous variables, $\beta$ is the $k \times 1$ vector of unknown parameters, and $\varepsilon$ is the disturbance term that follows:

$$
\varepsilon=\lambda M_{\varepsilon}+\mu \text { and } \mu \sim \mathrm{N}\left(0, \sigma^{2} I\right)
$$

$M_{\varepsilon}$ is the $n \times n$ spatial weighting matrix of known constants, $\lambda$ is the spatial error coefficient, and $\mu$ is an $n \times 1$ vector of innovations. The interpretation of the SEM is that the outcome in region $i$ depends on the observed exogenous factors of region $j$ and the error term, $\varepsilon$. $\varepsilon$ depends on the average of the error terms in neighboring regions and an idiosyncratic component defined 
as $\mu$ in (4.26). Theoretically, this type of problem can be eliminated by including proper explanatory variables, or the use of correct spatial boundaries (Anselin, 1988). However, it is not possible to include all relevant explanatory variables, and this typically results in the inclusion of irrelevant variables.

On the other hand, the spatial lag model (SLM) assumes that the value of the dependent variables of an area is dependent on the weighted average of the dependent variable of other nearby areas. Thus, the SLM assumes that the value of the dependent variable of an area $i$, is dependent on the weighted average of the dependent variable of another area $j$, and that there are no omitted variables. The implication is that the error terms are homoskedastic, as shown in equation (4.27) below.

$$
y=X \beta+\rho W y+\varepsilon, \text { with } \varepsilon \sim \mathrm{N}\left(0, \sigma^{2} I\right)
$$

$\mathrm{y}$ is the $n \times 1$ vector of observations of the dependent variable, $\rho$ represents the strength of spatial dependence in $y, W$ is the $n \times n$ weight matrix that specifies the spatial structure or connectivity between regions, $X$ is the $n \times k$ matrix of observations on $k$ exogenous variables, and $\varepsilon$ is the $n \times 1$ vector of regression disturbances and assumed to have a normal distribution with mean of zero. Since the matrix $W$ specifies the spatial dependence structure among the observations, it is that assumed that $W_{i j}>0$ when observation $j$ is a spatial neighbor to observation $i$, and where there is no connectivity between regions $W_{i j}=0$.

Since it is not possible to include all relevant explanatory variables in a model and because dependent variables may exhibit spatial dependence, LeSage and Pace (2009) explain that the correct model to use is one that includes both a spatial lag of the dependent variable and a spatial lag of the explanatory variables. In the spatial econometrics literature, this type of model which incorporates both the spatial lag of the dependent variable and the spatial lag of 
exogenous variables is known as a spatial Durbin model (SDM). LeSage and Fischer (2009) assert that the ability of the spatial Durbin model to deal with the problem of omitted variable bias and spatial dependences make it a better choice over other spatial econometric models. The spatial Durbin model can be expressed as:

$$
y=X \delta_{1}+\rho W y+W X \delta_{2}+\varepsilon, \text { with } \varepsilon \sim \mathrm{N}\left(0, \sigma^{2} I\right)
$$

The notations for the variables $y, W, \rho, X, \beta$, and $\varepsilon$ are defined in (4.27) while $\delta_{2}$ represents a $k \times 1$ vector that shows the strength of the relationship for each explanatory variable in the $X$ matrix. The matrix $W X$ is the spatial lag of explanatory variables and reflects the characteristics of explanatory variables related to neighboring regions.

The use of the SDM implies that economic growth and environmental regulations $\left(y_{i}\right)$ of county $i$ are dependent upon the neighboring county's economic growth and environmental regulations $\left(y_{j}\right)$, as well as the county's own explanatory variables plus the average of the same explanatory variables of nearby counties. Following the above discussion, the spatial Durbin model to be estimated is expressed as follows:

$$
\begin{aligned}
& \Delta P O P=\rho W \triangle P O P+\beta_{1 P}(I+W) \Delta E M P+\beta_{2 P}(I+W) \Delta Y+\beta_{3 P}(I+W) \Delta E R+\beta_{4 P}(I+ \\
& W) P O P+\beta_{5 P}(I+W) E M P+\beta_{6 P}(I+W) E R+\sum \delta_{I P}(I+W) \Omega^{P}+\mu_{1} \\
& \Delta E M P=\rho W \Delta E M P+\beta_{1 E}(I+W) \Delta P O P+\beta_{2 E}(I+W) \Delta Y+\beta_{3 E}(I+W) \Delta E R+ \\
& \beta_{4 E}(I+W) P O P+\beta_{5 E}(I+W) E M P+\beta_{6 E}(I+W) E R+\sum \delta_{I E}(I+W) \Omega^{E}+\mu_{2} \\
& \Delta Y=\rho W \Delta Y+\beta_{1 Y}(I+W) \Delta E M P+\beta_{2 Y}(I+W) \Delta P O P+\beta_{3 Y}(I+W) \Delta E R+ \\
& \beta_{4 E}(I+W) P O P+\beta_{5 E}(I+W) E M P+\beta_{6 E}(I+W) E R+\sum \delta_{I E}(I+W) \Omega^{E}+\mu_{3} \\
& \Delta E R=\rho W \Delta E R+\beta_{1 E R}(I+W) \Delta E M P+\beta_{2 E}(I+W) \Delta Y+\beta_{3 E}(I+W) \Delta P O P+ \\
& \beta_{4 E}(I+W) P O P+\beta_{5 E}(I+W) E M P+\beta_{6 E}(I+W) E R+\sum \delta_{I E R}(I+W) \Omega^{E R}+\mu_{1}
\end{aligned}
$$


$I$ is the $n \times n$ identity matrix, the terms $(I+W)$ represent the spatial weights of the dependent and explanatory variables, while $\rho W$ denotes the spatial dependences of the dependent variables. In particular, $\rho$ measures the strength of the spatial dependence or the level of influence from neighboring regions' growth rates. The explanatory variables included in the spatial Durbin model validly remain the same as those specified in the non-spatial model.

LeSage and Pace (2009) explain that interpretation of the SDM model differs from conventional non-spatial regression in that the SDM model takes into account the spatial spillover effects arising from a change in the variable $x_{j}$ (contained in the $X$ vector of exogenous variables) in one county with respect to the change in $y_{i}$ in other counties. LeSage and Pace assert that the spatial connectivity relationships incorporated in the spatial Durbin model entail that a change in the explanatory variable in one region directly impacts the region where changes emanate from, also indirectly impacts other nearby regions. They show that the partial derivative that takes into account the effect of changes in the dependent variable $y_{i}$ in region $i$ due to changes on the variable $x_{i}$ in region $i$ can be expressed as a $n \times n$ matrix, as shown below:

$$
\frac{\partial y_{i}}{\partial x_{i}}=\left(I_{n}-\rho W\right)^{-1}\left(I_{n} \delta_{1}+W \delta_{2}\right)
$$

$\delta_{1}$ and $\delta_{2}$ represent the coefficient parameter coefficients, $\left(I_{n}-\rho W\right)^{-1}\left(I_{n} \delta_{1}+W \delta_{2}\right)$ is the main diagonal of the partial derivatives, and represents the direct effects of the impacts arising from own-county changes in the variable $x$. To be more precise, the direct effects represent the change in $y$ in a particular county due to a change in a county's own explanatory variables. LeSage and Pace (2009) also explain that the row sum of the off diagonal terms produce the indirect effects (spatial spillovers) and these are associated with the marginal effects of the firstorder, second-order, third-order neighbors, etc. Another important interpretation offered by 
LeSage and Pace (2009) is that of the total effect, which is defined as the sum of the direct and indirect effects.

Following LeSage and Kirby (2009), the relative impacts of the spillover effects in this study are presumed to be influenced by the spatial proximity of counties, the degree of connectivity between counties reflected by the matrix $W$, the magnitudes of the coefficient parameter coefficients $\delta_{1}$ and $\delta_{2}$, and the strength of the spatial dependences, denoted by $\rho$. This can also be construed to mean that there is a decay of influence in terms of spillover impacts as the distance between counties increases.

\subsection{Data Description}

The data are for counties in the Appalachian region and cover the years 1992 to 2007. The dependent variables used in the models are measured as absolute changes in population, employment, income, and environmental regulations (1992-2007). Table 4.1 gives the description and sources of the endogenous variables and the initial condition variables used. County-level data for population, employment, and income are obtained from the Bureau of Economic Analysis, Regional Economic Information System (REIS) and County and City Data Book (C\&CDB) covering the years 1992 to 2007 . County attainment status is used as a proxy for environmental regulation stringency and the data will be obtained from the Federal Code of Regulations, Title 40, part 81, subpart C, covering the years 1992 to 2007.

Given that a county can be out-of-attainment with respect to several air pollutants, the environmental regulation variable is an index of the total number of pollutants for which a county is out-of-attainment. The environmental regulation index is constructed using Henderson's (1997) methodology of summing the number of criteria pollutants a county is out-

of-attainment. The criteria pollutants considered are ozone $\left(\mathrm{O}_{3}\right)$, sulfur dioxide $\left(\mathrm{SO}_{2}\right)$, carbon 
monoxide $(\mathrm{CO})$, lead $(\mathrm{Pb})$, and total suspended particulates (TSP). Following Henderson (1997) and List (2001), the attainment variable takes on values from 0 (cleanest county and least regulated) to 5 (dirtiest and most regulated) — and generally depends on the number of pollutants the county is out-of-attainment. For example, a county in attainment for five criteria pollutants takes on a value of 0 , whereas a county out-of-attainment in all five criteria pollutants will be coded 5. With regard to the ozone standard, when part of the county has not met the complete federal ozone standard, the EPA assigns to these counties partial attainment or non-attainment status. For this reason, counties which are in partial attainment are coded $1 / 2$. The year 1992 is the start period for analysis.

Table 4.1: List of Endogenous Variables and Initial Conditions

\begin{tabular}{|c|c|c|}
\hline $\begin{array}{l}\text { Endogenous } \\
\text { Variable }\end{array}$ & Description & Data Source \\
\hline POPCH & Change in population (1992-2007) & Computed: $\left(\mathrm{POP}_{2007}-\mathrm{POP}_{1992}\right)$ \\
\hline PCICH & Change in Per Capita Income (1992-2007) & Computed: $\left(\mathrm{PCI}_{2007}-\mathrm{PCI}_{1992}\right)$ \\
\hline EMPCH & Change in total employment (1992-2007) & Computed: $\left(\mathrm{EMP}_{2007}-\mathrm{EMP}_{1992}\right)$ \\
\hline ENREG & $\begin{array}{l}\text { Change in attainment status (1992-2007): } \\
0=\text { attainment, } 1 / 2 \text { to } 5=\text { number of } \\
\text { pollutants out-of-attainment }\end{array}$ & Computed: $\left(\mathrm{ENREG}_{2007}-\mathrm{ENREG}_{1992}\right)$ \\
\hline \multicolumn{3}{|c|}{ Initial Conditions } \\
\hline POP92 & County population in 1992 & REIS/C\&CDB \\
\hline PCI92 & County Per capita income in 1992 & REIS/C\&CDB \\
\hline EMP92 & County Employment in 1992 & REIS/C\&CDB \\
\hline ENREG92 & County attainment status in 1992 & $\begin{array}{l}\text { CFR, Title } 40 \text {, Part } 81 \text {, Subpart C and } \\
\text { EPA Green book }\end{array}$ \\
\hline
\end{tabular}

A number of explanatory variables are included to explain changes in population, employment, income, and environmental regulations. Table 4.2 presents the description and sources of all the exogenous variables included in the empirical models. For convenience, the variables are divided into five distinct categories: 


\section{a) Accessibility variables}

Accessibility variables include state road density (ROADDEN) and counties classified as metro $(M E T R O)$. State road density data reflect the level of infrastructure development and the data comes from the Natural Resource Analysis Centre (NRAC) of West Virginia University (WVU), while data on county classification comes from the United States Department of Agriculture (USDA) Economic Research Service (ERS).

\section{b) Human Capital variables}

Human capital factors include proportion of population 25 years and above with Bachelor's degree or higher (DEGREE) and proportion of population between 18 and 64 years (ACTIVE). All human capital data are obtained from the County and City Data Book (C\&CDB, 1994).

\section{c) Economic Variables}

Economic variables considered are per capita local government expenditure (LGEXP), per capita taxes $(P C T A X)$; poverty rate (POVRATE); property taxes (PROPTAX); manufacturing establishments (MFG); percentage of employees working in manufacturing (MFGEMP); median housing value $(M H V A L)$; and unemployment rate (UNEMP) indicates whether the local population is employable. Data on manufacturing establishments is obtained from the Business Dynamic Statistics of the U.S. Census bureau (BDS). The BDS database contains data on number of firms by category, age, size, and location, including key economic data such as employment, number of establishments, and so forth. All other economic data are obtained from the C\&CDB. 


\section{d) Demographic variables}

This group of variables include percentage of Black population (BLACK); proportion of population below 5 years and proportion of population above 65 years (RISK); crime rates $(C R I M E)$; and population density $(P O P D E N)$. Demographic data was obtained from the

\section{C\&CDB.}

\section{e) Environmental Quality variables}

To capture environmental quality, the following factors are used: presence of a Sierra chapter in a county (SIERRA); votes cast for Democratic President in 1992 elections (VOTE); USDA natural amenities index (AMEND); and percentage of population 16 and above driving to work (POPDRIVE). Environmental quality data comes from different sources, including internet searches. Data on county Sierra chapters was obtained from the Sierra Club Website, while data on the amenity index comes from the USDA-ERS. The amenity index reflects individual's preference for environmental quality and was constructed by combining six measures of climate, topography, and water. Data on percent of votes cast for the Democratic presidential candidate and proportion of population considered to be risky comes from the C\&CDB.

\subsubsection{Population Equation}

Specification of variables in the population equation follows economic theory and existing literature. The dependent variable is the change in population $(P O P C H)$, which is defined as the difference between population in 2007 and population in 1992. The population equation includes the initial conditions of the endogenous variables as explanatory variables. This specification follows on the convergence hypothesis suggested by Barro and Sala-i-Martin (1992), which suggests that there is a negative relationship between the growth in population over time and the initial level of population. The implication of this negative relationship is that 
population growth in counties with higher population levels will be slower than counties which have low population levels. The initial conditions of the endogenous variables include 1992 levels of population $\left(P O P_{92}\right)$, employment $\left(E M P_{92}\right)$, and environmental regulations $\left(E N V R_{92}\right)$, including the three endogenous variables of employment $(E M P C H)$, per capita income $(P C I C H)$, and environmental regulations (ENREGCH).

Environmental regulation stringency in this context refers to whether a county is inattainment or out-of-attainment. It is hypothesized that counties in attainment will experience high population increases because of people's perceptions on improved environmental quality. This might also mean that firms are going to positively view counties in attainment and hence influence their investment decisions.

Other control variables in the population equation include fiscal factors such as per capita income taxes (PCTAX), property taxes (PROPTAX), and per capita local government expenditure (LGEXP). It is hypothesized that PROPTAX has a negative effect on population change, as this represents an additional cost to households and firms, and thus deters in-migration while encouraging out-migration. On the other hand, LGEXP is expected to have a positive effect on population growth considering the fact that government expenditure increases provision of public goods and services, such as highways, education, health, and other public safety services (police, fire departments, etc.).

Other control variables for population change are the natural amenity index (AMEND), county unemployment rate (UNEMP), median housing values (MHVAL), manufacturing establishments $(M F G)$, and accessibility variables, such as road density of state roads $(R O A D D E N)$. Amenity variables $(A M E N D)$ are included in order to capture quality of life and are expected to have a positive impact on population change. Counties with high unemployment 
rates (UNEMP) signal a limited number of economic opportunities available in the local economy, and thus, the coefficient for unemployment rate is expected to be negative.

Housing values (MHVAL) are included in order to account for the cost of living, and thus it is expected that high housing prices negatively affect population growth and, conversely, low housing values positively influence population growth. State road density (ROADDEN) measures the extent and coverage of the paved road infrastructure within a county and this is associated with improved mobility, and thus may result in increased population.

Two variables are included to control for differences in growth patterns among counties, a dummy variable (METRO) representing metropolitan counties and number of manufacturing establishments in a county $(M F G)$. It is hypothesized that metropolitan counties (METRO) and counties with a high number of manufacturing establishments $(M F G)$ experience faster population growth due to the presence of agglomeration economies.

$$
\begin{aligned}
& \text { POPCH }=\beta_{0}+\beta_{1} P C I C H+\beta_{2} E M P C H+\beta_{3} E N R E G+\beta_{4} P_{92}+\beta_{5} E N R E G_{92}+\beta_{6} E_{9 P} P_{92}+ \\
& \beta_{7} P C T A X+\beta_{8} P R O P T A X+\beta_{9} L G E X P+\beta_{10} A M E N D+\beta_{11} P_{\text {OVRATE }+\beta_{12} M H V A L+}+ \\
& \beta_{13} \text { ROADDEN }+\beta_{14} M F G+\beta_{15} M E T R O+\mu_{1}
\end{aligned}
$$

\subsubsection{Employment Equation}

Variables in the employment equation have been chosen for their ability to reflect longrun supply and demand conditions in the labor market in a given county. The dependent variable in the employment equation is the change in employment $(E M P C H)$ between 1992 and 2007. Like the population equation, the employment equation includes the initial conditions of the endogenous variables as explanatory variables, including the three endogenous variables of changes in population $(P O P C H)$, per capita income $(P C I C H)$, and environmental regulations $\left(\right.$ ENREGCH). The initial conditions included are 1992 levels of population $\left(P O P_{92}\right), 1992$ 
employment conditions $\left(E M P_{92}\right)$, and environmental regulations $\left(E N R E G_{92}\right)$. Past studies show that higher initial levels of population positively affect employment growth.

Fiscal related control variables are included in order to determine their impact on employment growth. Fiscal variables included in the employment are per capita local government expenditure (LGEXP), property tax (PROPTAX), and per capita taxes (PCTAX). Given that local government expenditures are associated with provision of public goods, it is hypothesized that LGEXP is positively related to employment growth. The impact of taxes on consumers is illustrated in Tiebout's (1956) work, which shows that a reduction in government programs or an increase in taxes by a local jurisdiction results in out-migration and discourages in-migration. Therefore, it is hypothesized that PROPTAX and PCTAX are negatively related to employment growth.

Other important explanatory variables for employment growth are human capital factors. Human capital variables included in the employment equation is the proportion of county's population 25 years and over with a bachelor's degree or higher (DEGREE). The proportion of population of persons 25 and above is included in the equation in order to control for the effect of labor force quality, with the assumption that a person with a college degree has higher skills and knowledge which can be used to expand firms' production as well as entice other firms to locate in the area. Also related to employment growth is the notion that the Democratic Party pursues pro-employment policies (Levitt and Poterba, 1999). Percent of votes cast for the Democratic presidential candidate (VOTE) are used as a proxy for the Democratic Party's control of the executive office. It is hypothesized that VOTE will be positively related to employment growth. 
To account for labor availability, county unemployment rates (UNEMP) are included in the employment equation. High unemployment rates generally indicate that the local economy is in distress, which consequently discourage firms from locating to an economically depressed county. Therefore, it is hypothesized that unemployment rate (UNEMP) is negatively related to employment growth. Similarly, counties experiencing high crime rates may discourage firms from locating there, and consequently affect employment growth. The variable CRIME is included to account for the negative externality, and it is hypothesized that CRIME is negatively related to employment growth.

Following the seminal work by Aschauer (1989), numerous studies (Carlino and Mills, 1987; Duffy-Deno, 1998; Munnell, 1990) have shed light on the impact of transport investment on employment growth. Location theory suggests that provision of highway infrastructure investment can significantly reduce marginal costs of production and consumption in a given area by reducing the cost of transporting goods and services. Therefore, it is hypothesized that interstate road density $(R O A D D E N)$ is positively related to employment growth.

Another measure of agglomeration economies included is the number of manufacturing establishments $(M F G)$. Within this context, it is hypothesized that manufacturing establishment is positively related to employment growth.

$$
\begin{aligned}
& \text { EMPCH }=\beta_{0}+\beta_{1} \text { PCICH }+\beta_{2} \text { ENREGCH }+\beta_{3} \text { POPCH }+\beta_{4} E M P_{92}+\beta_{5} E N R E G_{92}+ \\
& \beta_{6} \text { POP }_{92}+\beta_{7} \text { PCTAX }+\beta_{8} \text { PROPTAX }+\beta_{9} L G E X P+\beta_{10} D E G R E E+\beta_{11} \text { AMEND }+ \\
& \beta_{12} \text { UNEMP }+\beta_{13} \text { ROADDEN }+\beta_{14} \text { CRIME }+\beta_{15} \text { METRO }+\beta_{16} M F G+\beta_{17} \text { VOTE }+\mu_{2}
\end{aligned}
$$

\subsubsection{Per Capita Income Equation}

Variables in the income equation have been chosen based on their hypothesized relationship to productivity gains, which translates into increased per capita income. The per capita income equation is estimated as a function of endogenous variables, namely employment 
$(E M P C H)$, population $(P O P C H)$, and environmental regulations (ENREGCH), including the initial conditions of the endogenous variables, PCI92 and POP92.

Other variables included in the per capita income equation include per capita local government expenditure (LGEXP), which measures provision of services and goods and is assumed to be an important input in the development of human capital as well as productivity improvement for manufacturing, agriculture, wholesale, and trade industries (Connolly and Fox, 2004). Therefore, it is hypothesized that local government expenditure is positively related to income growth. Another fiscal variable included is the per capita income tax (PCTAX), a variable whose impact on per capita income growth remains open. Therefore, no priori assumptions are made with regard to the impact of $P C T A X$ on income growth.

Natural amenities $(A M E N D)$ are presumed to explain income growth since they reflect the quality of life available to the local population. Based on previous studies (Kahsai, 2009, McGranahan, 1999), it is expected that $A M E N D$ has a positive relationship with income growth. The literature shows that access to amenities attracts wealthy retirees, who subsequently increase a given areas' per capita income. Another measure that has been used in previous studies to explain income growth is the political party in control of the federal government. Levitt and Poterba (1994) find evidence that show that states with a large share of Democrats in the House of Representatives experience faster per capita income growth relative to those with fewer democrats. To account for party control, the percentage of votes cast for the Democratic presidential candidate in the 1992 elections (VOTE) is included, and it is hypothesized that VOTE is positively related to income growth.

To capture the effects of demographic factors on income growth, the percent of population 65 years or older is included to represent the retired labor force (RETIRE). Generally, 
the main source of income for retirees is social security benefits. Ceteris paribus, counties with a high proportion of retired labor force experience slower income growth. On the other hand, the active labor force represented by the proportion of population between 18 years and 65 years (ACTIVE) derive most of their income from wage and salaried jobs. Thus it is expected that ACTIVE is positively related to income growth.

High income growth is also associated with educational attainment as this increases an individual's productive and entrepreneur knowledge and skills. To account for the impact of education in income growth, proportion of population 25 years or older with a bachelor's degree or higher education (DEGREE) is included. Another important measure that is hypothesized to increase per capita income growth is the number of manufacturing establishments $(M F G)$ present in a county, due to its large labor demands.

The percent of population that is African Americans $(B L A C K)$ is included to control for the relative impact of the black population on income. This variable has been widely used in income inequality studies because of its ability to capture labor market discrimination which results in lower wages (Garofalo and Fogarty, 1979). A negative relationship is hypothesized between percent of population that is black and per capita income. Also, in order to explain income growth, the percent of families living below the poverty rate (POVRATE) is included, and ceteris paribus, counties with a high percentage of the population below the poverty line are expected to experience slow income growth.

$$
\begin{aligned}
& P C I C H=\beta_{0}+\beta_{1} E M P C H+\beta_{2} P O P C H+\beta_{3} \text { ENREGCH }+\beta_{4} P O P_{92}+\beta_{5} P_{C I}+\beta_{6} P C T A X+ \\
& \beta_{7} D E G R E E+\beta_{8} L G E X P+\beta_{9} A M E N D+\beta_{10} \text { POVRATE }+\beta_{11} B L A C K+\beta_{12} \text { ACTIVE }+ \\
& \beta_{13} M F G+\beta_{14} \text { RETIRE }+\beta_{15} \text { VOTE }+\mu_{3}
\end{aligned}
$$




\subsubsection{Environmental Regulations Equation}

The environmental regulations equation is estimated as a function of initial conditions for environmental regulations and all endogenous variables, including the initial conditions. Considering the fact that environmental quality has a high income elasticity of demand, the coefficient for income is expected to be positive as will be the coefficients of population and employment change.

Other control variables include the share of population under 5 years and above 65 years $($ RISK). Share of population below 5 years and above 65 years is designed to capture the population which is more susceptible to suffer from chronic illnesses due to environmental exposures. Ceteris paribus, an increase in the proportion of the sensitive group of people results in an increase in the demand for stringent environmental regulations. To control for urban or metro effects, a metro (METRO) dummy variable is included and this accounts for the congestion effects. Metro areas generally have an array of economic activities which rely on trucks, trains, and cars for transportation of inputs and outputs to the markets. This high concentration of economic activity may result in large emissions of pollutants, thereby increasing the demand for stricter enforcement of environmental regulations. Thus the metro variable is hypothesized to have a positive effect on environmental regulations stringency. In addition, metro areas have a large presence of lobby groups, which means more pressure for stringent environmental regulation.

Another demographic factor included as an explanatory variable is the percent of the black population $(B L A C K)$ that controls for the marginal exposures to pollution. The environmental justice literature documents that the African American population and Hispanic population are marginally more exposed to environmental damages than the white population 
(Morrone, 2008; Sicotte, 2009). Therefore, it is hypothesized that percentage of black population $(B L A C K)$ is negatively related to environmental regulation stringency. Additional evidence from the environmental justice literature indicates that the prevailing socio-economic conditions of individuals and areas will influence environmental outcomes, and thus low income and high poverty areas are associated with poor environmental quality. County poverty rates (POVRATE) are included to control for economic condition, and it is expected that high poverty rates are negatively associated with environmental regulation stringency.

Community/public activism towards environmental issues emanates from the population that is susceptible to illnesses due to environmental exposure, as well as from environmental pressure and other interest groups. The presence of Sierra Clubs in counties (SIERRA) controls for community/public environmental activism. These groups are known to be pro-environment and thus will exert pressure for stringent environmental regulations. Therefore, it is hypothesized that the Sierra variable is positively related to enforcement of environmental regulations.

Additional pressure on environmental regulations comes from manufacturing workers who may demand lower environmental standards in order to protect their jobs. In this case, a negative relationship between manufacturing employment and environmental regulations is found. However, when viewed from the perspective of a pollution-intensive sector, an increase in manufacturing employment (MFGEMP) may imply an increase in environmental regulation enforcements due to increased pollution. Therefore, the expected sign on MFGEMP can be positive or negative as explained above.

Population density (POPDEN) controls for the congestion externalities, which imply that densely populated areas lead to more waste generation, and thus it is expected that counties with higher population densities positively influence environmental regulation stringency. Other 
control variables include proportion of persons 25 years and older with a bachelor's degree (DEGREE) and proportion of population driving to work (POPDRIVE), and the state road density (ROADDEN). The level of human capital development influences an individual's interest, knowledge, and understanding of environmental issues, including the effectiveness of the group to lobby against pollution. Thus, it is hypothesized that education (DEGREE) is positively related to environmental regulation stringency.

Undoubtedly, employment growth and population growth entail increased usage of vehicles, and given that vehicles are a major source of emissions which contribute to air pollution it is hypothesized that the proportion of persons driving to work (POPDRIVE) will be positively related to strict environmental regulations. According to Cassady (2004), highway expansions have increased vehicle miles traveled and this has also resulted in increased emission of pollutants due to changes in land use and neighborhood characteristics. State road density controls for the traffic density and it hypothesized that state road density (ROADDEN) is positively related to environmental regulation stringency.

Another measure which can explain environmental outcomes is political party ideology. Previous studies show that the stringency of U.S. environmental regulations is influenced by the political party that controls the executive branch and legislature (Lynch, et al. 2004; Regens et al., 1997). Accordingly, the Democratic Party is considered to be more supportive of stringent environmental regulations than the Republican Party. To account for political ideology, the percentage of votes cast for the democratic president (VOTE) in the 1992 election is included as a proxy for environmental regulation preference for the elected officials. The variable VOTE is hypothesized to be positively related to environmental regulation stringency. 


$$
\begin{aligned}
& \text { ENREG }=\beta_{0}+\beta_{1} P C I C H+\beta_{2} E M P C H+\beta_{3} P O P C H+\beta_{4} P O P_{92}+\beta_{5} P C I_{92}+\beta_{6} E_{N R E G_{90}}+ \\
& \beta_{7} R I S K+\beta_{8} B L A C K+\beta_{9} P O V R A T E+\beta_{10} S I E R R A+\beta_{11} M F G E M P+\beta_{12} P O P D E N+ \\
& \beta_{13} D E G R E E+\beta_{14} \text { POPDRIVE }++\beta_{15} \text { VOTE }+\beta_{16} M E T R O+\beta_{17} \text { ROADDEN }+\mu_{4}
\end{aligned}
$$

\subsection{Estimation Methods}

Because the equations specified in (4.34) to (4.37) are structural equations, three stage least squares (3SLS) estimation will be used. 3SLS is preferred to two stage least squares (2SLS) because of the possible correlation of the error terms, which is not addressed by 2SLS estimation. Therefore, the advantage of using 3SLS is that it is a full information estimation technique which takes into account information from other equations, and thereby producing asymptotically efficient estimates than the two stage least squares (2SLS). However, Wooldridge (2002) explains that when a system of equations is just-identified, 2SLS is algebraically identical to 3SLS, and in this situation, both estimation techniques produce consistent and efficient parameter estimates. The spatial Durbin model (SDM) represented by equations (4.29) to (4.32) will be estimated using the codes contained in James LeSage's Spatial Econometrics MATLAB toolbox.

Table 4.3 presents the summary statistics of the exogenous variables and endogenous variables used in the models. Columns 1 and 2 show the standard deviation and average values of the variables, while columns 3 and 4 show the minimum and maximum values of the variables. A perusal of column shows that the maximum number of pollutants that counties were out of attainment is four. Out of the 410 counties, three counties were out-of-attainment for four criteria pollutants (particulate matter, sulfur dioxide, carbon monoxide, and ozone). 
Table 4.2: Description of Exogenous Variables

\begin{tabular}{|c|c|c|}
\hline $\begin{array}{l}\text { Exogenous } \\
\text { Variables }\end{array}$ & Description & Data Source \\
\hline & Human Capital Variables & \\
\hline ACTIVE & Percentage of population between 18 years and 64 years & C\&CDB, 1994 \\
\hline \multirow[t]{2}{*}{ DEGREE } & Percent of persons 25 yrs \& above with college degree & C\&CDB/Computed, 1994 \\
\hline & Demographic Variables & \\
\hline POPDEN & Total population/land area & REIS/Computed \\
\hline RISK & Percentage of population below 5 years plus above 65 & CC\&CDB 1994 \\
\hline \multirow[t]{2}{*}{ RETIRE } & Percentage of population above 65 years & CC\&CDB 1994 \\
\hline & Economic Variables & \\
\hline PROPTAX & Per capita local property tax & C\&CDB, 1994 \\
\hline MFG & Number of manufacturing establishments in a county & $\begin{array}{l}\text { U.S. Census Bureau Dynamic } \\
\text { Business Series (DBS) }\end{array}$ \\
\hline MFGEMP & $\begin{array}{l}\text { Percent of civilian labor force employed in } \\
\text { manufacturing }\end{array}$ & REIS/C\&CDB, 1994 \\
\hline UNEMP & Civilian labor force unemployment rate (percent) & REIS/C\&CDB, 1994 \\
\hline POVRATE & Percent of families with income below poverty rate & REIS/C\&CDB, 1994 \\
\hline PCTAX & Local tax per capita, 1992 & C\&CDB, 1992 \\
\hline CRIME & Serious Crimes per 100,000 of population, 1992 & C\&CDB, 1992 \\
\hline MHVAL & County median housing value & $\mathrm{C} \& \mathrm{CDB}, 1994$ \\
\hline \multirow[t]{2}{*}{ LGEXP } & Per capita local government expenditure & $\mathrm{C} \& \mathrm{CDB}, 1994$ \\
\hline & Accessibility/Location Variables & \\
\hline METRO & Metropolitan counties, dummy variable $=1,0$ otherwise & $\begin{array}{l}\text { USDA/ERS-Creative class } \\
\text { code }\end{array}$ \\
\hline \multirow[t]{2}{*}{ ROADDEN } & Miles of state roads per square mile & NRAC, WVU \\
\hline & Environmental Quality & \\
\hline AMEND & Natural amenities index & USDA/ERS \\
\hline DRIVE & Percentage of population 16 and above driving to work & C\&CDB, 1994 \\
\hline VOTE & Percentage of votes cast for Democratic President & C\&CDB, 1994 \\
\hline SIERRA & Dummy: $1=$ Sierra Chapters in a County, 0 otherwise & Sierra Club \\
\hline POPDRIVE & Percentage of population above 17 years driving to work & C\&CDB, 1992 \\
\hline
\end{tabular}


Table 4.3: Summary Statistics

\begin{tabular}{|l|l|l|l|l|}
\hline Variable Name & STD & Mean & Min & Max \\
\hline ACTIVE & 30.582 & 62.61 & 0 & 456.04 \\
\hline AMEND & 1.1632 & 0.13266 & -3.72 & 3.55 \\
\hline CRIME & 1560.8 & 2251.9 & 0 & 8487 \\
\hline DEGREE & 4.981 & 10.498 & 3.7 & 41.7 \\
\hline EMP92 & 53959 & 25010 & 0 & 820000 \\
\hline EMPCH & 13524 & 5453.5 & -6124 & 203000 \\
\hline ENREG92 & 0.73343 & 0.329268 & 0 & 4 \\
\hline ENREGCH & 0.647933 & 0.282926 & 0 & 3 \\
\hline LGEXP & 2344.7 & 3782.7 & 0 & 33391 \\
\hline METRO & 0.44102 & 0.26341 & 0 & 1 \\
\hline MFG & 120.53 & 67.824 & 0 & 1627 \\
\hline MFGEMP & 11.367 & 26.236 & 0 & 53.6 \\
\hline MHVAL & 13528 & 47631 & 15800 & 118000 \\
\hline PCI92 & 2530.2 & 13630 & 0 & 22226 \\
\hline PCICH & 2152.3 & 10867 & 0 & 19917 \\
\hline PCTAX & 160.88 & 285.31 & 0 & 1317 \\
\hline POP92 & 89059 & 50945 & 0 & 1340000 \\
\hline POPCH & 22862 & 6196.8 & -102000 & 363000 \\
\hline POPDEN & 133.03 & 101.27 & 6.33 & 1838.3 \\
\hline POPDRIVE & 5.3388 & 73.827 & 51.9 & 85.1 \\
\hline POVRATE & 8.0139 & 19.019 & 0 & 52.1 \\
\hline PROPTAX & 17.519 & 72.362 & 0 & 99.1 \\
\hline RISK & 2.6548 & 20.921 & 0 & 30.45 \\
\hline ROADDEN & 0.11601 & 0.32637 & 0 & 0.73933 \\
\hline SIERRA & 0.46872 & 0.67561 & 0 & 1 \\
\hline UNEMP & 3.1947 & 9.3524 & 3.4 & 22.6 \\
\hline VOTE & 10.065 & 42.386 & 17.1 & 82.8 \\
\hline & & & & \\
\hline
\end{tabular}

In 1992, 22 of the 410 Appalachian counties were completely out of attainment for at least one criteria pollutant. Between 1992 and 2007, this number increased to 89, representing a 75 percent increase. A majority of these counties were out-of-attainment for the TSP and ozone standard. 


\section{CHAPTER 5}

\section{EMPIRICAL RESULTS AND ANALYSES}

\subsection{Introduction}

The focus of this chapter is to estimate the empirical models on the relationship between environmental regulations and regional growth. Indicators for regional growth are per capita income growth, population growth, and employment growth, while county attainment status is used as a proxy for environmental regulation stringency. The models are estimated using two techniques; three stage least squares and the spatial Durbin model (SDM). The rest of this chapter is organized as follows. Section 5.1 presents a discussion on the results for the nonspatial model, while section 5.2 presents a discussion on the results for the spatial Durbin Model.

\subsection{Non-Spatial Growth Model Results}

Given that estimation of the non-spatial model involves four structural equations represented by change in employment, population, environmental regulations, and per capita income, it is highly plausible that the error terms in each equation are related. Consequently, estimation by ordinary least squares will provide inconsistent and inefficient estimates. In order to overcome this problem, full information estimation techniques such three stage least squares (3SLS), GMM, or the full information maximum likelihood (FIML) have been suggested as appropriate estimation methods because they take into account the restrictions on parameters in all structural equations (Wooldridge, 2002). For the purpose of this study, three stage least squares will be used for estimating the non-spatial structural equations (4.34 to 4.37 ) and estimation will be done in Eviews. Tables 5.1 through 5.4 summarize the non-spatial structural equation estimates. 


\subsubsection{Change in Population Equation}

Table 5.1 presents summary results for the population growth equation. The coefficient estimate for the initial condition of population (POP92) has the expected negative sign and is significant at the 1 percent level. This finding confirms the convergence hypothesis, which suggests that counties which had initial high levels of population will tend to experience a lower growth rate than counties which had low levels of population in the initial period. On the other hand, the coefficient estimate for EMP92 is positive and is significantly different from zero. The positive coefficient for EMP92 confirms the 'jobs follow people' hypothesis.

Change in environmental regulations $(E N R E G C H)$ has a positive impact on population growth and the coefficient is statistically significant at the 10 percent level. One possible explanation for this positive relationship between environmental regulations and population growth may be that stringent environmental regulations result in improved environmental quality and thus make local areas to become attractive for businesses and households. This argument is similar to the one advanced by Goetz et al. (1996, p.100) who assert that when environmental regulation results in improved environmental quality, growth rates may subsequently increase. Change in employment $(E M P C H)$ has a positive effect on population growth, indicating that an increase in employment growth (or an increase in labor demand) stimulates population growth. The coefficient for EMPCH is statistically significant at the 1 percent level, and thus shows that jobs follow people. Also, the role of per capita income change $(\mathrm{PCICH})$ in explaining growth in population is strong, as reflected by the magnitude and positive sign of the coefficient (significant at the 5 percent level).

As hypothesized, the unemployment rate (UNEMP) has a negative effect on population growth and is statistically significant at the 10 percent level. Generally, high unemployment rates 
indicate economic distress and a dearth of employment opportunities. Consequently, counties with high unemployment rates discourage in-migration and conversely encourage out-migration. These findings are consistent with results from past studies (Gebremariam, 2006; Mojica, 2009). Estimated results also show that median housing values (MHVAL) and population growth have a negative relationship, but the coefficient for $(M H V A L)$ is not significant. Manufacturing establishment $(M F G)$ has an unexpected negative effect on population growth and its coefficient is insignificantly different from zero. The negative coefficient may be due to the declining role of manufacturing in the Appalachian economy. State road density (ROADDEN) appears to have a positive effect on population growth, but is also insignificantly different from zero.

The estimated coefficient for local government expenditure (LGEXP) is positive and statistically significant at the 5 percent level. This implies that local government spending programs that are aimed providing a mix of goods and services stimulate population growth in that area. By contrast, per capita local property tax (PROPTAX) is negatively related to population growth and its coefficient is insignificant at the 5 percent level. This finding reinforces the notion that individuals avoid locating in jurisdictions with higher taxes. The relationship between per capital local taxes $(P C T A X)$ and population growth indicate a positive relationship. This finding, definitely counters economic theory and it is not surprising that the coefficient for PCTAX is statistically insignificant.

The coefficient for metropolitan location (METRO) is positive and statistically significant at the 1 percent level. The regression analysis also reveals a significant positive relationship between the amenities (AMEND) and population growth. One possible explanation is that high amenity counties provide a variety of recreation activities which create employment opportunities for the local communities, and thus high amenity counties become attractive 
locations for business investment and households. These findings are consistent with results from previous studies (Kahsai, 2009; McGranahan, 1999; Deller et al. 2001).

Table 2.1: 3SLS Regression Estimation of Change in Population

\begin{tabular}{|lccc|}
\hline $\begin{array}{c}\text { Independent } \\
\text { Variable }\end{array}$ & Expected Sign & Coefficient & $\boldsymbol{\rho}$-value \\
\hline \hline POP92 & - & -0.1479 & 0.0000 \\
EMP92 & + & 0.6389 & 0.0030 \\
ENREG92 & $-/+$ & -0.0324 & 0.1036 \\
PCICH & + & 1.8852 & 0.0016 \\
EMPCH & + & 2.0809 & 0.0000 \\
ENREGCH & $-/+$ & 0.8429 & 0.0148 \\
MHVAL & - & -0.0084 & 0.7933 \\
PCTAX & - & 3.0792 & 0.1915 \\
AMEND & + & 1760.273 & 0.0014 \\
PROPTAX & - & -36.7472 & 0.1856 \\
UNEMP & - & -211.1728 & 0.0370 \\
MFG & + & -6.5621 & 0.7137 \\
LGEXP & + & 1.2900 & 0.0041 \\
METRO & + & 8401.985 & 0.0006 \\
ROADDEN & + & 2329.112 & 0.5705 \\
CONSTANT & & 9013.233 & 0.0019 \\
$\bar{R}^{2}=0.883053$ & & & \\
$\mathrm{~N}=410$ & & & \\
\hline
\end{tabular}

\subsubsection{Change in Employment Equation}

The estimated results for the employment growth equation are shown in table 5.2. The initial condition for employment (EMP92) has a statistically significant and negative effect on employment growth. The implication of this finding is that counties with initial low employment levels in the 1990s are experiencing faster growth in employment than counties which had high initial levels of employment. These results are consistent with findings from previous studies 
(Gebremariam, 2006; Black et al., 2007) about the convergence in employment rates in the Appalachian region. Black et al. (2007) attributes the convergence of employment in the Appalachia to the wide diversification of the Appalachian economy. Accordingly, this diversification has resulted in the growth of the service sector, retail sector, and growth in government employment.

The estimated coefficient on initial conditions for population (POP92) is statistically significant and positive, thus confirming the hypothesis that people follow jobs. An increase in population entails a larger supply of labor. The interpretation of the results is that a 1 point increase in population is associated with a 1.09 points increase in employment. The positive effect of population on employment growth is supported by evidence from the Appalachian Regional Commission which shows that between 2002 and 2004, there was a large of growth of employment in both the Appalachia and the nation as a whole. ${ }^{7}$ Therefore, it is surmised that the increase in population did not diminish employment opportunities, but rather was necessary to meet the increasing demand for labor.

The coefficient on the initial condition for environmental regulations (ENREG92) has a negative and statistically significant effect on employment growth. The plausible explanation for this negative correlation is that, following the designation of counties as attainment or nonattainment in 1990, the EPA required states to submit state implementation plans (SIPs) at the end of 1992, and therefore, between 1990 and 1992 polluting firms faced stringent measures with regard to pollution control. This is an important finding because it reveals that stringent environmental regulations negatively affect employment growth in the initial years of implementation due to the fact that polluting firms have to install expensive pollution abatement

\footnotetext{
${ }^{7}$ See Appalachian Region Employment Report on http://www.arc.gov/images/appregion/AppalachianRegionEmploymentReport2009Q2.pdf
} 
control equipment. The effect of this may inadvertently be transmitted to other sectors of the economy, which, consequently results in overall slow-down of total employment growth.

On the other hand, the coefficient on the change in environmental regulations (ENREGCH) is positive and statistically significant at the 1 percent level. These results reinforce the Porter hypothesis and show that firms' marginal costs of abatement may decrease over time as firms invest in efficient technology. Therefore, the efficient technology firms invest in serves the dual role of improving productivity and enhancing environmental quality, such that areas become important locations for businesses and households.

The coefficient on the change in population $(P O P C H)$ is statistically significant at the 1 percent level and is positively related to employment growth. This finding, again, confirms the "people follow jobs" hypothesis espoused by Steinnes (1982). Similarly, change in per capita income $(\mathrm{PCICH})$ is statistically significant at the 1 percent level and is positively related to employment growth. This means that Appalachian counties with high income experienced increased growth in employment, and this could be attributed to the economy-wide diversification that has taken place in the Appalachia.

Another variable that might be expected to affect labor demand is the percentage of the population with a bachelor's degree or higher (DEGREE). The coefficient for DEGREE is positive as hypothesized, but has no significant effect on employment growth. Conceptually, metropolitan counties are expected to have high employment growths, but the coefficient for metro counties $(M E T R O)$ is negative and insignificantly different from zero. Similarly, state road density $(R O A D D E N)$ does not appear to be an important explanatory factor for employment growth. 
Local government expenditure (LGEXP) is also regressed against employment growth. The coefficient estimate for local government expenditure (LGEXP) is positive as hypothesized and is statistically significant (5\% level). Another fiscal factor likely to affect employment growth is the local tax per capita $(P C T A X)$. The coefficient on local tax per capita (PCTAX) has an unexpected positive sign, but statistically insignificant. The positive coefficient on PCTAX counters economic theory, and can perhaps be construed to mean that an increase in the local tax rate entails an increase in local government revenue; therefore, an increase in local government revenue may entail provision of more services to the local communities. The last fiscal variable is per capita local property tax (PROPTAX), and its coefficient is also insignificantly different from zero.

Employment growth is also positively influenced by the number of manufacturing establishments, as reflected by the positive and statistically significant coefficient for manufacturing establishment $(M F G)$. Unemployment rate (UNEMP) is negatively related to employment growth and its coefficient is statistically insignificant. Another factor believed to influence employment growth relates to political ideology. The percent of votes cast for the Democratic presidential candidate (VOTE) in the 1992 presidential elections is regressed against employment growth. The estimated coefficient for VOTE is positive but highly insignificant.

The coefficient for the amenities index $(A M E N D)$ is negative and statistically significant at the $5 \%$ percent level. This means that high amenities are associated with a decline in overall employment growth. The negative correlation can be attributed to the fact that the amenities index is a composite score which represents a variety of attributes and thus the importance of individual attributes may be overshadowed. Another variable that has an unexpected sign is the crime rate (CRIME), which has a positive but statistically insignificant coefficient. This positive 
correlation between crime rate and employment growth can be attributed to the fact that other location factors available within counties are more important in stimulating employment growth and thus may overshadow the negative externalities stemming from crime.

Table 5.2: 3SLS Regression Estimation of Change in Employment

\begin{tabular}{|c|c|c|c|}
\hline $\begin{array}{c}\text { Independent } \\
\text { Variable }\end{array}$ & Expected Sign & Coefficient & $\rho$-value \\
\hline EMP92 & - & -0.0638 & 0.0007 \\
\hline ENREG92 & $+/-$ & -0.0862 & 0.0000 \\
\hline РОР92 & + & 1.0916 & 0.0000 \\
\hline PCICH & + & 2.1597 & 0.0000 \\
\hline POPCH & - & 0.4509 & 0.0000 \\
\hline ENREGCH & $+/-$ & 0.5199 & 0.0000 \\
\hline DEGREE & + & 14.5365 & 0.5409 \\
\hline$L G E X P$ & - & 0.7006 & 0.0037 \\
\hline PROPTAX & - & -7.3759 & 0.5747 \\
\hline UNEMP & - & -96.6829 & 0.1419 \\
\hline METRO & + & -2611.307 & 0.0655 \\
\hline$M F G$ & + & 22.7049 & 0.0103 \\
\hline AMEND & + & -764.2158 & 0.0038 \\
\hline CRIME & - & 0.0171 & 0.8337 \\
\hline ROADDEN & + & 606.3321 & 0.7850 \\
\hline PCTAX & - & 2.4506 & 0.1145 \\
\hline VOTE & + & 0.6503 & 0.9686 \\
\hline CONSTANT & & 7389.006 & 0.0199 \\
\hline $\begin{array}{l}\bar{R}^{2}=0.8580 \\
\mathrm{~N}=410\end{array}$ & & & \\
\hline
\end{tabular}




\subsubsection{Change in Per Capita Income Equation}

Three stage least squares regression results for the per capita income equation are reported in table 5.3. The estimated coefficient for initial condition for per capita income (PC192) is negative and its coefficient is statistically significant at the 1 percent level. The negative coefficient for PCI92 confirms the convergence hypothesis, which suggests that counties with lower incomes grow faster than higher income counties. Gebremariam (2006) and Santopietro (2002) also find evidence of income convergence in the Appalachia. On the other hand, the coefficient estimate for initial population (POP92) has a positive effect on per capita income growth and is statistically significant at the 5 percent level. The interpretation of this result is that initial levels of population are representative of labor supply and thus have a positive impact on output and per capita income growth. Although this estimate for this variable is statistically significant, its magnitude is relatively small.

The sign and level of significance for the initial condition for environmental regulation (ENREG92) mirrors results obtained in the employment and population equations (negative and significant at the 1 percent level). The interpretation of this result is that the extent to which environmental regulations influence population growth depends on environmental regulations' direct effect on economic performance. Under this circumstance, it can be assumed that stringent environmental regulations will initially negatively affect economic performance due to firms' investments in abatement technology, which subsequently reduces labor demand. This negatively affects per capita income growth.

Except for the change in population $(P O P C H)$ variable, all growth factors (endogenous variables) are significant in explaining growth in per capita income. Economic theory shows that growth in employment $(E M P C H)$ results in an increase in aggregate labor demand, and as a 
result, higher per capita income. The variable $E M P C H$ has the correct positive sign and is significant at the 5 percent level. These findings provide empirical evidence of the hypothesized positive impact of employment growth on per capita income growth. Similar effects are also seen with respect to change in environmental regulations $(E N R E G C H)$. The estimated coefficient for change in environmental regulations $(E N R E G C H)$ is positive and statistically significant at the 1 percent level.

Several economic variables are regressed against change in per capita income. High local government expenditures generally indicate increased provision of public goods and services. Despite having a positive effect on per capita income growth, the coefficient for local government expenditure (LGEXP) is insignificant. As hypothesized, an increase in local tax per capita $(P C T A X)$ has a negative effect on per capita income growth, because taxes are an additional cost to individuals. Thus high tax counties will become unattractive locations for households. Regression results show that the percent of population below the poverty level (POVRATE) is inversely related to per capita income growth. The coefficient for poverty rate (POVRATE) is significant at the 5 percent level. The estimated coefficient for manufacturing establishment $(M F G)$ shows a negative relationship with per capita income growth and is only significant at the 10 percent level. Perhaps the logical explanation for this negative correlation may be that manufacturing's role in the Appalachian region has evidently declined over the years, to the extent of reducing its contribution to per capita income growth, and gross state product in general.

One variable included to capture political party influence on economic growth is the percent of votes cast for the Democratic presidential candidate (VOTE). The hypothesis that Democratic Party control is associated with increased economic growth is confirmed, based on 
the positive and significant coefficient for VOTE. Similarly, location attributes, such as amenities $(A M E N D)$ are positively related to income growth, but its coefficient is insignificant.

The coefficient for the percentage of population with a bachelor's degree or above (DEGREE) is positive and significant, providing evidence for the well known relationship between human capital skills and income growth. The percentage of population between 18 years and 64 years (ACTIVE) is used to indicate the demographic group that is typically considered to be in wage and salaried employment. The coefficient for ACTIVE has the correct positive sign, but is insignificant. By contrast, an increase in the percent of population 65 years and older (RETIRE) is negatively related to per capita income growth and the estimated coefficient for RETIRE is significant at the 1 percent level.

Another demographic variable related to income growth is the percent of Black population $(B L A C K)$. The coefficient for $B L A C K$ is negative and significant at the 10 percent level. This finding confirms the hypothesis that counties with larger Black populations are inversely related to income growth. These findings are realistic in view of the fact that majority of the black population in the Appalachia live in the southern and central counties. ${ }^{8}$ By all standards, the Appalachian Regional Commission considers the southern and central counties of Appalachia to be the most economically distressed.

\subsubsection{Change in Environmental Regulations Equation}

Table 5.4 presents estimated results for the environmental regulations equation. The estimated coefficient for 1992 environmental regulations (ENREG92) is positive and statistically significant at the 1 percent level. One explanation for this positive coefficient is that counties

\footnotetext{
${ }^{8}$ Young et al. (2007) examine the relationship between race and economic growth using county level data on per capita income, socioeconomic, and demographic factors for Mississippi. They find evidence that indicate that an increase in percentage of Black population is negatively related to income growth.
} 
which are out-of-attainment in the initial period are likely to attract regulatory attention and thus positively influence changes in environmental regulations. This is in view of the fact that some counties will be out-of-attainment in a number of pollutants. Initial condition for population (POP92) is positively related to change in environmental regulation and is significant at the 1 percent level. This finding illustrates that air pollution varies with population and therefore, an increase in population will positively influence environmental regulations stringency. However, the magnitude of population is very small.

Table 5.3: 3SLS Regression Estimation of Change in Per Capita Income

\begin{tabular}{|c|c|c|c|}
\hline $\begin{array}{c}\text { Independent } \\
\text { Variable } \\
\end{array}$ & $\begin{array}{c}\text { Expected } \\
\text { Sign } \\
\end{array}$ & Coefficient & $\rho$-value \\
\hline ENREG92 & $-/+$ & -0.7414 & 0.0000 \\
\hline PCI92 & - & -0.3823 & 0.0001 \\
\hline POP92 & + & 0.0600 & 0.0017 \\
\hline EMPCH & + & 0.0396 & 0.0061 \\
\hline ENREGCH & $+/-$ & 0.1378 & 0.0001 \\
\hline POPCH & + & 0.0142 & 0.7423 \\
\hline PCTAX & - & -1.7783 & 0.0943 \\
\hline DEGREE & + & 11.8178 & 0.0063 \\
\hline$A M E N D$ & + & 863.8531 & 0.1507 \\
\hline POVRATE & - & -85.8305 & 0.0072 \\
\hline$B L A C K$ & - & -128.5698 & 0.0807 \\
\hline ACTIVE & + & 37.9073 & 0.1725 \\
\hline$M F G$ & + & -7.0195 & 0.0566 \\
\hline RETIRE & - & -39.7288 & 0.0002 \\
\hline VOTE & + & 99.8252 & 0.0429 \\
\hline$L G E X P$ & + & 34.1256 & 0.2280 \\
\hline CONSTANT & & 0.5909 & 0.0054 \\
\hline $\begin{array}{l}\bar{R}^{2}=0.4318 \\
\mathrm{~N}=410\end{array}$ & & & \\
\hline
\end{tabular}


On the other hand, 1992 per capita income (PCI92) has a positive effect and thus reinforces the hypothesis that an increase in income increases the demand for environmental quality, assuming that environmental quality is a normal good. Similarly, a change in per capita income $(\mathrm{PCICH})$ has a positive effect on environmental regulation change and thus lends support to the theory that at high income levels, the policy response towards environmental degradation is stronger. The coefficient estimate for $\mathrm{PCICH}$ is statistically significant at the 1 percent level. Employment change $(E M P C H)$ is positively related to change in environmental regulations but does not attain any statistical significance, while the coefficient for population change $(P O P C H)$ is negative and statistically significant at the 10 percent level.

The EPA considers children below 5 years and adults above 65 years to be particularly sensitive to exposure to air pollutants. The percentage of the population who are considered sensitive $(R I S K)$ to environmental exposures has the expected positive sign. Another variable that is likely to result in increased emissions is the percentage of population driving to work (POPDRIVE). The coefficient for POPDRIVE has the expected positive sign and is significant at the 1 percent level. These findings further confirm the association between increased vehicular traffic and air pollution. Regression results also indicate that state road density (ROADDEN) positively influences changes in environmental regulation. In general, metropolitan counties are associated with large population densities and commuters in metro areas typically drive long distances to work. Thus, metro areas are associated with increased pollution. Surprisingly, the estimated coefficient for METRO is negative and significant at the 1 percent level.

As expected, the coefficient for population density $(P O P D E N)$ is positive and significant at the 5 percent level. This follows because a dense population entails increased economic activity and this typically translates into increased emissions of pollutants from both firms and 
households. The percent of votes cast for the Democratic president (VOTE) appears to have a positive influence on environmental regulations outcomes. This finding is in accord with Kahn and Matsusaka's (1997) finding that Democratic presidential voting patterns explain environmental outcomes.

Table 5.4: 3SLS Regression Estimation of Change in Environmental Regulations

\begin{tabular}{|lccc|}
\hline Independent Variable & $\begin{array}{c}\text { Expected } \\
\text { Sign }\end{array}$ & Coefficient & $\rho$-value \\
\hline \hline ENREG92 & $+/-$ & 0.6756 & 0.0000 \\
POP92 & + & 0.0021 & 0.0156 \\
PCI92 & + & 0.0411 & 0.0247 \\
PCICH & + & 0.0623 & 0.0007 \\
POPCH & + & 0.0044 & 0.0523 \\
EMPCH & + & 0.0536 & 0.3744 \\
POVRATE & - & 0.0081 & 0.0000 \\
BLACK & - & 0.0015 & 0.0003 \\
RISK & + & 0.0078 & 0.0015 \\
POPDRIVE & + & 0.0044 & 0.0000 \\
METRO & + & -0.2506 & 0.0000 \\
ROADDEN & + & 0.1237 & 0.0022 \\
SIERRA & + & 0.0227 & 0.0065 \\
DEGREE & + & 0.0025 & 0.0005 \\
MFGEMP & $+/-$ & 0.0032 & 0.4777 \\
VOTE & + & 0.0028 & 0.0000 \\
POPDEN & + & 0.0026 & 0.0013 \\
MFG & + & 0.0070 & 0.0380 \\
CONSTANT & & 0.52781 & 0.0000 \\
$\bar{R}^{2}=0.9251$ & & & \\
N=410 & & &
\end{tabular}


The coefficient for manufacturing establishment $(M F G)$ has the expected positive sign and is significant at the 10 percent level. This implies that counties with a high number of manufacturing establishments are likely to have more pollution and thus attract more enforcement of environmental regulations. Similarly, the estimated coefficient for percentage of population employed in manufacturing (MFGEMP) has the expected positive sign, but is insignificant.

The strength of environmental pressure groups on environmental outcomes is captured by the presence of Sierra chapters in a county. The coefficient estimate for SIERRA is positive and significant at the 5 percent level. These results provide evidence that environmental pressure groups are pro-environment and thus will support stringent environmental regulations. Additional information on the support for environmental regulation is provided by the positive and significant coefficient for proportion of population with a bachelor's degree (DEGREE). These findings suggest that counties featuring high levels of college graduates more strongly support stringent environmental regulations.

Surprisingly, regression results indicate that counties exhibiting an increase in black population $(B L A C K)$ are associated with an increase in the stringency of environmental regulations. Similarly, the coefficient estimate for poverty rate (POVRATE) is also positive and significant at the 1 percent level. These findings contradict the widely held view in the environmental justice literature that environmental regulations are more strictly enforced in predominantly white (Melosi and Pratt, 2007) and affluent neighborhoods than in black and economically depressed neighborhoods. These findings are reinforced by anecdotal evidence presented in figure 5.2 which shows, for example, that between 1992 and 2007 none of Mississippi’s counties had a non-attainment designation. This is important in view of the fact that Mississippi contains 
the largest number of Black population and has the highest unemployment rates in the Appalachian Region. These findings corroborate Gray and Deily's (1996) finding that more enforcement actions are directed towards plants located in communities with high unemployment rates. By the same token, it can be inferred that more enforcement actions will be directed towards plants located in minority neighborhoods in order to increase political support.

\subsection{Spatial Durbin Model Results}

Estimated results using the 8 nearest neighbors' spatial weight matrix are presented in tables 5.5 through 5.8. The existence of spatial interdependences in the variables is confirmed by the highly statistically and positive coefficients for rho $(\rho)$. In the analyses that follow, the focus is on the interpretation of the direct, indirect, and total effects. The interpretation of these results is based on the methodology suggested by LeSage and Pace (2009).

\subsubsection{SDM Results for Change in Population Equation}

Table 5.5 presents the estimated results for the change in population equation. The positive and significant coefficient for the spatial dependence parameter (rho $=0.5210$ ) provides evidence for the existence of the spatial effects working through the dependent variable (change in population) and explanatory variables. The estimated direct effect associated with initial population level (POP92) is -0.157 . This means that, all else equal, a 1 point increase in initial population in county $\boldsymbol{i}$ will reduce growth in population by 0.157 points in that county. However, it is highly plausible that a change in the initial levels of population in county $\boldsymbol{i}$ not only induces direct effects on population change in this county, but also induces indirect effects (spatial spillovers) on neighboring counties. The estimated coefficient for the indirect or spatial spillover impact for initial population is -0.063 , but it is insignificant. Likewise, the total effect associated 
with initial population is negative and significant. The estimated parameter for the total effect suggests that a 1 point increase in initial population will reduce growth in population in county $\boldsymbol{i}$ and neighboring counties by 0.216 . Overall, these findings confirm the convergence hypothesis which states that on average, counties with small population levels will grow faster than counties with high population levels.

Turning to employment, the estimated results indicate that initial employment levels (EMP92) have a positive direct, indirect, and total effect on population growth. The estimated coefficients for initial employment levels are insignificant. By the same token, growth in employment $(E M P C H)$ has a positive direct effect on population growth, hence providing additional evidence that increased labor demand induces population growth. The estimated coefficient for the indirect effect of $E M P C H$ is positive and insignificant, while the total effect is positive and highly significant.

The estimated results further show that initial environmental regulations (ENREG92) have a negative direct effect on population growth and its coefficient is significant at the 1 percent level. This finding is in accord with results from the non-spatial model. Similarly, the indirect effects of initial environmental regulation are negative and significant. These results further show that changes in environmental regulation in one county have negative spillover effects in surrounding counties and reduce population growth. Although the direct and indirect estimates for initial environmental regulations are significant, the total effect estimate for initial environmental regulations is insignificant. The insignificant result for the total effect may be due to the fact that the linear combination of the direct and indirect fails to attain the restrictive 0.99 confidence interval and, thus causes the linear combination of the direct and indirect effects to be 
insignificant. ${ }^{9}$ After changing the confidence from the $99 \%$ to the upper $95 \%$ confidence interval, the coefficient estimates for the direct, indirect, and total effects are all highly significant (see appendix A).

Notable also is that the direct effect estimate of change in environmental regulations $(E N R E G C H)$ is positive and significant at the 1 percent level, while the indirect and total effect estimates are insignificant. The parameter estimate for direct effect of per capita income growth $(\mathrm{PCICH})$ has the anticipated positive sign and is statistically significant. Further, per capita income growth appears to exhibit a positive indirect effect on population growth and is significant at the 5 percent level. The positive indirect or spillover effect suggests that growth in per capita income in a given county influences population growth in neighboring counties. The total effect of per capita income growth is positive and significant. The parameter estimate for the total effect suggests that a 1 point increase in per capita income in a given county increases population growth for that county and other neighboring counties by 1.744 points.

Consistent with expectations, manufacturing establishment $(M F G)$ has a positive direct effect on population growth and its coefficient is significant at the 10 percent level. Similarly, manufacturing establishment has a positive indirect and total effect on population, but the coefficients for both (indirect and total effect) are insignificantly different from zero. Unemployment rate (UNEMP) has the expected negative direct effect, and a further review also shows that unemployment rate has a positive indirect effect on population growth. This means than an increase in unemployment rate in one county will positively influence population growth in neighboring counties.

\footnotetext{
${ }^{9}$ Derivation of the direct, indirect, and total effects uses an iterative process known as the Markov Chain Monte Carlo methods (MCMC) and the estimates reported in table 5.5 are based on the upper 99 percent confidence interval. I thank Professor Donald Lacombe for his help in understanding why it is possible to have significant individual effect results, but insignificant total effect results.
} 
Local government expenditure (LGEXP) has a positive direct, indirect, and total effect on population growth. These findings reveal that goods and services provided by local governments will induce population growth in own county and neighboring counties. By comparison, per capita local tax $(P C T A X)$ has a negative direct effect on population growth, but is insignificant. The indirect and total effect of the local tax variable is negative and significant at the 10 percent level, respectively. Estimated results show that when median housing values (MHVAL) increase in a given county, this has a negative direct effect on the county's population growth. Likewise, an increase in median housing values in one county appears to exert a negative indirect or spatial spillover effect on population growth in other neighboring counties. The total effect for median housing value is negative and is insignificant.

Like housing values, local property taxes (PROPTAX) have a negative direct effect on population growth. The implication of this finding is that an increase in county property taxes discourages firms and households from locating in that county, thereby thwarting population growth. The indirect effect of property taxes is similarly negative and its coefficient is statistically significant at the 1 percent level. The direct effect for amenities index (AMEND) is positive and significant, while the indirect effect is insignificant. The total effect for amenities is positive and significant at the 5 percent level. Based on the positive direct effect of state road densities, it is inferred that an increase in state road density (ROADDEN) increases population growth.

\subsubsection{SDM Results for Change in Employment Equation}

Estimated results for the change in total employment equation are presented in table 5.6. The estimated coefficient for $\rho$ is positive (0.6467) and significant at the 5 percent level, and thus provides evidence of strong spatial dependence. An examination of the results reveals that 
initial condition for total employment (EMP92) has a negative and significant direct effect on change in employment. This finding confirms the non-spatial results that there is convergence in employment in the Appalachia. Initial employment has a positive indirect effect, but the coefficient is insignificant. The initial condition for population (POP92) and change in population $(P O P C H)$ have a positive direct, indirect, and total effect on employment growth. These findings show that employment growth can be influenced by the growth of labor supply from within a county and labor supply from other neighboring counties. Over all, these findings support the "people follow jobs" hypothesis.

Change in income $(\mathrm{PCICH})$ has the expected positive direct effect on employment growth but is insignificantly different from zero. Like in other estimations, the initial condition for environmental regulation (ENREG92) exhibits a negative direct effect on employment growth. The negative effect can be attributed to initial high investment costs in abatement capital, which directly reduces firms' output and labor demand. The indirect effect estimate for initial environmental regulations is negative and thus suggests that a change in environmental regulations in a given county reduces employment growth in neighboring counties. Further, estimates show that a change in a county's initial environmental regulation has a negative total effect on that county and its neighbors.

By contrast, the change in environmental regulations variable appears to have a positive effect on employment growth. These finding are consistent with previous studies (Goetz et al. 1996; Porter and van der Linde, 1995; Ringquist, 1993) in revealing that the short-run effects of environmental regulation are reduced employment growth, but in the long-run environmental regulation positively influences employment growth. 
Contrary to expectations, the number of manufacturing industries (MFG) has a negative direct, indirect, and total effect on employment growth. The coefficient for the direct, indirect, and total effect of manufacturing establishment is significant at the 5 percent, 10 percent, and 5 percent respectively. The negative indirect effect of manufacturing establishment implies that an increase in neighboring counties' manufacturing establishments reduces employment growth in a given county. Similarly, the total effect suggests that an increase in manufacturing establishments in one county decreases that county's and neighboring counties' employment growth.

Spatial regression results, again, confirm that unemployment rates (UNEMP) have a negative direct effect on employment growth. Similarly, unemployment rate appears to exert a negative indirect effect on employment growth. The interpretation of this negative indirect effect is that, an increase in the county unemployment rate negatively affects employment growth in neighboring counties. Also, regression results indicate that the amenities index (AMEND) has a positive direct effect on employment growth and is significant at the 1 percent level. State road density $(R O A D D E N)$ has the hypothesized positive direct effect on employment and is significant at the 1 percent level.

Consistent with economic theory and past studies (Carlino and Mills, 1987; Helms, 1991), local government expenditure (LGEXP) has a positive direct effect on employment growth. The estimated positive indirect effect for local government implies that an increase in local government expenditure in one county will influence employment growth in neighboring counties. Similarly, the percentage of population with bachelor's degree (DEGREE) has a positive direct effect and is significant at the 10 percent level. The estimate for the indirect impact of DEGREE is equal to -42.517 , suggesting that an increase in the number of people with bachelor's degrees in a given county will negatively influence employment growth in 
neighboring counties. The number of crimes has the anticipated negative direct effect on employment growth, but parameter estimates for the indirect and total effects are insignificant.

\subsubsection{SDM Results for Change in Per Capita Income Equation}

SDM estimation results for the change in per capita income $(\mathrm{PCICH})$ equation are presented in table 5.7 and the estimated coefficient for the spatial dependence variable $\boldsymbol{\rho}$, is positive (0.7259) and significant at the 5 percent level. As expected, the estimated coefficient for initial per capita income (PCI92) exhibits a negative direct effect on per capita income growthand therefore, suggests that there is convergence in income in the Appalachia. This result is similar to Gebremariam et al. (2007) and Santopietro's (2002) finding of income convergence in the Appalachia. Estimated results further reveal that initial per capita income has a negative indirect and total effect on income growth, and both are significant at the 5 percent and 10 percent levels, respectively.

Results for initial population (POP92) closely match the non-spatial results, where initial population has a positive direct effect on per capita income growth. This is consistent with the view that initial population levels represent available labor supply, and thus an increase in labor supply will positively influence growth in income. Results further reveal that an increase in initial population in one county has a negative indirect effect on per capita income growth in other neighboring counties. Equally, change in population $(P O P C H)$ has a positive direct effect on per capita income growth, implying that an increase in county labor supply increases county per capita income. This seems plausible if we assume that population growth leads to increased output, which in turn positively influences growth in per capita income. The estimated indirect and total effects are positive and significant at the 5 percent level and 10 percent level, respectively. 
The direct effect estimates for environmental regulations (ENREG92) show that an increase in environmental regulations reduces per capita income growth in a county. One explanation for this may be that the high abatement investment costs firms incur in the initial period of pollution control negatively affects the labor demand within counties, which in turn, results in the decline of per capita income growth. The indirect and total effects are insignificant. Parallel to initial environmental regulations, change in environmental regulations (ENREGCH) is associated with a positive direct effect on per capita income growth. These findings are similar to the results from the non-spatial regressions. However, the indirect and total effect estimates of a change in environmental regulation are insignificantly different from zero.

As hypothesized, employment growth $(E M P C H)$ has a positive direct effect on income growth and is significant at the 1 percent level. The estimated positive coefficient for the direct effect of employment suggests that a 1 point increase in employment within a county increases that county's per capita income by 0.202 points. The indirect and total effects for employment growth are negative and significantly different from zero. The indirect effect results suggest that a change in a given county's employment negatively affects income growth of neighboring counties. The estimated coefficient for the unemployment rate (UNEMP) has the anticipated negative direct effect on per capita income growth and is significant at the 10 percent level. The negative coefficient implies that the unemployment rate works by discouraging population growth, and this in turn retards income growth. Similarly, the unemployment rate has a negative indirect effect and is significant at the 10 percent level.

The percentage of the population above 65 years (RETIRE) has the anticipated negative direct effect, but its coefficient is insignificant. By contrast, the indirect effect for percentage of population above 65 years is negative and significant at the 10 percent level. The direct effect 
estimate of percent of Black population $(B L A C K)$ has the anticipated negative sign and confirms findings from the non-spatial regression model about the inverse relationship between Black population and income.

\subsubsection{SDM Results for Change in Environmental Regulations Equation}

Table 5.8 presents summary SDM results for the change in environmental regulations equation $(E N R E G C H)$. The estimated coefficient for $\rho$ is positive $(\hat{\rho}=0.539)$ and significant at the 5 percent level, hence providing evidence for the existence of spatial dependence. The direct effects estimate for initial environmental regulations (ENREG92) has the expected positive sign, and its coefficient is statistically significant at the 1 percent level. This means that counties with stringent initial environmental regulation are likely to experience stringent environmental regulation in future. The estimated indirect effect for initial environmental regulation is positive but insignificant, while the total effect estimate for initial environmental regulation is positive and significant at the 1 percent. The estimate of the total effect is equal to 0.6594 and is significant at the 5 percent level. The interpretation of this is that a one point increase in county $i$ 's initial environmental regulation will increase environmental regulation stringency in that county and neighboring counties by 0.6594 . The positive total influence of county $i$ 's environmental regulations on neighboring counties environmental regulations is suggestive of the strategic interaction phenomena, which is consistent with the race to the top hypothesis. This means that an increase in environmental regulations in one county provides an incentive for neighboring counties to increase their environmental regulations. Eliste and Fredriksson (2002) 
find evidence of strategic interaction among a cross-section of countries in the determination of environmental regulations for the agricultural sector. ${ }^{10}$

Consistent with expectations, initial per capita income (PCI92) has a direct positive effect on environmental regulations. This finding supports the hypothesis that higher income people will demand better environmental quality, and thus will demand more stringent environmental regulation. The estimated indirect and total effect for initial levels of per capita is positive and significant at the 1 percent level, respectively. Change in population $(P O P C H)$ has a positive direct effect on environmental regulations as hypothesized. This finding is very important because it shows that an increase in population will lead to greater pollution levels and thus exert an upward pressure on environmental regulations. By the same token, change in population level has a positive indirect and total effect.

Change in per capita income $(P C I C H)$ also exhibits a positive direct effect on environmental regulations and is significant at the 1 percent level. The indirect effect for change in per capita income is negative and insignificant. The effect of increasing a single county's per capita income has a positive cumulative effect on neighboring counties' environmental regulation. In a related manner, the direct effect estimate of total employment change $(E M P C H)$ has the expected positive sign and is significant at the 1 percent level. Total employment change is associated with a positive indirect and total effect on environmental regulations. These findings are important in that they reveal the transboundary problem of pollution, which may stem from different employment sectors in neighboring counties.

There is strong evidence that an increase in manufacturing establishments $(M F G)$ has a positive direct effect on environmental regulations and the coefficient is significant at the 1

\footnotetext{
${ }^{10}$ Eliste and Fredriksson (2002) emphasize that the degree to which countries strategically interact depends on the geographical distance and degree of trade openness. Fredriksson and Millimet (2002) also find evidence of strategic interaction in environmental policymaking among neighboring U.S. states.
} 
percent level. This finding illustrates that manufacturing industries are more likely to emit large quantities of pollutants, which negatively affect air quality and thus influence the stringency of environmental regulation. Both the indirect and total effects associated with manufacturing establishments have insignificant coefficients. On the other hand, the percentage of population employed in manufacturing $(M F G E M P)$ has negative direct, indirect, and total impacts on environmental regulations. However, only the indirect and total effects are significantly different from zero.

The direct effect estimate for the percentage of the population below 5 years and above 65 years $($ RISK) is positive. This suggests that an increase in these two segments of the population positively influences environmental regulation stringency in the affected county. Support for stringent environmental regulation also comes from environmental interest groups, such as the Sierra Club (SIERRA). The direct and indirect effect of Sierra chapters is positive but insignificant, while the total effect is positive and significant. The percentage of the population driving to work (POPDRIVE) has the expected positive direct effect on environmental regulation stringency, but its coefficient is not significantly different from zero. On the other hand, the indirect and total effect estimates for POPDRIVE are positive and significantly different from zero. These findings support the theory that increased vehicle miles travelled contribute to air pollution and thus induce more stringent environmental regulation. State road density $(R O A D D E N)$ has positive direct and total effects. 
Table 5.5: SDM Estimation Results of Change in Population

\begin{tabular}{|c|c|c|c|c|c|c|c|c|}
\hline \multirow{2}{*}{$\begin{array}{l}\text { Independent } \\
\text { Variable }\end{array}$} & \multicolumn{2}{|c|}{$\begin{array}{l}\text { Model Estimates \& } \\
\text { Spatially lagged } \\
\text { Estimates }\end{array}$} & \multicolumn{2}{|c|}{ Direct Effect } & \multicolumn{2}{|c|}{ Indirect Effect } & \multicolumn{2}{|c|}{ Total Effect } \\
\hline & Coefficient & p-level & Coefficient & t-prob & Coefficient & t-prob & Coefficient & t-prob \\
\hline POP92 & $-0.157^{* * *}$ & 0 & $-0.153^{* * *}$ & 0 & -0.063 & 0.9464 & $-0.216^{* *}$ & 0.002 \\
\hline EMP92 & 0.084 & 0.239 & 0.082 & 0.469 & 0.042 & 0.9987 & 0.124 & 0.851 \\
\hline ENREG92 & $-0.426 * * *$ & 0 & $-0.446 * * *$ & 0 & $-0.782 * *$ & 0.0046 & -0.928 & 0.222 \\
\hline EMPCH & $2.034^{* * *}$ & 0 & $2.036 * * *$ & 0 & 0.013 & 0.9672 & $2.049 * * *$ & 0 \\
\hline $\mathrm{PCICH}$ & $1.076^{* * *}$ & 0 & $1.090 * * *$ & 0 & $0.655^{* *}$ & 0.0031 & $1.744 *$ & 0.011 \\
\hline ENREGCH & $0.198^{* * *}$ & 0 & $0.184^{* * *}$ & 0 & 0.662 & 0.5402 & 0.846 & 0.226 \\
\hline MFG & $6.835 *$ & 0.028 & $6.893 *$ & 0.050 & 2.582 & 0.8139 & 9.475 & 0.409 \\
\hline UNEMP & -49.235 & 0.127 & -46.415 & 0.272 & 140.921 & 0.2816 & 94.506 & 0.483 \\
\hline LGEXP & $0.293^{* * *}$ & 0 & $0.299 * * *$ & 0 & $0.285^{* *}$ & 0.0012 & $0.583^{* *}$ & 0.003 \\
\hline PCTAX & -0.519 & 0.307 & -0.619 & 0.551 & $-4.915^{*}$ & 0.0831 & $-5.534 *$ & 0.046 \\
\hline METRO & -554.293 & 0.054 & -533.646 & 0.124 & $1046.955^{*}$ & 0.0339 & 513.310 & 0.645 \\
\hline MHVAL & $-0.047^{* * *}$ & 0 & $-0.048^{* * *}$ & 0 & 0.062 & 0.9989 & 0.014 & 0.186 \\
\hline PROPTAX & $-32.917^{* *}$ & 0.001 & $-32.67^{* * *}$ & 0 & $-13.036 * * *$ & 0.0004 & $-45.713 * *$ & 0.009 \\
\hline AMEND & $768.664 * * *$ & 0 & $773.99 * * *$ & 0 & 225.352 & 0.4732 & $999.347^{* *}$ & 0.001 \\
\hline ROADDEN & $3370.606^{* *}$ & 0.008 & $3430.85^{*}$ & 0.012 & 2839.834 & 0.3894 & $6270.685^{*}$ & 0.057 \\
\hline W-POP92 & -0.131 & 0.005 & & & & & & \\
\hline W-EMP92 & 0.063 & 0.472 & & & & & & \\
\hline W-ENREG92 & -0.898 & 0.090 & & & & & & \\
\hline W-EMPCH & 2.426 & 0.007 & & & & & & \\
\hline W-PCICH & -1.294 & 0.272 & & & & & & \\
\hline W-ENREGCH & 0.165 & 0.019 & & & & & & \\
\hline W-MFG & 5.600 & 0.481 & & & & & & \\
\hline W-UNEMP & -23.308 & 0.115 & & & & & & \\
\hline W-LGEXP & -0.165 & 0 & & & & & & \\
\hline W-PCTAX & -0.828 & 0.006 & & & & & & \\
\hline W-METRO & 959.226 & 0.143 & & & & & & \\
\hline W-MHVAL & 0.010 & 0 & & & & & & \\
\hline W-PROPTAX & -17.495 & 0.123 & & & & & & \\
\hline W-AMEND & 614.334 & 0.486 & & & & & & \\
\hline W-ROADDEN & 1549.367 & 0.284 & & & & & & \\
\hline rho & $0.5210 * *$ & 0.009 & & & & & & \\
\hline
\end{tabular}

Note: $* * *, * *$, and $*$ denote 1,5 , and 10 percent significance level, respectively 
Table 5.6: SDM Estimation Results of Change in Employment

\begin{tabular}{|c|c|c|c|c|c|c|c|c|}
\hline \multirow{2}{*}{$\begin{array}{l}\text { Independent } \\
\text { Variable }\end{array}$} & \multicolumn{2}{|c|}{$\begin{array}{c}\text { Model Estimates \& } \\
\text { Spatially lagged } \\
\text { Estimates }\end{array}$} & \multicolumn{2}{|c|}{ Direct Effect } & \multicolumn{2}{|c|}{ Indirect Effect } & \multicolumn{2}{|c|}{ Total Effect } \\
\hline & Coefficient & p-level & Coefficient & t-prob & Coefficient & t-prob & Coefficient & t-prob \\
\hline POP92 & $0.0991 * * *$ & 0 & $0.099 * * *$ & 0 & $0.0203 *$ & 0.041 & $0.119 * * *$ & 0 \\
\hline EMP92 & $-0.0192 *$ & 0.028 & $-0.019 * * *$ & 0.057 & 0.011 & 0.735 & -0.0087 & 0.375 \\
\hline ENREG92 & $-0.124 * * *$ & 0 & $-0.123^{* * *}$ & 0 & $-0.0901 *$ & 0.051 & $-0.0667 * *$ & 0.005 \\
\hline $\mathrm{PCICH}$ & 0.040 & 0.151 & 0.0397 & 0.303 & -0.064 & 0.614 & -0.024 & 0.860 \\
\hline ENREGCH & $0.744 * * *$ & 0 & $0.739 * * *$ & 0 & 0.041 & 0.605 & $0.781 * *$ & 0.001 \\
\hline $\mathrm{POPCH}$ & $0.533^{* * *}$ & 0 & $0.531 * * *$ & 0 & 0.0142 & 0.858 & $0.546 * * *$ & 0 \\
\hline UNEMP & $-40.221 *$ & 0.039 & $-40.581 * * *$ & 0.087 & $-116.48 *$ & 0.066 & $-157.065^{*}$ & 0.015 \\
\hline LGEXP & $0.136 * * *$ & 0 & $0.134 * * *$ & 0 & 0.0939 & 0.238 & $0.228 * *$ & 0.007 \\
\hline DEGREE & $26.934 *$ & 0.017 & $26.849 *$ & 0.033 & $-42.518^{*}$ & 0.039 & $-15.669 *$ & 0.036 \\
\hline PROPTAX & -3.8406 & 0.226 & -3.865 & 0.456 & -8.3874 & 0.340 & $-12.25^{*}$ & 0.074 \\
\hline MFG & $-6.2909 * *$ & 0.001 & $-6.321 * *$ & 0.001 & $-8.368 *$ & 0.096 & $-14.689 * *$ & 0.004 \\
\hline CRIME & -0.0281 & 0.260 & -0.0276 & 0.540 & 0.1836 & 0.172 & 0.156 & 0.269 \\
\hline METRO & 439.367* & 0.011 & 439.893* & 0.022 & 20.5329 & 0.968 & 460.4266 & 0.356 \\
\hline AMEND & $332.47 * * *$ & 0 & $333.63^{* * *}$ & 0 & $-290.709 *$ & 0.053 & $42.926 * * *$ & 0 \\
\hline VOTE & 6.1980 & 0.196 & 6.3061 & 0.391 & 39.194* & 0.013 & $45.499 * *$ & 0.003 \\
\hline ROADDEN & $312.91 * * *$ & 0 & $316.88^{* * *}$ & 0 & 232.298 & 0.878 & $549.177 *$ & 0.012 \\
\hline W-POP92 & $0.016^{* * *}$ & 0 & & & & & & \\
\hline W-EMP92 & -0.017 & 0.366 & & & & & & \\
\hline W-ENREG92 & 0.283 & 0.212 & & & & & & \\
\hline W-PCICH & 0.063 & 0.305 & & & & & & \\
\hline W-ENREGCH & 0.764 & 0.334 & & & & & & \\
\hline W-POPCH & -0.0023 & 0.482 & & & & & & \\
\hline W-UNEMP & $-68.864 *$ & 0.035 & & & & & & \\
\hline W-LGEXP & 0.087 & 0.111 & & & & & & \\
\hline W-DEGREE & $42.156 *$ & 0.019 & & & & & & \\
\hline W-PROPTAX & -8.0512 & 0.165 & & & & & & \\
\hline W-MFG & $-7.9363 *$ & 0.044 & & & & & & \\
\hline W-CRIME & $-0.1789 *$ & 0.080 & & & & & & \\
\hline W-METRO & 5.7949 & 0.492 & & & & & & \\
\hline W-AMEND & $\begin{array}{r}-272.303 \\
* \\
\end{array}$ & 0.019 & & & & & & \\
\hline W-VOTE & $37.904 * *$ & 0.009 & & & & & & \\
\hline W-ROAD & -124.871 & 0.464 & & & & & & \\
\hline rho & $0.647 * *$ & 0.004 & & & & & & \\
\hline
\end{tabular}

Note: $* * *, * *$, and $*$ denote 1,5 , and 10 percent significance level, respectively 
Table 5.7: SDM Estimation Results of Change in Per Capita Income

\begin{tabular}{|c|c|c|c|c|c|c|c|c|}
\hline \multirow{2}{*}{$\begin{array}{l}\text { Independent } \\
\text { Variable }\end{array}$} & \multicolumn{2}{|c|}{$\begin{array}{c}\text { Model Estimates \& } \\
\text { Spatially lagged } \\
\text { Estimates }\end{array}$} & \multicolumn{2}{|c|}{ Direct Effect } & \multicolumn{2}{|c|}{ Indirect Effect } & \multicolumn{2}{|c|}{ Total Effect } \\
\hline & Coefficient & p-level & Coefficient & t-prob & Coefficient & t-prob & Coefficient & t-prob \\
\hline $\mathrm{PCl} 92$ & $-0.467 * * *$ & 0 & $-0.435^{* * *}$ & 0.0003 & $-0.310 * *$ & 0.0066 & $-0.746 *$ & 0.0468 \\
\hline POP92 & $0.218^{* * *}$ & 0 & $0.202 * * *$ & 0 & -0.037 & 0.3577 & $0.165^{* *}$ & 0.0047 \\
\hline ENREG92 & $-0.201 * * *$ & 0 & $-0.267^{* * *}$ & 0 & 0.135 & 0.719 & -0.132 & 0.1247 \\
\hline EMPCH & $0.289^{* * *}$ & 0 & $0.203^{* * *}$ & 0 & $-0.983 *$ & 0.0933 & $-0.781^{* *}$ & 0.0048 \\
\hline ENREGCH & $0.103^{* * *}$ & 0 & $0.109 * * *$ & 0 & -0.001 & 0.9844 & 0.109 & 0.3194 \\
\hline $\mathrm{POPCH}$ & $0.168^{* * *}$ & 0 & 0.197 & 0.3713 & $0.308^{* *}$ & 0.0095 & $1.205^{*}$ & 0.0644 \\
\hline BLACK & -36.351 & 0.428 & $-34.53^{* * *}$ & 0 & -33.285 & 0.5056 & $-67.819 * *$ & 0.0051 \\
\hline RETIRE & $-2.378^{* * *}$ & 0 & -2.572 & 0.4736 & $-1.501 *$ & 0.013 & -4.073 & 0.9693 \\
\hline MFG & -24.709 & 0.214 & -23.999 & 0.9667 & -21.636 & 0.7851 & -45.636 & 0.1106 \\
\hline UNEMP & $-0.913 *$ & 0.087 & $-0.978 *$ & 0.0369 & $-0.877 *$ & 0.0184 & $-1.856^{*}$ & 0.0700 \\
\hline PCTAX & $-0.579 *$ & 0.014 & -0.599 & 0.4819 & $0.128 *$ & 0.0866 & -0.472 & 0.1643 \\
\hline DEGREE & -33.584 & 0.224 & -35.724 & 0.1372 & -1.885 & 0.319 & 33.838 & 0.812 \\
\hline AMEND & $-88.870 *$ & 0.059 & -91.825 & 0.3501 & -21.003 & 0.743 & 112.828 & 0.286 \\
\hline ACTIVE & $5.946 *$ & 0.014 & 4.255 & 0.1307 & 93.923 & 0.6336 & 98.178 & 0.9707 \\
\hline VOTE & $4.283 *$ & 0.064 & 4.792* & 0.0857 & 3.921 & 0.6436 & 8.712 & 0.3928 \\
\hline W*PCl92 & $-0.543 *$ & 0.059 & & & & & & \\
\hline W*POP92 & 0.093 & 0.177 & & & & & & \\
\hline W*ENREG92 & $0.115^{*}$ & 0.064 & & & & & & \\
\hline$W^{*}$ EMPCH & $-0.548^{* * *}$ & 0 & & & & & & \\
\hline W*ENREGCH & 0.107 & 0.334 & & & & & & \\
\hline W*POPCH & 0.239 & 0.167 & & & & & & \\
\hline W*BLACK & 56.475 & 0.133 & & & & & & \\
\hline$W^{*}$ RETIRE & -1.848 & 0.427 & & & & & & \\
\hline $\mathrm{W} * \mathrm{MFG}$ & $22.092 *$ & 0.045 & & & & & & \\
\hline W*UNEMP & -1.103 & 0.425 & & & & & & \\
\hline W*PCTAX & 0.1247 & 0.113 & & & & & & \\
\hline$W^{*}$ DEGREE & -31.695 & 0.279 & & & & & & \\
\hline W*AMEND & $-22.33^{* * *}$ & 0.005 & & & & & & \\
\hline W*ACTIVE & 8.7412 & 0.378 & & & & & & \\
\hline W*VOTE & $28.317^{*}$ & 0.011 & & & & & & \\
\hline rho & 0.726 & 0.002 & & & & & & \\
\hline
\end{tabular}

Note: $* * *, * *$, and $*$ denote 1,5 , and 10 percent significance level, respectively 
Table 5.8: SDM Estimation Results of Change in Environmental Regulations

\begin{tabular}{|c|c|c|c|c|c|c|c|c|}
\hline \multirow{2}{*}{$\begin{array}{l}\text { Indepen- } \\
\text { dent } \\
\text { Variables }\end{array}$} & \multicolumn{2}{|c|}{$\begin{array}{c}\text { Model Estimates \& } \\
\text { Spatially lagged } \\
\text { Estimates }\end{array}$} & \multicolumn{2}{|c|}{ Direct Effect } & \multicolumn{2}{|c|}{ Indirect Effect } & \multicolumn{2}{|c|}{ Total Effect } \\
\hline & Coefficient & p-level & Coefficient & t-prob & Coefficient & t-prob & Coefficient & t-stat \\
\hline PCI92 & $0.060^{* * *}$ & 0 & $0.059 * * *$ & 0 & $0.0033^{* * *}$ & 0.0009 & $0.0623^{* * *}$ & 0 \\
\hline ENREG92 & $0.676^{* * *}$ & 0 & $0.679 * * *$ & 0 & 0.0205 & 0.9190 & $0.7004 * *$ & 0.0020 \\
\hline POPCH & $0.0013^{* * *}$ & 0 & $0.0012^{* * *}$ & 0 & $0.018^{*}$ & 0.0100 & $0.0192^{* * *}$ & 0 \\
\hline$E M P C H$ & $0.0413^{* * *}$ & 0 & $0.039 * * *$ & 0 & $0.042 *$ & 0.0555 & $0.081^{* * *}$ & 0.0004 \\
\hline $\mathrm{PCICH}$ & $0.0825^{* * *}$ & 0 & 0.0983 & 0 & -0.064 & 0.4548 & $0.0343 *$ & 0.0400 \\
\hline MFG & $0.0021^{* * *}$ & 0 & $0.0020 * * *$ & 0.0002 & -0.0015 & 0.4155 & 0.001 & 0.7642 \\
\hline MFGEMP & -0.0096 & 0.4835 & -0.0054 & 0.9991 & $-0.0101 *$ & 0.0296 & $-0.0156 *$ & 0.0205 \\
\hline POVRATE & $0.0057 *$ & 0.0895 & 0.0055 & 0.1947 & -0.0142 & 0.1353 & -0.0087 & 0.3411 \\
\hline$B L A C K$ & 0.0040 & 0.434 & 0.0041 & 0.8646 & 0.0017 & 0.6954 & 0.0058 & 0.5446 \\
\hline RISK & $0.0244 * * *$ & 0 & $0.0245^{* * *}$ & 0.0004 & 0.0027 & 0.8754 & 0.0272 & 0.1966 \\
\hline DEGREE & 0.0034 & 0.147 & 0.0034 & 0.3040 & 0.0051 & 0.3661 & 0.0085 & 0.7361 \\
\hline METRO & $-0.1032 * *$ & 0.0055 & $-0.1033^{*}$ & 0.0109 & -0.0043 & 0.9718 & -0.1076 & 0.3723 \\
\hline SIERRA & 0.0138 & 0.3665 & 0.0148 & 0.7336 & 0.1025 & 0.2023 & $0.1173 *$ & 0.0893 \\
\hline VOTE & $0.0031 *$ & 0.0515 & $0.0031 *$ & 0.0985 & 0.0047 & 0.2549 & $0.0078 *$ & 0.048 \\
\hline POPDRIVE & 0.0022 & 0.2725 & 0.0019 & 0.6004 & $0.0266 * *$ & 0.0051 & $0.0285^{* *}$ & 0.0082 \\
\hline ROADDEN & $0.3523 *$ & 0.0345 & $0.3586 *$ & 0.0588 & 0.6025 & 0.1466 & $0.9611 *$ & 0.0127 \\
\hline W-PCI92 & $-0.0015^{* * *}$ & 0 & & & & & & \\
\hline W-ENREG92 & $0.0868^{* *}$ & 0.005 & & & & & & \\
\hline W-POPCH & 0.0032 & 0.484 & & & & & & \\
\hline W-EMPCH & $0.0343 *$ & 0.032 & & & & & & \\
\hline W-PCICH & $0.0284 * *$ & 0.008 & & & & & & \\
\hline W-MFG & -0.0015 & 0.17 & & & & & & \\
\hline W-MFGEMP & $-0.0092 *$ & 0.016 & & & & & & \\
\hline W-POVRATE & $-0.0135^{*}$ & 0.0555 & & & & & & \\
\hline W-BLACK & 0.0015 & 0.3575 & & & & & & \\
\hline W-RISK & -0.0049 & 0.385 & & & & & & \\
\hline W-DEGREE & -0.005 & 0.164 & & & & & & \\
\hline W-METRO & 0.0656 & 0.471 & & & & & & \\
\hline W-SIERRA & 0.0915 & 0.1115 & & & & & & \\
\hline W-VOTE & -0.004 & 0.143 & & & & & & \\
\hline $\begin{array}{l}\text { W- } \\
\text { POPDRIVE }\end{array}$ & 0.024 & 0.003 & & & & & & \\
\hline rho & 0.539 & 0.0018 & & & & & & \\
\hline
\end{tabular}

Note: $* * *, * *$, and $*$ denote 1,5 , and 10 percent significance level, respectively 
Figure 5.2: 2004 Attainment and Non-attainment Areas in the U.S. 8 Hour Ozone Standard

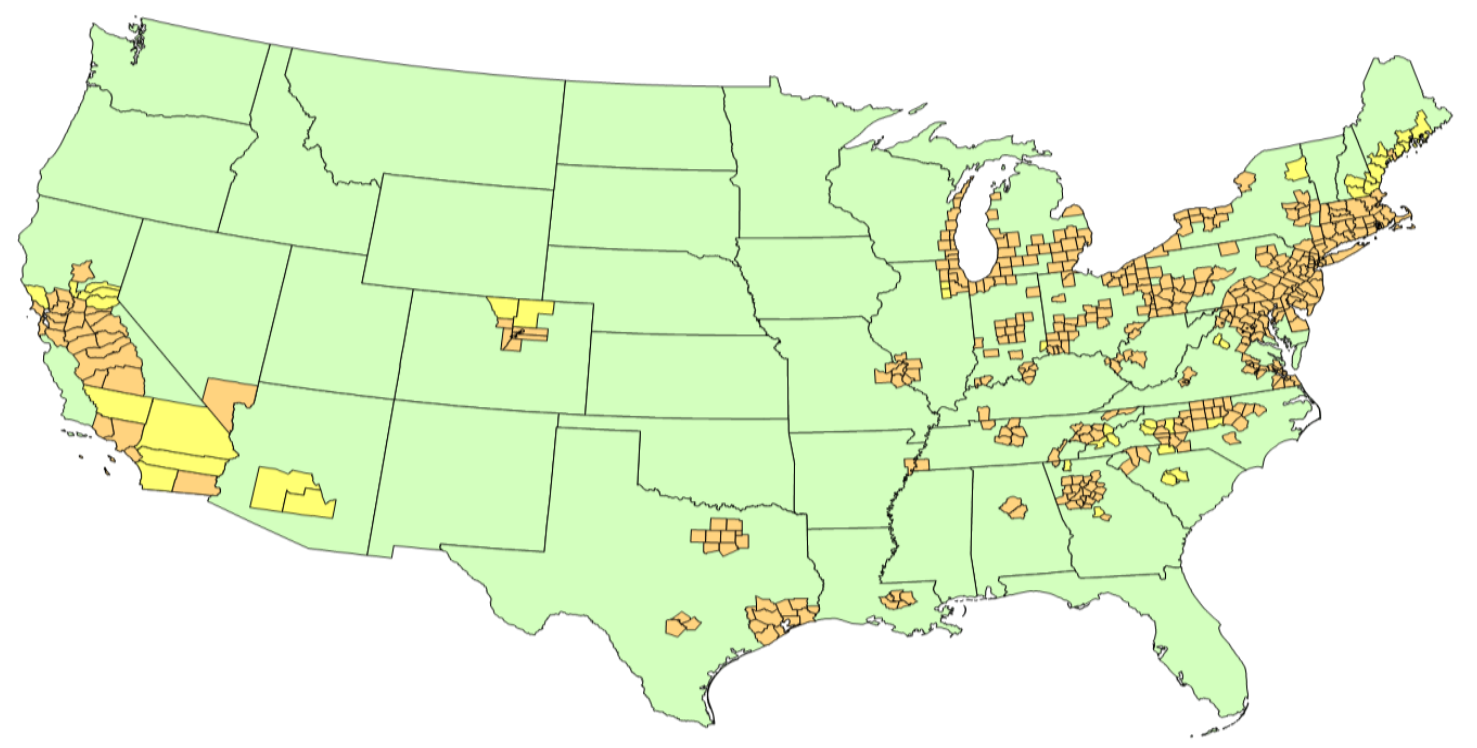

Attainment or unclassified area (2668 counties)

Non-attainment areas (423 entire counties)

Non-attainment areas (42 partial counties)

Source: EPA

Figure 5.3: 2007 Attainment and Non-Attainment Counties in Appalachia

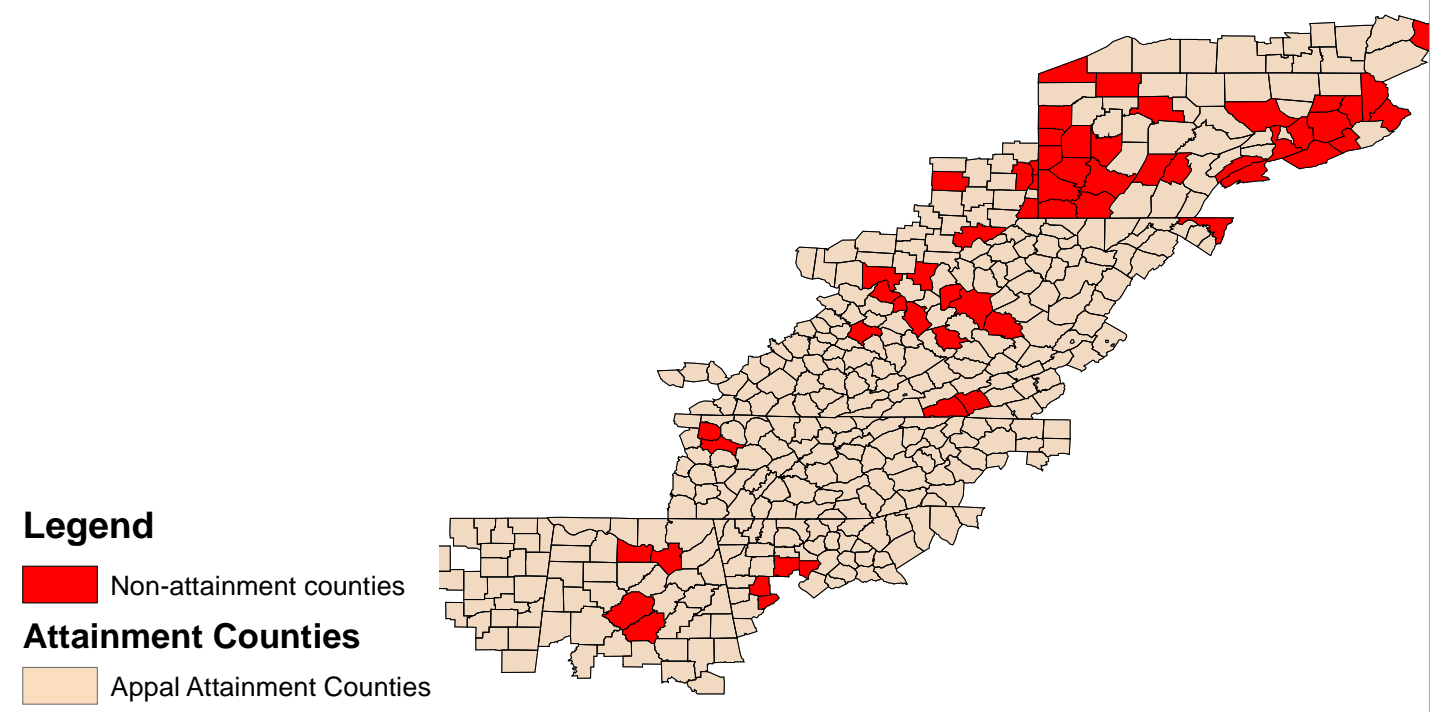


Figure 5.4: 1994 DISTRIBUTION OF AFRICAN AMERICANS IN APPALACHIA

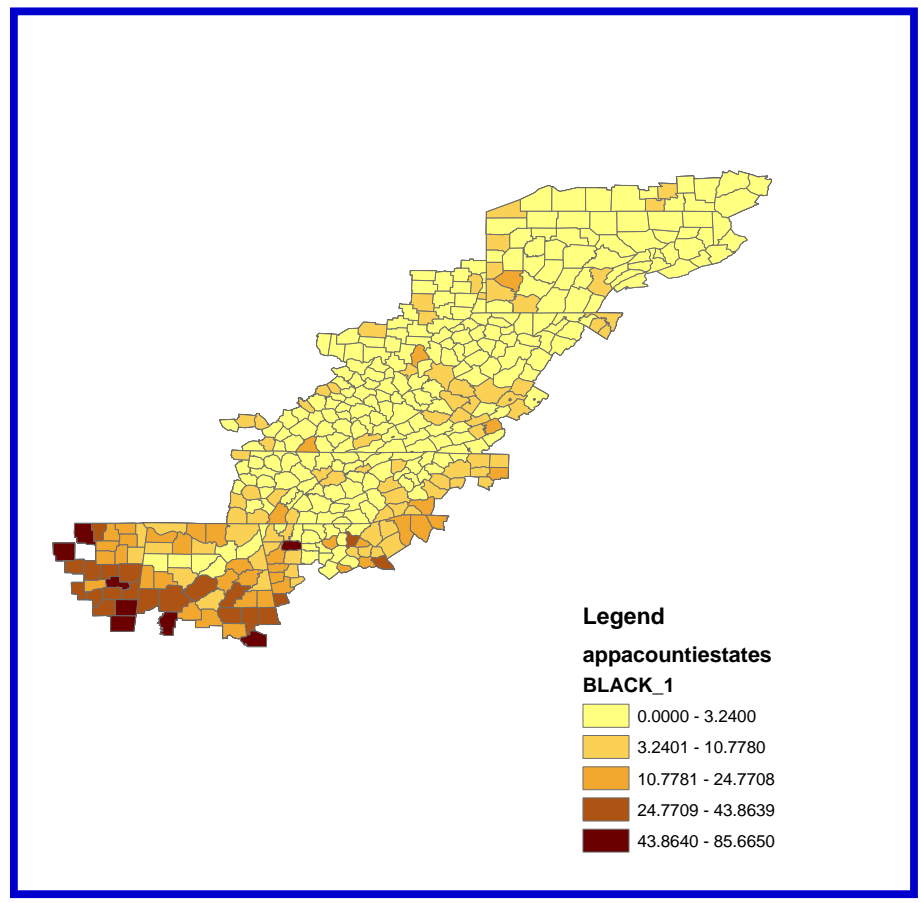

Figure5.5: 1992 UNEMPLYMENT RATES IN APPALACHIA

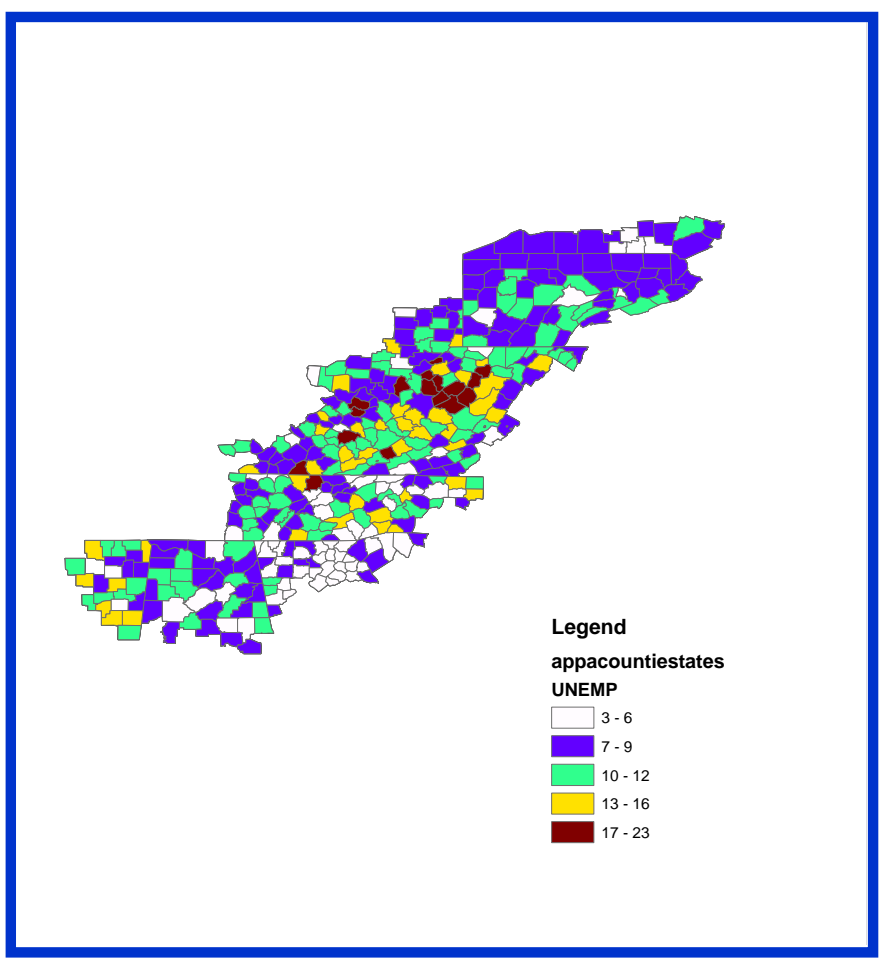




\section{CHAPTER 6}

\section{CONCLUSIONS AND RECOMMENDATIONS}

\subsection{Introduction}

The relationship between environmental regulation and economic growth has been a subject of long standing debate among economists and policymakers. The purpose of this research is to address a number of questions that have arisen concerning the relationship between environmental regulation and economic growth. The questions are: to what extent does environmental regulation influence regional growth patterns and to what extent do regional factors influence environmental regulations? To address these questions, this study, unlike previous research, assumes that simultaneous interactions exist among changes in environmental regulations, per capita income, population, and employment. In this vein, the first contribution of this research is the ability to theoretically and empirically model the simultaneous relationships among changes in environmental regulations, population, total employment, and per capita income at the county-level. The analysis in this study assumes that the effects of environmental regulations go beyond regulated firms.

Two econometric techniques are used to empirically examine the relationship between changes in per capita income, employment, population, and environmental regulations. First, the four systems of equations are estimated using the three-stage least squares technique. The second estimation uses the Spatial Durbin Model (SDM) and is estimated in MATLAB using the 8 nearest neighbors' spatial weight matrix. Thus, the second contribution of this study is the use of the Spatial Durbin Model (SDM) that quantifies the direct effects, indirect effects (spatial spillovers), and the total or cumulative impacts. The direct effects represent the changes on a given county's growth outcomes due to changes in own county characteristics, while the indirect 
impacts are spatial spillovers on neighboring counties that stem from changing a given county's characteristics. The total or cumulative effects quantified as the sum of the direct and indirect effect, measures the cumulative impact of a change in a county's characteristics averaged over all other regions.

On the whole, both the three-stage least squares and SDM estimations produce robust results by showing that environmental regulations implemented at the county-level are not detrimental to regional growth. Model estimates show that initial environmental regulation stringency is negatively related to growth (population, employment, and per capita income), while the change in environmental regulation is positively associated with regional growth. The initial conditions for environmental regulations intuitively mean that firms in non-attainment counties invest in pollution abatement technologies in order to bring the air quality in compliance with federal standards. As a consequence, the initial conditions can be interpreted as the shortrun effects of environmental regulations due to the fact that firms in non-attainment regions will invest in pollution abatement technologies in the initial period. Investments in the initial period result in increased production costs and reduced output. However, because of the spinoff effects, other sectors of the economy will also be negatively affected and thus negatively affect regional growth.

Considering the length of the period of analysis in this study (15 years), the change in environmental regulations can be interpreted as the long-run effects. Within the endogenous growth theory framework, firms adopt improved technologies which expand their production functions as well as improve environmental quality. Theoretically, this means that the long-run effect of environmental regulations is improved output and better environmental quality. Thus, it 
is not surprising that the change in environmental regulations is consistently found to have a positive effect on growth in employment, population, and per capita income.

\subsection{Summary and Conclusions, Non-Spatial Models}

In the three-stage least squares estimation, population change or growth is positively associated with growth in per capita income and employment. This is a key finding that suggests that an increase in labor demand through expansions in economic output positively influences population growth in Appalachia. Results from the non-spatial model show that change in environmental regulation is positively associated with population growth. The presumption is that the initial conditions of environmental regulations increase the compliance and operating costs for regulated firms and thus retard economic growth. The change in environmental regulations is intuitively interpreted as the long-run effects; therefore, the long-run benefit of environmental regulation stringency is improved environmental quality, which also directly stimulates population growth. The unexpected negative effect of manufacturing establishments on population growth demonstrates the declining role of manufacturing in the Appalachian economy and could also be construed to mean that manufacturing jobs in the Appalachia are low paying. Local government expenditure programs seem to be important in explaining Appalachian population growth. This is very important because it shows that local government expenditure policies play key roles in the development process in Appalachian counties.

Three-stage least squares estimate further reveal that employment growth can be stimulated by population growth. This finding seems plausible if we assume that labor demand parallels labor supply, or if the rate of growth of population is slow relative to employment growth. Environmental regulations pursued at the county level seem to negatively affect employment growth only in the initial stages of implementation, but after a certain time lag, 
environmental regulations positively influence employment growth. Thus, this study concludes that environmental regulation does not slow long-term economic growth, but rather stimulates employment growth. This seems reasonable because the initial cost outlays for abatement technology are sunk costs, and therefore, rational profit maximizing firms do not base their future production decisions on sunk costs. Under this assumption, the efficient technology that firms invest in serves the dual role of improving productivity and enhancing environmental quality. These findings complement the theoretical analysis in chapter 3. In addition, these findings support Tannenwald's (1997) hypothesis that internalization of externalities makes jurisdictions attractive to business, households, and leisure travelers. Therefore, these findings should offer some consolation to businesses, politicians, and local policymakers who fret about the negative economic impacts of environmental regulation implementation.

Similarly, three-stage least squares estimation reveals that environmental regulation only negatively affects per capita income growth in the short-term, but has a positive influence on per capita income growth in the long-run. Under this circumstance, these findings reinforce the notion that environmental regulation enhances a jurisdiction's environmental quality, thereby making the area more attractive to workers, executives, businesses, retirees, and so on. Furthermore, the results indicate that growth in employment, combined with percentage increase in population with bachelor's degrees are associated with growth in per capita income. Results further support the bidirectional causal relationship between population growth and per capita income growth. However, the percent of Black population, property taxes, poverty rate, percentage of the population above 65 years, and local taxes significantly reduce growth in per capita income. 
Last but not least, empirical results from the three-stage least squares estimation show that environmental regulation stringency is influenced by employment growth, initial environmental regulation, per capita income, county poverty rate, percent of black population, and percentage of vulnerable population. An increase in the number of county manufacturing establishments and employment tends to exert upward pressure on environmental regulation. The study also finds empirical evidence that suggest that environmental interest groups, percentage of population with bachelor's degree, Democratic Party influence, population density, percentage of population driving to work, and road density have a positive effect on environmental regulations stringency.

\subsection{Summary and Conclusions from the SDM Model}

To provide insights concerning spatial interdependences among the variables, the spatial Durbin Model (SDM) is employed. The motivation for using the SDM model stems from the plausibility that a county's characteristics (both dependent variable and explanatory variables) may influence growth rates in neighboring counties. In this case, there is a need to capture the spillover impacts, which cannot be captured in non-spatial regressions. The SDM estimation allows inferences to be made in terms of direct impacts, indirect or spillover impacts, and total (cumulative) impacts.

Overall, SDM estimations are consistent with the non-spatial regressions by revealing that environmental regulations negatively affect regional growth only in the short-term period, but in the long run, environmental regulations stimulate growth in population, per capita income, and employment. Similarly, SDM estimations present strong evidence that environmental regulation outcomes are positively influenced by changes in employment, population, and per capita income. The SDM estimations further reveal that changes in a county's environmental 
regulation, per capita income, employment, and population do not only depend on own-county characteristics (direct effects), but are influenced by other counties' characteristics (indirect effects). For example, based on the positive coefficients for the total effects of initial environmental regulations, this study concludes that there is some form of strategic interaction among some Appalachian counties in environmental policymaking. The strategic interaction is in a form of the race to top, which means that a given county's environmental regulation stringency has a positive impact on neighboring counties' environmental regulation outcomes. This finding is very important because it shows that even in the face of stiff interstate economic competition counties (and states) do not lower environmental regulations, but instead mimic neighboring counties' stringent environmental standards.

The results from the SDM estimations overall show that a county's growth rate will not only depend on its characteristics, but also on indirect impacts emanating from neighboring counties. These indirect impacts arise due to the spatial connectivity of the counties and tend to be localized (LeSage and Fischer, 2009). Therefore, the second contribution of this research is the ability to illustrate the important role spillover effects play in regional growth.

\subsection{Policy Recommendations}

Empirical findings from both the non-spatial model and spatial Durbin model have important policy implications. First, the results indicate that population growth is stimulated by an increase in per capita income, employment growth, local government expenditure, and amenities. Population growth entails supply of labor with a variety of skills, and therefore, counties that are concerned about population growth should adopt economic strategies that will stimulate growth in employment and provide high incomes. By creating a strong economy, the educated Appalachians will be encouraged to stay in the region. 
Second, cognizant of the positive direct and indirect impacts that local government expenditure policies have on regional economies, economically distressed Appalachian counties should find means of increasing the provision of public goods and services. The increased and continued supply of public goods and services has a direct effect of attracting new firms and stimulating growth of existing firms, and this indirectly induces population and per capita income growth. Consistent with economic base theory, manufacturing's role cannot be ignored, given that manufacturing has the potential to generate a large number of jobs. This study shows that employment growth and per capita income growth can be stimulated by manufacturing establishments. Therefore, there is a need to revitalize the role of manufacturing in Appalachia.

Third, the analyses conducted in both the non-spatial and spatial model underscore the fact that environmental regulation has a negative impact on regional growth only in the shortterm. The long-term benefit of environmental regulation is improved firm competitiveness, as hypothesized by Porter and van der Linde (1995), and improved environmental quality. Therefore, states working to simultaneously improve their business climate and stimulate economic growth should not neglect environmental regulation by lobbying for less stringent standards. Instead, state governments should develop state implementation plans (SIPs) that enhance their jurisdictions' environmental quality, induce innovation in firms, and thus stimulate long-term growth through migration of firms and households.

The analyses conducted also highlight that environmental regulation outcomes are positively influenced by socio-economic and demographic factors. Thus, another policy implication is that, besides imposing stringent environmental regulation on polluting industries, there is need to pay attention to socio-economic and demographic forces that contribute to pollution. 


\subsection{Research Limitations and Suggestions of Future Research}

There are several issues in the research that have not been effectively addressed. The first limitation of this study pertains to data. For example, data related to land use patterns could have been incorporated in the model in order to highlight its impact on regional growth and environmental regulation setting because land use patterns reflect human impacts on the environment. Other data problems pertain to the inability to account for effects of technological changes on regional growth and environmental regulation outcomes. Inarguably, technological changes have implications for both regional growth and air quality. Lastly, while the use of the county attainment status is a good proxy for environmental regulation stringency, it contains only a limited amount of information. However, because the environmental regulation index constructed provides some spatial variation in implementation, we believe that the county attainment status is a reasonable proxy in this study.

The empirical findings indicate that environmental regulation positively influences economic growth in the long-term. This result needs further attention in the form of further research that investigates the time lag between environmental regulation change and improved economic performance. This can be achieved by using a dynamic model and data that cover a considerable time period.

Empirical evidence that indicates that counties with high unemployment rates and high Black populations are associated with stringent environmental regulation stringency should be interpreted with caution. Could we be committing a type I error by inferring that poor neighborhoods are not excessively exposed to air pollution relative to other communities? Therefore, there is a need to further investigate the simultaneous relationship between rate of exposure to pollutants and environmental regulation stringency. 


\section{REFERENCES}

Acs, Z. J., and K. Kallas. (2008). "State of Literature on Small to Medium-Size Enterprises and Entrepreneurship in Low-Income Communities." In Glenn, Y., J. R. Barth, and B. Zeidman. Entrepreneurship in Emerging Domestic Markets. Springer, U.S., pp. 21-45.

Aghion, P. and P. Howitt. (1998). Endogenous Growth Theory. Cambridge, MA: MIT Press.

Anselin, L. C. (1988). Spatial Econometrics: Methods and Models. New York: Spinger-Verlag

Anselin, L. C., R. J. G. M. Florax, and S. J. Rey. (2004). Advances in Spatial Econometrics: Methodology, Tools and Application. New York: Springer.

Anton, W. R. Q., and D. M. Khanna (2004). "Incentives for Environmental Self-Regulation and Implications for Environmental Performance." Journal of Environmental Economics and Management 48(1): 632-654.

APOGEE Research. (1991). “The Effects on Industry of Environmental Protection Regulations." Report Prepared for the EPA, available from http://yosemite.epa.gov/ee/epa/eermfile.nsf/vwAN/EE-0273-01.pdf/\$File/EE-027301.pdf; accessed 23 February, 2009.

Arrow, K., B. Bolin, R. Costanza, P. Dasgupta, C. Folke, S. Holling, B-O. Jansson, S. Levin, K-G. Mäler, C. Perrings, and D. Pimentel. (1995). "Economic Growth, Carrying Capacity and the Environment". Journal of Ecological Economics 15 (2): 91-95.

Aschauer, D. A. (1989). "Is Public Expenditure Productive?" Journal of Monetary Economics 23(2): $177-200$

Barbera, A. J., and V. D. McConnell. (1986). "Effects of Pollution Control on Industry Productivity: A Factor Demand Approach." Journal of Industrial Economics 35(1): 161172.

Barro, R.J., and X. Sala-i-Martin. (1991). "Convergence across States and Regions." Brookings Papers on Economic Activity 1: 107-82.

Barro, R. J. (1999). “Notes on Growth Accounting.” Journal of Economic Growth 4(2): 119-137.

Bartik, T. J. (1985). "Business Location Decisions in the United States: Estimates of the Effects of Unionization, Taxes, and Other Characteristics of States." Journal of Business and Economic Statistics 3(1): 14-22.

Becker, R. A., and V. Henderson. (2000). "Effects of Air Quality Regulations on Polluting Industries." Journal of Political Economy 108(2): 379-421. 
Becker, R. A. (2001). "Air Pollution Abatement Costs Under the Clean Air Act: Evidence from the PACE Survey." Journal of Environmental Economics and Management 50(1): 144169.

Berman, E., and L. T. M. Bui. (1998). "Environmental Regulation and Productivity: Evidence from Oil Refineries.” National Bureau of Economic Research Working Paper 6776.

Black, D. A., K. M. Pollard, and S. G. Sanders. (2007). “The Upskilling of Appalachia: Earnings and the Improvements of Skill Levels, 1960 to 2000.” Population Reference Bureau, Washington D.C.

Brueckner, J. K. (2000). "Welfare reform and the Race to the Bottom: Theory and Evidence." Southern Economic Journal 66(3): 505-525.

Brunnermeier, S.B., and M.A. Cohen. (2003). "Determinants of environmental innovation in U.S. manufacturing industries." Journal of Environmental Economics and Management 45, 278-293.

Carlino, G., and E. S. Mills. (1987). “The Determinants of County Growth.” Journal of Regional Science 27(1): 39-54.

Cassady, A. (2004). "More Highways, More Pollution: Road-Building and Air Pollution in America's Cities." U.S. PIRG Education Fund, Washington, D.C., available from https://www.policyarchive.org/handle/10207/5542.

Case, A., J. Hines, and H. Rosen. (1993). "Budget Spillovers and Fiscal Policy Interdependence: Evidence from the States." Journal of Public Economics 52(3): 285-307.

Cohen, S. (2006). Understanding Environmental Policy. New York, NY: Columbia University Press.

Cole, M. A., and R. J. Elliot. (2007). "Do Environmental Regulations Cost Jobs? An IndustryLevel Analysis of the UK." B.E. Journal of Economic Analysis and Policy 7(1):1-25.

Cole, M. A., R. J. R. Elliot, and P. G. Fredriksson. (2006). "Endogenous Pollution Havens: Does FDI Influence Environmental Regulations?” Scandinavian Journal of Economics 108(1): 157-178.

Condliffe, S., and O. A. Morgan. (2009). "The Effects of Air Quality Regulations on the Location of Pollution-Intensive Manufacturing Plants.” Journal of Regulatory Economics 36(1): 83-93.

Crandall, Robert W. (1993). Manufacturing on the Move. Washington, D.C.: The Brookings Institution. 
Crissman, C.C., J. M. Antle, and S. M. Capalbo. (1997). Economic, Environmental, and Health Tradeoffs in Agriculture: Pesticides and the Sustainability of Andean Potato Production. The Netherlands: Kluwer Academic Publishers.

Dean, T. J., R. L. Brown, and V. Stango. (1999). "Environmental Regulation as a Barrier to the Formation of Small Manufacturing Establishments: A Longitudinal Examination." Journal of Environmental Economics and Management 40(1): 56-75.

Deller, S. C., T. H. Tsai, D. W. Marcouiller, and D. B. K. English. (2001). "The Role of Amenities and Quality of Life in Rural Economic Growth." American Journal of Agricultural Economics 83(2): 352-365.

Denison, E. F. (1979). Accounting for Slower Economic Growth: The U.S. in the 1970s. Washington, D.C.: The Brookings Institution.

Duffy-Deno, K.T. (1992). "Pollution Abatement Expenditures and Regional Manufacturing Activity." Journal of Regional Science 32(4): 419-436.

Eliste, P., and P. G. Fredriksson. (2002). "Environmental Regulations, Transfers and Trade: Theory and Evidence." Journal of Environmental Economics and Management 43(2): 234-250.

Engel, K. H. (1997). "State Environmental Standard-Setting: Is there a 'Race' and is it to the Bottom." Hastings Law Journal 48(3): 271-398.

EPA. (2001). "A Technical Review of the Interactions between Land Use, Transportation, and Environmental Quality." U.S. EPA Office of Policy, Economics, and Innovation, available from http://epa.gov/smartgrowth/pdf/built exec_summary; accessed 23 June, 2009.

Esworthy, R. (2007). "Particulate Matter ( $\left.\mathrm{PM}_{2.5}\right)$ : Implementation of the 1997 National Ambient Air Quality Standards (NAAQS).” Report for Congress, Congressional Service Research.

Fredriksson, P. G., and D. L. Millimet. (2002). "Strategic Interaction and the Determination of Environmental Policy across U.S. States." Journal of Urban Economics 51(1): 101-122.

Fredriksson, P. G., and D. L. Millimet. (2002). "Is There a 'California Effect' in U.S. Environmental Policymaking.” Regional Science and Urban Economics 32(6): 737-764.

Fullerton, D., and S-R. Kim. (2006). "Environmental Investment and Policy with Distortionary Taxes and Endogenous Growth." National Bureau of Economic Research Working Paper No. 12070.

Garofalo, G., and M. S. Fogarty. (1979). "Urban Income Distribution and the Urban Hierarchy Equality Hypothesis." Review of Economics and Statistics 61(3): 381-388. 
Gebremariam, G. H., T. G. Gebremedhin, P. V. Schaeffer, R. W. Jackson, and T. T. Phipps (2007). "An Empirical Analysis of Employment, Migration, Local Public Services, and Regional Income Growth in the Appalachia." West Virginia University Regional Research Institute, Working Research Paper No. 10.

Glasmeier, A., and K. G. Fuellhart. (1999). "Building Past Experiences: Creating a New Future for Distressed Counties." Report to the Appalachian Regional Commission.

Goetz, S. J., R. C. Ready, and B. Stone. (1996). "U.S. Economic Growth vs. Environmental Conditions." Growth and Change 27(1): 97-110.

Goetz, S. J., A. Pagoulatos, and D. Debertin. (1998). Human Capital, Income, and Environmental Quality: State-Level Analysis. Agricultural and Resource Economics Review 79(3): 838850 .

Gottlieb, P. D. (1995). "Residential Amenities, Firm Location and Economic Development." Urban Studies 32(9): 1413-1436.

Gottlieb, P. D. (1994). "Amenities as an Economic Development Tool: Is there Enough Evidence?” Economic Development Quarterly 8(3): 270-285.

Gradus, R., and S. Smulders. (1992). "The Trade-off between Care and Long-Term Growth: Pollution in Three Prototype Growth Models." Journal of Economics 58(1): 25-51

Gray, W. B. (1997). "Manufacturing Plant Location: Does State Pollution Regulation Matter?" National Bureau of Economic Research, Working Paper 5880.

Gray, W. B., and R. J. Shadbegian. (1993). "Environmental Regulation and Manufacturing Productivity at the Plant Level." National Bureau of Economic Research Working Paper No. W4321.

Gray, W. B., and M. Deily. (1995). "Compliance and Enforcement: Air Pollution Regulation in the U.S. Steel Industry." Journal of Environmental Economics and Management 31(1): 96-111.

Greenstone, M. (2002). "The Impacts of Environmental Regulations on Industrial Activity: Evidence from the 1970 \& 1977 Clean Air Act Amendments and the Census of Manufactures.” Journal of Political Economy 110(6): 1175-1219.

Greenstone, M., and J. Gallagher. (2005). "Does Hazardous Waste Matter? Evidence from Housing Market and the Superfund Program." National Bureau of Economic Research Working Paper No. 11790.

Grossman, G., and A. Krueger. (1995). "Economic Growth and the Environment." Quarterly Journal of Economics 110(2): 353-377. 
Hackett, S. C. (1995). "Pollution Controlling Innovation in Oligopolistic Industries: Some Comparisons between Patent Races and Research Joint Ventures." Journal of Environmental Economics Management 29(3): 339-356.

Hackett, S. C. (2001). Environmental and Natural Resource Economics: Theory, Policy and the Sustainable Society. New York: ME Sharpe Inc.

Hailu, Y. G. (2006). "A Spatial Simultaneous Growth Equilibrium Modeling of Agricultural Land in the Northeast United States." Ph.D. Dissertation, West Virginia University.

Harper, R. K., and S. C. Adams. (1996). "CERCLA and Deep Pockets: Market Response to the Superfund Program.” Contemporary Economic Policy 14(1): 107-115.

Harrison, D. (2008). "Estimated Attainment Costs and Economic Impacts in Selected Regions of Proposed Revisions to the EPA 8-Hour Ozone Standard." National Economic Research Associates, available from www.nera.com/image/PUB_Ozone_Standard_Jan2008.pdf; accessed 20 April, 2009.

Harrison, D., and M. Dreyfus. (1995). "Socioeconomic Effects of Alternative Electric Utility Resources." Report prepared for Northern States Power Company by National Economic Research Associates.

Helms, L. H. (1985). "The Effects of State and Local Taxes on Economic Growth: A Time Series-Cross Sectional Approach," Review of Economics and Statistics, 67(4): 574-582.

Henderson, V. (1996). "The Effect of Air Quality Regulation." American Economic Review 86(4): 789-813.

Henderson, V. (1997). "The Impact of Air Quality Regulation on Industrial Location.” Annales d'Économie et de Statistique No.45.

Hendryx, M. (2008). "Mortality Rates in Appalachian Coal Mining Counties: 24 Years behind the Nation." Environmental Justice 1(1): 5-11.

Henry, M. S., B. Schmitt, K. Kristensen, D. L. Barkley, and S. Bao. (1999). "Extending CarlinoMills Models to Examine Urban Size and Growth Impacts on Proximate Rural Areas." Growth and Change 30(4): 526-548.

Hosoe, M., and T. Naito. (2006). "Trans-Boundary Pollution Transmission and Regional Agglomeration Effects." Journal of Regional Science 85(1): 99-119.

Izraeli, O. (1985). "The Effect of Environmental Attributes on Earnings and Housing Values Across SMSAs." Journal of Urban Economics 22(3): 361-376.

Izraeli, O., and L. Mobley. (1995). "Are Jobs and the Quality of the Environment Mutually Exclusive?" Journal of Environment and Planning A 27(5): 781-791. 
Jaffe, A. B., and K. L. Palmer. (1996). "Environmental Regulation and Innovation: A Panel Study."National Bureau of Economic Research Working Paper 5545.

Jeppesen, T., J. A. List, and H. Folmer. (2002). "Environmental Regulation and New Plant Location Decisions: Evidence from a Meta-Analysis. Journal of Regional Science 42(1): $19-49$.

Jorgenson, D. W., and P. J. Wilcoxen. (1990). "Environmental Regulation and U.S. Economic Growth.” RAND Journal of Economics 21(2): 314-340.

Jones, B. D. (1990). "Public Policies and Economic Growth in the American States," The Journal of Politics 52(1): 219-233.

Kahn, M. E. (2008). "Regional Growth and Exposure to Nearby Coal Fired Power Plant Emissions." Regional Science and Urban Economics 39(1): 15-22.

Kahn, M. (2000). "Demographic Change and Demand for Environmental Regulation." Policy Analysis and Management 21(1): 45-62.

Kahn, M., and J. G. Matsusaka. (1997). "Demand for Environmental Goods: Evidence from Voting Patterns on California Initiatives." Journal of Law and Economics 40(1): 137173.

Kale, S. R. (1984). "U.S. Industrial Development Incentives and Manufacturing Growth During the 1970's." Growth and Change 15(1): 26-34.

Kahsai, M. S. (2009). "An Analysis of Amenity-Led Rural Economic Development in Northeast Region: A Spatial Simultaneous Equations Approach.” Ph.D. Dissertation, West Virginia University.

Keller, W., and A. Levinson. (1999). "Environmental Compliance Costs and Foreign Direct Investment Inflows to U.S. States." National Bureau of Economic Research Working Paper No: 7369.

Kohn, R. (1985). "A General Equilibrium Analysis of the Optimal Number of Firms in a Polluting Industry." Canadian Journal of Economics 18(2): 347-354.

Krugman, P. R. (1991). "Increasing Returns and Economic Geography." Journal of Political Economy 99(3): 483-499.

Kunce, M. (2006). "What Factors Affect a State's manufacturing Employment? Evidence from 1974-1994 State Panel Data. RURDS 18(1): 1-10.

Lawrence, C. M., and I. K. Khurana. (1997). "Superfund Liabilities and Governmental Reporting Entities: An Empirical Analysis." Journal of Accounting and Public Policy, 16(2): 155186. 
LeSage, J. P., and M. M. Fischer. (2009). "The Impact of Knowledge Capital on Regional Total Factor Productivity. Working Paper Series, Social Science Research Network.

LeSage, J. P., and D. K. Kirby. (2009). "Changes in Commuting to Work Times Over the 1990 to 2000 Period.” Regional Science and Urban Economics 39(4): 460-471.

LeSage J.P. and R. K. Pace. (2009). Introduction to Spatial Econometrics. Boca Raton, London and New York: CRC Press (Taylor \& Francis Group).

Levinson, A. (1999). “An Industry-Adjusted Index of State Environmental Compliance." National Bureau of Economic Research Working Paper No. 7297.

Levitt, S. D., and J. M. Poterba. (1994). "Congressional Distributive Politics and State Economic Performance.” National Bureau of Economic Research Working Paper No. W4721.

Li, C. (2006). "The Effect of Local Economic and Environmental Policies on County Population and Employment Growth.” Ph.D. Dissertation, The Ohio State University.

Lieu, S. (1991). "Regional Impacts of Air Quality Regulation: Applying an Economic Model." Contemporary Policy Issues 9(3): 24-34.

List, J. (2001). "U.S. County-Level Determinants of Inbound FDI: Evidence from a Two-Step Modified Count Data Model.” International Journal of Industrial Organization 19 (6): 953-973.

List, J. A., D. L. Millimet, W. W. McHone, and P. G. Fredriksson. (2003). "Effects of Environmental Regulations on Manufacturing Plant Births: Evidence from a Propensity Score Matching Estimator." Review of Economics and Statistics 85(4): 944-952.

List, J. A., and W. W. McHone. (2000). "Measuring the Effects of Air Quality Regulations on 'Dirty' Firm Births: Evidence from the Neo-and Mature-Regulatory Periods." Papers in Regional Science 79(2): 177-190.

List, J., and C. Y. Co. (1999). "The Effects of Environmental Regulations on Foreign Direct Investment." Journal of Environmental Economics and Management 40(1): 1-20.

Lundberg, J. (2004). "Using Spatial Econometrics to Analyze Local Growth in Sweden." CERUM Working Paper No: 52.

Maloney, M. T., and R. E. McCormick. (1982). “A Positive Theory of Environmental Quality Regulation." Journal of Law and Economics 25(1): 99-123.

Margulis, S. (1992). "Back of the Envelope Estimates of Environmental Damage Costs in Mexico.” Policy Research Working Papers, World Bank. 
McConnell, V. D., and R. M. Schwab. (1990). "The Impact of Environmental Regulation on Industry Location Decisions: The Motor Vehicle Industry." Land Economics 66(1): 6781 .

McGranahan, D. A. (1999). "Natural Amenities Drive Rural Population Change.” Food and Rural Economics Division, Economic Research Service, USDA.

Melosi, M. V., and J. A. Pratt. (2007). Energy Metropolis: An Environmental History of Houston and the Gulf. Pittsburgh, U.S.: University of Pittsburgh Press.

Mills, E. S., and R. Price. (1984). "Metropolitan Suburbanization and Central City Problems." Journal of Urban Economics 15(1): 1-17.

Mojica, M. N. (2009). "Examining the Role of Entrepreneurship in Economic Development in Appalachia.” Ph.D. Dissertation, West Virginia University.

Morrone, M. (2008). "Environmental and Health Disparities in Appalachia, Ohio: Local Cases with Global Implications.” In Liotta, P. H., D. A. Mouat, W. G. Kepner, and J. D. Lancaster. Environmental Change and Human Security: Recognizing on Hazard Impacts. Springer, Netherlands, pp. 299-323.

Munnell, A. H. (1990). How Does Public Infrastructure Affect Regional Economic Performance? New England Economic Review, Sept.: 11-33.

Nelson, R., T. Tietenberg, and M. R. Donihue. (1986). "Differential Environmental Regulation: Effects on Electric Utility Capital Turnover and Emissions." Review of Economics and Statistics 75(2): 368-373.

Ostro, B. D. (1983). "The Effect of Air Pollution on Work Loss and Morbidity." Journal of Environmental Economics and Management 10(4): 371-382.

Pagoulatos, A., S. Goetz, D. Debertin, and T. O Johansson. (2002). "Interactions Between Economic Growth and Environmental Quality in U.S. Counties." Growth and Change 35(1): $90-108$.

Plaut, T. R., and J. E. Pluta. (1983). "Business Climate, Taxes and Expenditures, and State Industrial Growth in the United States." Southern Economic Journal 50: 99-119

Polzin, P. E. (2001). "Why Some States Grow Faster than Others: New Growth Models for State Economic Policy." Growth and Change 32(3): 413-425.

Potoski, M. (2002). "Clean Air Federalism: Do States Race to the Bottom?" Public Administration Review 61(3): 335-343.

Porter, M. E. (1991). “America’s Greening Strategy.” Scientific American 264:168. 
Porter, M. E., and C. van der Linde. (1995). "Toward a New Conception of EnvironmentCompetitiveness Relationship." Journal of Economic Perspectives 9(4): 97-118.

Portney, P. R. (1981). “The Macroeconomic Impacts of Federal Environmental Regulation.” In Peskin, H. M., P. R. Portney, and A. V. Kneesen, editors, Environmental Regulation and the U.S. Economy. Baltimore: John Hopkins University Press, pp. 25-77.

Regens, J., B. J. Seldon, and E. Elliot. (1997). "Modeling Compliance to Environmental Regulation: Evidence from Manufacturing Industries. Journal of Policy Modeling 19(6): 683-696.

Ringquist, E. J. (1993). Environmental Protection at the State-Level: Politics and Progress in Controlling Pollution (Bureaucracies, Public Administration, and Public Policy). Armonk, New York: M. E. Sharpe.

Roediger-Schluga, T. (2004). The Porter Hypothesis and the Economic Consequences of Environmental Regulation: A Neo-Schumpeterian Approach. Camberley Surray, UK: Edward Elgar Publishing.

Romer, P. M. (1990). “Endogenous Technological Change.” Journal of Political Economy 98(2): S71-S 102.

Sanyal, P. (2007). "The Effects of Deregulation on Environmental Research by Electric Utilities." Journal of Regulatory Economics 31(3): 335-353.

Santopietro, G. D. (2002). "Analyzing Income Convergence at the County Level: The Case of Development in Central Appalachia." Journal of Economic Issues 36(4): 893-906.

Shafik, N. (1994). "Economic Development and Environmental Quality: An Econometric Analysis." Oxford Economic Papers 46(5): 757-773.

Sicotte, D. (2009). "Power, Profit, and Pollution: The Persistence of Environmental Injustice in a Company Town." Human Ecology Review 16(2): 141-150.

Sigman, H. (2005). "Transboundary Spillovers and Decentralization of Environmental Policies." Journal of Environmental Economics and Management 50(1): 82-101.

Smulders, S. (2000). "Economic Growth and Environmental Quality", In Folmer, H and L. Gabel (ed). Principles of Environmental and Resource Economics. Brookfield, MA: Edward Elgar, pp. 17-47.

Smulders, S. and R. Gradus (1996). "Pollution Abatement and Long-term Growth," European Journal of Political Economy 12(3): 505-532.

Steinnes, D. (1982). "Do People Follow Jobs or Do Jobs Follow People: A Causality Issue in Urban Economics." Journal of Urban Economics 19(2): 187-192. 
Swanson, T. (2008). "Economic Growth and Environmental Regulations: A Discussion of International Experiences.” Discussion Paper, Asian Development Bank.

Tannenwald, R. (1997). "State Regulatory Policy and Economic Development." New England Economic Review: 83-108.

Templet, P. H. (1995). "The Positive Relationship between Jobs, Environment and the Economy: An Empirical Analysis and Review." Spectrum: 37-49.

Tiebout, C. (1956). “A Pure Theory of Local Expenditure.” Journal of Political Economy 64(5): 416-424.

U.S. Environmental Protection Agency. (1999). AQPS Economic Analysis Resource Document. Office of Air Quality Planning and Standards Innovative Strategies and Economics Group.

Van. P. N. (2002). “Endogenous Population and Environmental Quality.” BETA Working Paper.

Vogel, D. (1995). Trading Up: Consumer and Environmental Regulation in a Global Economy. Cambridge, MA: Harvard University Press.

Walden, W. D., and B. N. Schwartz. (1997). "Environmental Disclosures and Public Policy Pressure." Journal of Accounting and Public Policy, 16 (2): 115-244.

Wadell, T. E. (1974). “The Economic Damages of Air Pollution.” Washington Environmental Research Center, Economic Analysis Branch.

Weber, W. L., and B. R. Domazlicky. (2006). "Capital Deepening and Manufacturing's Contribution to Regional Economic Convergence." Regional Analysis and Policy 36(1): $31-44$.

Wooldridge, J. M. (2002). Econometric Analysis of Cross Section and Panel Data. Cambridge, MA: MIT Press.

Wood, L. E. (2005). “Trends in National and Regional Economic Distress: 1960-2000.” Report Prepared for Appalachian Regional Commission, available from http://www.arc.gov/images/aboutarc/grants/pdf/trends_final 05.pdf, accessed 12 June, 2009.

Xepapadeas, A. (2003). Economic Growth and the Environment, in K. G. Mäler and J. Vincent, (eds), Handbook of Environmental Economics, Vol. 3, Amsterdam, The Netherlands: Elsevier Publishers, pp 1219-1271.

Yandle, B. (1984). "Environmental Control and Regional Growth." Growth and Change 15(3): $39-42$. 
Young, A. T., M. J. Higgins, and D. Levy. (2007). "Black Populations and Economic Growth: An Extreme Bound Analysis of Mississippi County-Level Data." Emory Law and Economic Research Paper No. 07-06. 


\section{APPENDIX A}

Table 5.6: SDM Estimation Results of Change in Population (95\% confidence Interval)

\begin{tabular}{|c|c|c|c|c|c|c|c|c|}
\hline \multirow{2}{*}{$\begin{array}{l}\text { Independent } \\
\text { Variables }\end{array}$} & \multicolumn{2}{|c|}{$\begin{array}{c}\text { Model Estimates \& } \\
\text { Spatially lagged } \\
\text { Estimates }\end{array}$} & \multicolumn{2}{|c|}{ Direct Effect } & \multicolumn{2}{|c|}{ Indirect Effect } & \multicolumn{2}{|c|}{ Total Effect } \\
\hline & Coefficient & p-level & Coefficient & t-prob & Coefficient & t-prob & Coefficient & t-prob \\
\hline POP92 & $-0.189 * * *$ & 0 & $-0.188^{* * *}$ & 0 & $-0.057^{* * *}$ & 0 & $-0.245^{* * *}$ & 0 \\
\hline EMP92 & $0.122 * * *$ & 0 & $0.124 * * *$ & 0 & $0.064 * * *$ & 0 & $0.188^{* * *}$ & 0 \\
\hline ENREG92 & -0.467 & 0 & $-0.467 * * *$ & 0 & $-0.322 * * *$ & 0 & $-0.789 * * *$ & 0 \\
\hline EMPCH & $1.854 * * *$ & 0 & $1.856^{* * *}$ & 0 & $0.087^{* *}$ & 0.007 & $1.943^{* * *}$ & 0 \\
\hline $\mathrm{PClCH}$ & $1.235^{* * *}$ & 0 & $1.235^{* * *}$ & 0 & $0.534 * * *$ & 0 & $1.769 * * *$ & 0 \\
\hline ENREGCH & $0.167 * * *$ & 0 & $0.171 * * *$ & 0 & $0.233^{* *}$ & 0.005 & $0.404 * * *$ & 0.0001 \\
\hline MFG & $6.663 *$ & 0 & $6.662 * * *$ & 0 & $2.582 * * *$ & 0 & $9.244 * * *$ & 0 \\
\hline UNEMP & $-48.235^{*}$ & 0.011 & $-48.232 *$ & 0.054 & 35.056 & 0.345 & -13.176 & 0.483 \\
\hline LGEXP & $0.297 * * *$ & 0 & $0.302 * * *$ & 0 & $0.268^{* *}$ & 0.0012 & $0.570 * * *$ & 0 \\
\hline PCTAX & $-0.545^{*}$ & 0.024 & $-0.545^{*}$ & 0.032 & $-0.234 *$ & 0.067 & $-0.779 *$ & 0.039 \\
\hline METRO & $-534.333^{* * *}$ & 0 & $-534.146 * * *$ & 0 & $234.012 *$ & 0.0245 & $-300.134 *$ & 0.023 \\
\hline MHVAL & $-0.054^{* * *}$ & 0 & $-0.055^{* * *}$ & 0 & $0.046^{* * *}$ & 0 & $-0.009 * * *$ & 0 \\
\hline PROPTAX & $-33.113^{* * *}$ & 0 & $-33.113^{* * *}$ & 0 & $-16.235^{* * *}$ & 0 & $-49.348^{* * *}$ & 0 \\
\hline AMEND & $763.321^{* * *}$ & 0 & $765.67^{* * *}$ & 0 & $223.241 * *$ & 0.0041 & $988.911^{* *}$ & 0.001 \\
\hline ROADDEN & $3254.403^{* * *}$ & 0 & $3254.231^{* * *}$ & 0 & $2634.002 * * *$ & 0 & $5888.233^{* * *}$ & 0 \\
\hline W-POP92 & $-0.178^{* * *}$ & 0 & & & & & & \\
\hline W-EMP92 & $0.143 *$ & 0.034 & & & & & & \\
\hline W-ENREG92 & $-0.658^{*}$ & 0.023 & & & & & & \\
\hline W-EMPCH & $2.033^{* * *}$ & 0 & & & & & & \\
\hline W-PCICH & $-1.445^{* *}$ & 0.0063 & & & & & & \\
\hline W-ENREGCH & $0.173 * *$ & 0.0014 & & & & & & \\
\hline W-MFG & 5.888* & 0.054 & & & & & & \\
\hline W-UNEMP & -27.032 & 0.312 & & & & & & \\
\hline W-LGEXP & $-0.156^{* * *}$ & 0 & & & & & & \\
\hline W-PCTAX & $-0.783^{* *}$ & 0.002 & & & & & & \\
\hline W-METRO & $931.023 *$ & 0.091 & & & & & & \\
\hline W-MHVAL & $0.0654 * * *$ & 0 & & & & & & \\
\hline W-PROPTAX & $-26.342 *$ & 0.081 & & & & & & \\
\hline W-AMEND & 634.421 & 0.356 & & & & & & \\
\hline W-ROADDEN & 2317.764 & 0.133 & & & & & & \\
\hline rho & $0.895^{* * *}$ & 0 & & & & & & \\
\hline
\end{tabular}

